\title{
Early motor, psychosocial and behavioural characteristics of Attention-Deficit/Hyperactivity Disorder
}

Citation for published version (APA):

Kroes, M. (2002). Early motor, psychosocial and behavioural characteristics of AttentionDeficit/Hyperactivity Disorder. [Doctoral Thesis, Maastricht University]. Universiteit Maastricht. https://doi.org/10.26481/dis.20020614mk

Document status and date:

Published: 01/01/2002

DOI:

10.26481/dis.20020614mk

Document Version:

Publisher's PDF, also known as Version of record

Please check the document version of this publication:

- A submitted manuscript is the version of the article upon submission and before peer-review. There can be important differences between the submitted version and the official published version of record.

People interested in the research are advised to contact the author for the final version of the publication, or visit the DOI to the publisher's website.

- The final author version and the galley proof are versions of the publication after peer review.

- The final published version features the final layout of the paper including the volume, issue and page numbers.

Link to publication

\footnotetext{
General rights rights.

- You may freely distribute the URL identifying the publication in the public portal. please follow below link for the End User Agreement:

www.umlib.nl/taverne-license

Take down policy

If you believe that this document breaches copyright please contact us at:

repository@maastrichtuniversity.nl

providing details and we will investigate your claim.
}

Copyright and moral rights for the publications made accessible in the public portal are retained by the authors and/or other copyright owners and it is a condition of accessing publications that users recognise and abide by the legal requirements associated with these

- Users may download and print one copy of any publication from the public portal for the purpose of private study or research.

- You may not further distribute the material or use it for any profit-making activity or commercial gain

If the publication is distributed under the terms of Article $25 \mathrm{fa}$ of the Dutch Copyright Act, indicated by the "Taverne" license above, 
Early motor, psychosocial and behavioural characteristics of Attention-Deficit / Hyperactivity Disorder 


\section{Illustration:}

Rineke Engwerda, Hengelo

Cover design:

Leon Polko, Hengelo

\section{Printing:}

Unigraphic, Maastricht

\section{(C) Mariëlle Kroes}

ISBN 90-568|- I33-9 


\section{Early motor, psychosocial and behavioural characteristics of Attention-Deficit / Hyperactivity Disorder}

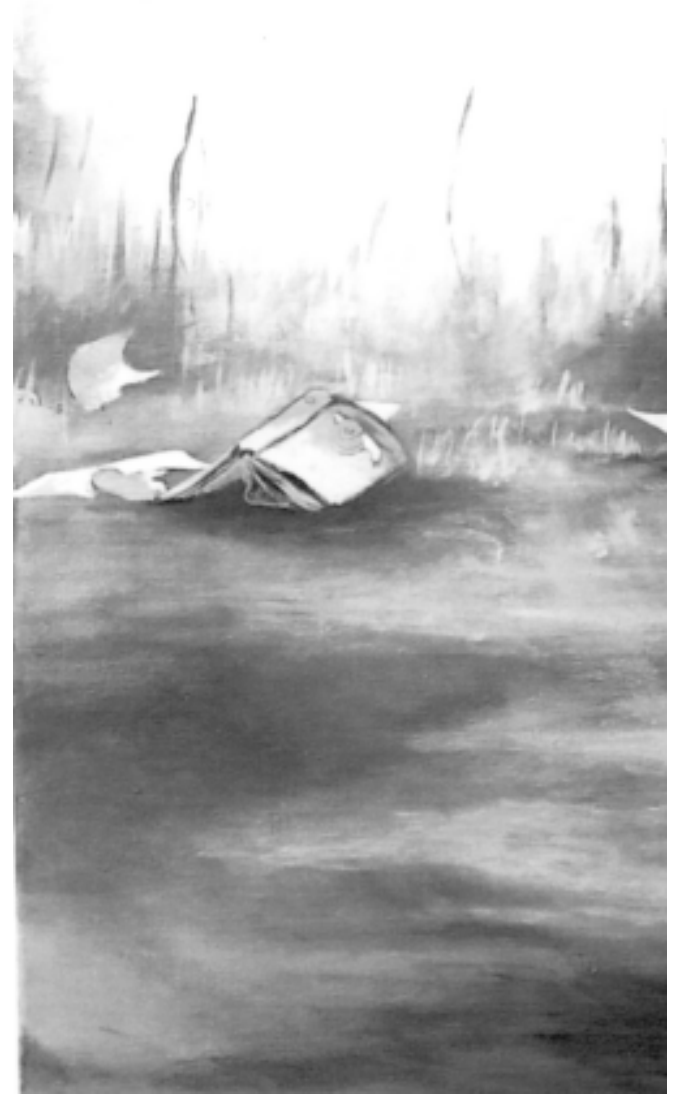

\section{PROEFSCHRIFT}

ter verkrijging van de graad van doctor aan de Universiteit Maastricht,

op gezag van de Rector Magnificus, Prof. Dr. A.C. Nieuwenhuijzen Kruseman volgens het besluit van het College van Decanen,

in het openbaar te verdedigen op

vrijdag 14 juni 2002 om 14.00 uur

door

Mariëlle Kroes 


\section{Promotores:}

Prof. dr. J.S.H. Vles

Prof. dr. J. Jolles

\section{Co-promotor:}

Dr. J.G.M. Hendriksen

\section{Beoordelingscommissie:}

Prof. dr. J. Troost (voorzitter)

Prof. dr. P.J.M.L. Casaer (Katholieke Universiteit Leuven, België)

Prof. dr. J.A. Knottnerus

Prof. dr. J.J. van Os

Prof. dr. L.M.E. Smit (Vrije Universiteit, Amsterdam)

\section{Co-pro-io:}

Drs. Ir. A.G.H. Kessels

The studies presented in this thesis were part of the "Study of Attention disorders in Maastricht (SAM-study)", performed at the Brain and Behaviour Institute, at the department of Neurology of the University Hospital in Maastricht.

Studies were financially supported by the University Hospital Maastricht (Profilerings Fonds), the Prevention Foundation of the Netherlands, and the the St.Clemens Foundation and Kanunnik Salden Nieuwenhof Foundation

Publication of this thesis was financially supported by: the Van Leersumfonds (KNAW), and Glaxo Wellcome B.V. 


\section{Uit de praktijk...}

Aan de keukentafel tijdens de lunch vliegen Jonas (II) en zijn zusje Lotte (5) elkaar in de haren waarbij Jonas zijn zusje een "stom hyperactief kind" noemt. Ontredderd en in tranen vraagt Lotte zich af wat haar broer eigenlijk met hyperactief bedoelt en Jonas legt dit haarfijn uit: "gewoon, dat je geschift bent...".

Nieuwsgierig hangt Lenny (5) over me heen als ik de gedragsobservatie lijst invul. Ze vraagt me wat ik doe en ik leg haar uit dat ik opschrijf of ik haar verdrietig, vrolijk of verlegen vind. "Nou verlegen in ieder geval niet", zegt ze stellig. Als ik haar vraag wat dat eigenlijk is, verlegen zijn, weet ze dit magnifiek te verwoorden: "verlegen is, dat je iemand een hand geeft en vervolgens een beetje stom gaat zitten lachen..."

Tijdens het motorisch onderzoek kijkt Sanne (5) me ineens doordringend aan en vraagt: "Ben jij eigenlijk een meisje of een mevrouw?" Verrast door deze scherpe observatie vertel ik haar dat ik het eigenlijk niet zo precies zou weten. $\mathrm{Na}$ afloop van het onderzoek vul ik de laatste gegevens in en pluist Sanne tussentijds nieuwsgierig mijn portemonnee uit, hetgeen haar de oplossing op haar vraagt oplevert: "Oooo, je hebt een rijbewijs, maar dan ben je wel een mevrouw..." 



\section{CONTENTS:}

\section{Chapter I}

General Introduction.

\section{Chapter 2}

Attention-Deficit / Hyperactivity Disorder (ADHD) and motor control....

\section{Chapter 3}

Reliability and validity of a qualitative and quantitative motor test

for 5 -to 6 years old children.

Appendix Maastricht Motor Test

\section{Chapter 4}

Quality of movement as predictor of Attention-Deficit / Hyperactivity Disorder: results from a prospective population study in 5- and 6-year-old children.

\section{Chapter 5}

Precursors of ADHD Questionnaire: development and some psychometric features..

\section{Chapter 6}

Child psychiatric diagnoses in a population of Dutch schoolchildren aged 6 to 8 years. 81

\section{Chapter 7}

A longitudinal community study: do psychosocial risk factors and Child Behavior Checklist (CBCL) scores at 5 to 6 years of age predict psychiatric diagnoses at a later stage?

\section{Chapter 8}

General discussion

Summary.

Samenvatting.

Dankwoord

Publications \&Curriculum Vitae. 



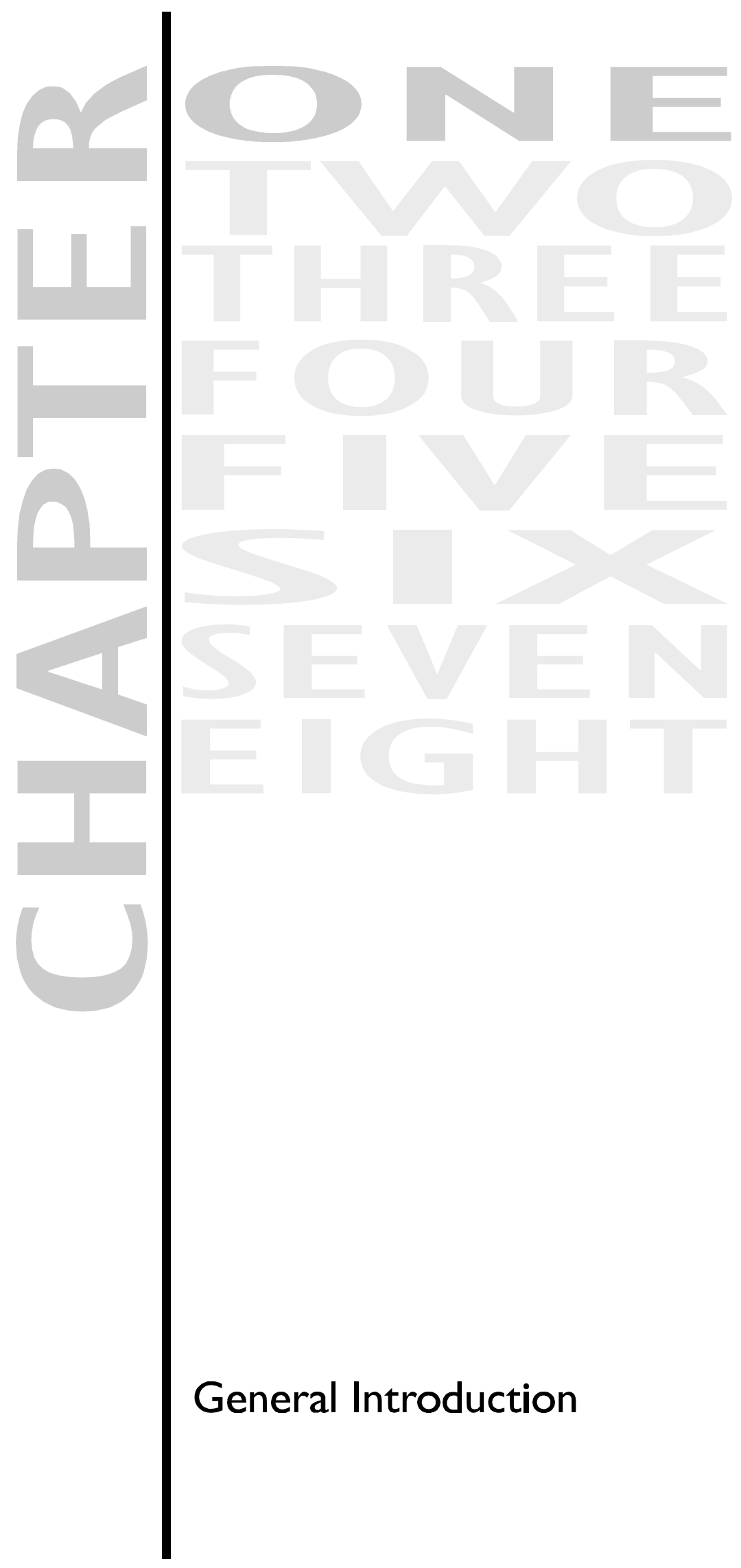





\section{BACKGROUND}

Attention-Deficit/Hyperactivity Disorder (ADHD) is an early onset, clinically heterogeneous disorder of inattention, hyperactivity, and impulsivity. Its impact on society is enormous in terms of its financial costs, stress to families, adverse academic and vocational outcomes, and negative effects on self-esteem (Faraone and Biederman, 1998). About $66 \%$ of individuals in whom ADHD is diagnosed in childhood still meet the criteria in adulthood, and in about $20 \%$ of such children a diagnosis of antisocial personality is made (Barkley, 1998). For this reason, early identification of children at risk of ADHD is important because it could lead to earlier treatment and might prevent further difficulties.

Although it is generally assumed that ADHD has its basis in the early years, it is usually first diagnosed during elementary school years, when children show poor adjustment to the school routine (American Psychiatric Association, 1994). Many of the behavioural symptoms that characterise ADHD in school-age, are not that specific in younger children. In some children the problems will persist, but many young children with hyperactive and impulsive behaviour will outgrow their difficulties (Pierce et al., 1999). For this reason, it is often difficult to distinguish between problem behaviours that are transient and not clinically relevant and those that are (Campbell, 1995). While several studies have shown that hyperactivity at a pre-school-age can predict ADHD at a later stage (Campbell, 1987; McGee et al., 1991; Pierce et al., 1999), it is still unclear in which of the children the problems will persist. At this age, the symptoms of ADHD as defined in DSM-IV, apparently do not necessarily reflect the disorder but may also be part of normal behavioural development. Although a tremendous amount of research has been published on children with ADHD, the vast majority of this research has involved school-aged children (Mariani and Barkley, 1997).

\section{AIMS OF THE STUDY}

To promote early identification of children at risk for ADHD, prospective community studies involving younger children are needed. These studies should focus not only on behavioural signs of ADHD but also on developmental profiles and risk factors for the disorder. To meet this need, the "Study of Attention disorders in Maastricht (SAM-study)" was designed, and started in 1996 (see below). The general aim of the SAM-study is to investigate the developmental profile and risk factors at 5 -and 6-years of age for developing ADHD.

The present thesis focuses on part of the SAM-study and will dilate upon the following questions:

I. Could certain aspects of motor performance at 5-and 6-years of age play a role in the early diagnosis of ADHD?

2. Which behavioural characteristics at 5-and 6-years of age could predict ADHD at later stage? 
3. What is the prevalence rate of ADHD and other psychiatric diagnoses in a schoolbased population of children aged 6-8?

4. Do psychosocial risk factors and $\mathrm{CBCL}$ scores at 5-and 6-years of age predict ADHD and other psychiatric diagnoses in later stage?

\section{STUDY OF ATTENTION DISORDERS IN MAASTRICHT: DESIGN}

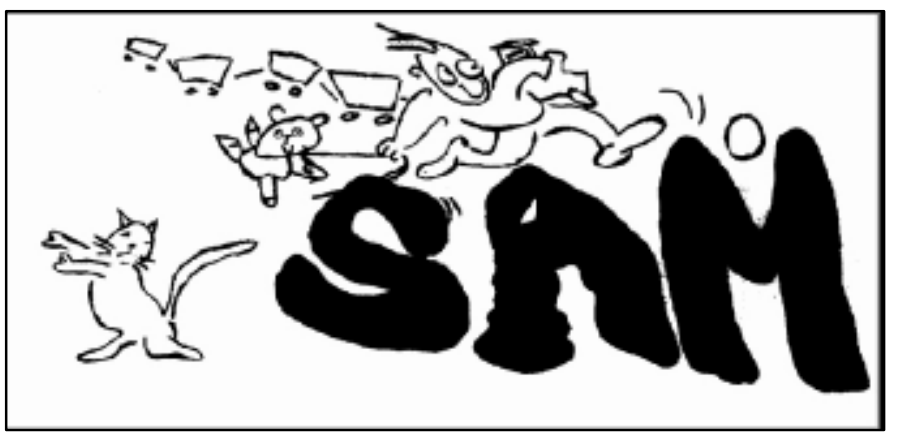

The above mentioned questions were embedded in the SAM study, which is a multidisciplinary research project and is carried out by the joint effort of the University Hospital of Maastricht (Department of Neurology, Department of Pediatrics, Department of Psychiatry and the Research Unit Patient Care), the University Maastricht (Department of Psychiatry and Neuropsychology), the Youth Health Care of the Municipal Health Centre and the Child Revalidation Centre Franciscusoord.

A prospective longitudinal (four-stage) research design was used and all children attending second grade of normal kindergarten schools in Maastricht and its surroundings were included in the study (see figure I.I). In the first stage, the children were selected using the Child Behavior Checklist (CBCL; Verhulst et al., 1996). Demographic information was collected from the medical records of the Youth Health Care organisation (YHC). In addition, an experimental questionnaire for early detection of children at risk of ADHD, the Precursors of ADHD Questionnaire (PAQ; Hendriksen and Steyaert, 1999), was completed by the parents. In the same year (second stage), the selected children were invited for further investigation. This consisted of the Maastricht Motor Test (MMT; Vles and Kroes, in preparation, Kroes et al, submitted) and a neuropsychological test battery. One year later, in the third stage, more detailed psychiatric information was collected from the selected children by using the Amsterdam Diagnostic Interview for Children and Adolescents (ADIKA; Kortenbout van der Sluijs et al., 1993). Finally, 3 years after the start of the study (fourth stage), all selected children were invited to return for psychiatric and neuropsychological follow-up investigations. In order to replicate our findings and enlarge the study group, the entire study has been repeated in a second cohort. This thesis focuses on the first three stages of the SAM-study. 


\begin{tabular}{|c|c|c|c|}
\hline \multicolumn{4}{|c|}{ Sampling design for the Study of Attention disorders in Maastricht } \\
\hline STAGE I & TAGE 2 & AGE 3 & GE 4 \\
\hline $\begin{array}{l}\text { Month I-9: } \\
\text { Responders }(\mathrm{N}=|3| 7) \\
\begin{aligned} \text { - } & \mathrm{CBCL} \\
\text { - } & \text { Demographic } \\
& \text { information } \\
\text { - } & \text { PAQ }\end{aligned}\end{array}$ & $\begin{array}{l}\text { Month 4-9: Sample for } \\
\text { longitudinal study } \\
(\mathrm{N}=452) \\
\text { - } \mathrm{MMT} \\
\text { - Neuropsy- } \\
\text { chological } \\
\text { test battery }\end{array}$ & $\begin{array}{l}\text { Month I5-25: Sample for } \\
\text { longitudinal study } \\
(\mathrm{N}=452) \\
\qquad \text { ADIKA }\end{array}$ & $\begin{array}{l}\text { Month 39-49: Sample } \\
\text { for longitudinal study } \\
(\mathrm{N}=452) \\
\text { - ADIKA } \\
\text { - Neuropsy- } \\
\text { chological } \\
\text { test-battery }\end{array}$ \\
\hline
\end{tabular}

$\mathrm{CBCL}=$ Child Behaviour Checklist, $\mathrm{PAQ}=$ Precurors of $\mathrm{ADHD}$ Questionnaire, MMT= Maastricht Motor Test, $\mathrm{ADIKA}=\mathrm{Amsterdam}$ Diagnostic Interview for Children and Adolescents

\section{THE OUTLINE OF THIS THESIS}

The main focus of this thesis is on the early characteristics of child psychopathology in general and of ADHD in particular. In line with the multidisciplinary nature of the SAM project, different aspects of child psychopathology were investigated and the questions above are answered in chapter 2 to 8 .

\section{Chapter 2: review of the literature}

A review of the literature is provided in chapter 2 . The review focuses on general aspects of ADHD, its aetiology, and associated problems. Special attention is paid to motor performance and its relation with ADHD.

\section{Chapter 3 and 4: the Maastricht Motor Test}

Motor performance in 5 to-6-year-old children may predict developmental problems and school functioning in later years. Currently used motor tests for this age group only assess quantitative aspects of a movement (=milestones). However, abnormalities of motor performance are not only revealed by actual developmental milestones but also by the pattern of a movement, which is called quality. The Maastricht Motor Test was developed to objectify and score both quantitative and qualitative aspects of different movements. It was developed in collaboration with the Department of Neurology of the University Hospital and the Youth Health Care of the Municipal Health Centre in Maastricht. A manual and CDROM of the instrument were prepared in close co-operation with the Audiovisual Department of the University Hospital in Maastricht and will be published by PITS (Leiden). The development of the Maastricht Motor Test is described in chapter 3 and the utility of the instrument to identify precursors of ADHD is described in chapter 4. 


\section{Chapter 5: the Precursors of ADHD Questionnaire.}

Behavioural characteristics of ADHD may be present at an early age but do not necessarily lead to the disorder. This is because some of the key symptoms of ADHD are also characteristic of normal pre-school age behaviour. Instruments that are often used in the Netherlands to screen children for ADHD were not specially developed and validated for kindergarten children. The 'Precursors of ADHD Questionnaire', which could be helpful in detecting early signs of ADHD, is described in Chapter 5.

\section{Chapter 6: Prevalence estimates of child psychopathology}

Little is known about the prevalence of DSM-based disorders in children younger than 9 years. Of the studies performed, most have concentrated on behavioural problems in general, without focusing on child psychiatric diagnoses. In this chapter, the estimated prevalence of psychopathology in a population of Dutch school-children aged 6 to 8 years is described.

\section{Chapter 7: Psychosocial risk factors and CBCL scores related to child psychopathology}

Knowledge of early risk factors of psychopathology may increase the possibility for early identification and subsequent treatment of such disorders. Given the relative absence of longitudinal community studies examining the development of child psychiatric disorders in young children, it is not surprising that very few studies have investigated which risk factors at kindergarten age contribute to child psychiatric disorders later. In Chapter 7 the value of certain psychosocial risk factors in 5-to 6-year-old children in relation to later psychopathology is investigated. In addition, the predictive value for different (sub-) scales of the $C B C L$ in relation to child psychopathology is examined.

\section{Chapter 8: General discussion}

While the predictive value of several tests and psychosocial risk factors for ADHD were described separately in chapter 3 to 7 , this chapter will be used to investigate the effect of integration of separate features and will note some recommendations for future research concerning the SAM study and the Maastricht Motor Test. 


\section{REFERENCES}

American Psychiatric Association (1994), Diagnostic and Statistical Manual of Mental Disorders. 4th edition (DSMIV) Washington D.C.: American Psychiatric Association

Barkley RA (1998), Attention Deficit Hyperactivity Disorder, A handbook for diagnosis and treatment. 2nd edition London: The Guilford Press

Campbell SB (1987), Parent-referred problem three-year-olds: developmental changes in symptoms. Journal of Child Psychology and Psychiatry and Allied Disciplines 28: 835-45

Campbell SB (1995), Behavior problems in preschool children: A review of recent research. Journal of Child Psychology and Psychiatry and Allied Disciplines 36: II3-149

Faraone SV, Biederman J (1998), Neurobiology of Attention-Deficit Hyperactivity Disorder. Biological Psychiatry 44: $951-958$

Hendriksen JGM, Steyaert J (1999), Ontwikkeling van de Vragenlijst Voorlopers ADHD. Interne publicatie, Academisch Ziekenhuis Maastricht

Kortenbout van der Sluijs MJ, Levita MJ, Manen de R, Defares BP (1993), ADIKA, Amsterdams diagnostisch interview voor kinderen en adolescenten. Lisse: Swets \& Zeitlinger

Kroes M, Vissers YLJ, Sleypen FAM, Feron F, Kessels AGH, Bakker E, Kalff AC, Hendriksen JGM, Steyaert J, van Zeben TMCB, Jolles J, Troost J, Vles JSH (submitted), Reliability and validity of a qualitative and quantitative motor test for kindergarten children.

Mariani MA, Barkley RA (1997), Neuropsychological and academic functioning in preschool boys with attention deficit hyperactivity disorder. Developmental Neuropsychology I3: I II-I29

McGee R, Partridge F, Williams S, Silva PA (199I), A twelve-year follow-up of preschool hyperactive children. Journal of American Academy of Child and Adolescent Psychiatry 30: 224-32

Pierce EW, Ewing LJ, Campbell SB (1999), Diagnostic status and symptomatic behavior of hard-to-manage preschool children in middle childhood and early adolescence. Journal of Clinical Child Psychology 28: 4457

Verhulst FC, Ende van der J, Koot HM (1996), Handleiding voor de CBCL 4-I8 Rotterdam: Afdeling Kinder en jeugdpsychiatrie, Sophia Kinderziekenhuis/Academisch Ziekenhuis Rotterdam/ Erasmus Universiteit Rotterdam

Vles JSH, Kroes M (in preparation), Handleiding bij “Instructie CD-ROM Maastrichtse Motoriek Test” Leiden: PITS 



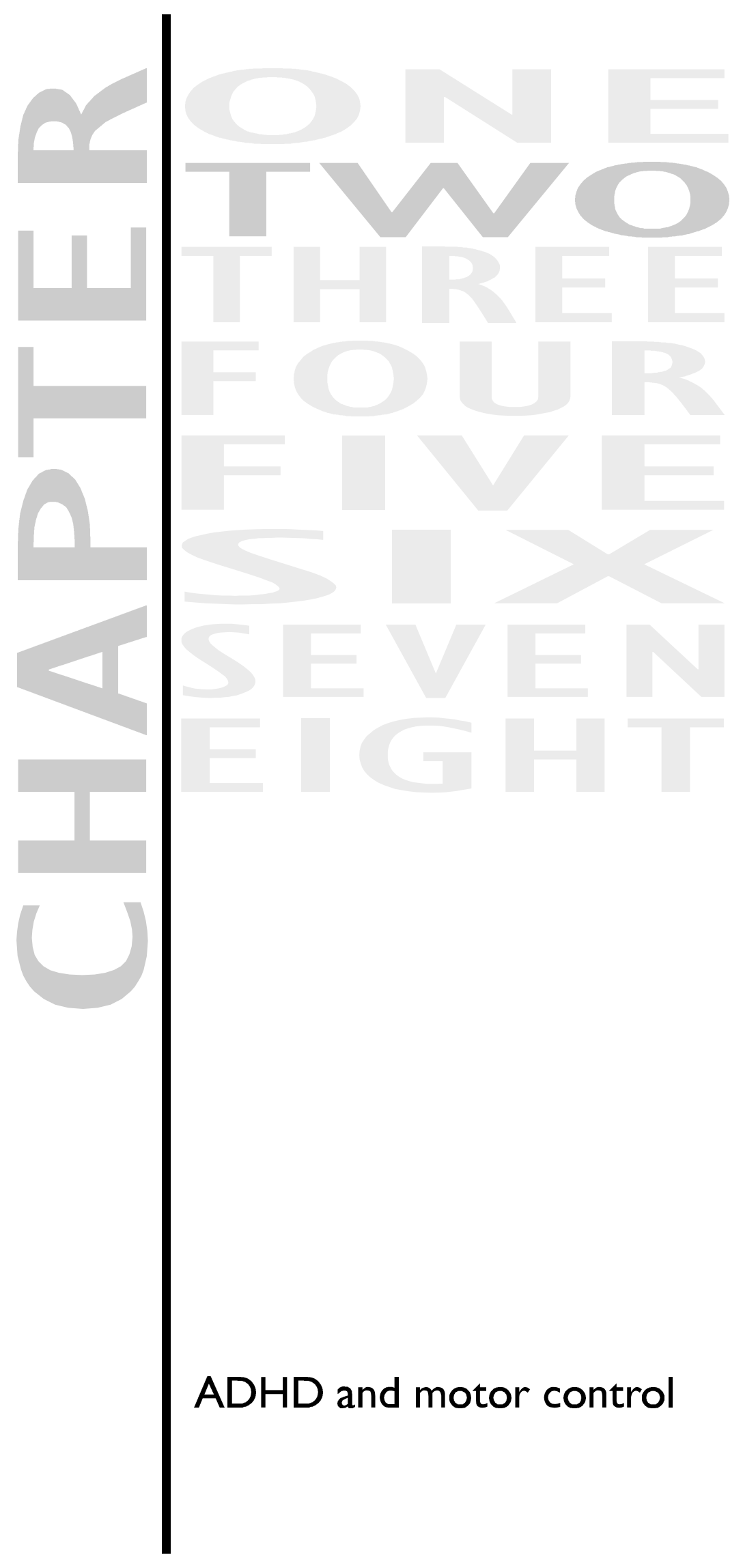



Attention-Deficit/Hyperactivity Disorder (ADHD) is an early onset, clinically heterogeneous disorder of inattention, hyperactivity, and impulsivity. Symptoms of the disorder are present before the age of seven and in about $66 \%$ of the children with ADHD, symptoms will persist into adulthood. Beside the primary symptoms, it is known that the disorder is often associated with various associated problems (e.g. emotional, cognitive, speech, motor problems). The following review will dilate upon ADHD in general, and besides, special attention is paid to motor performance and its relation with ADHD.

\section{Attention-Deficit / Hyperactivity Disorder: history}

No other childhood psychopathology has undergone as much renaming and reconceptualisation as ADHD. Already in 1902, George Still described a behavioural condition in children that most closely approximates to what today is known as AttentionDeficit / Hyperactivity Disorder (ADHD). He described a group of children characterised by "a defect in moral control" and suggested an underlying organic substrate, caused by a genetic predisposition (Still, 1902). Since the 1940s, psychiatrists have successively applied various labels to these children, varying from "Brain Injured Child" to, "Minimal Brain Damage" or, "Minimal Brain Dysfunction (MBD)".

In the late 1950s and early 1960s, the concept of MBD was disputed because of its nonspecific character (Chess, 1960) and the lack of neurological evidence of brain damage. In the late 1960s the American Psychiatric Association, in their diagnostic manual, considered behavioural aspects to be more important and introduced the term (DSM-II; American Psychiatric Association, 1968). Later, the Association put emphasis on the problems of attention that are characteristic of this disorder and formulated the new diagnostic term Attention Deficit Disorder (ADD, with or without hyperactivity) (DSM-III; American Psychiatric Association, 1980). The latter versions of the manual (DSM-IIIR and DSM-IV) use the term "Attention- Deficit / Hyperactivity Disorder" (AD/HD) (American Psychiatric Association, 1987; American Psychiatric Association, 1994). Although the term did not change in DSM-IV, the criteria for ADHD did.

\section{Attention-Deficit / Hyperactivity Disorder: diagnostic criteria}

The DSM-IV criteria of ADHD contain 18 symptoms in three separate dimensions: inattention, hyperactivity, and impulsivity. On the basis of these three dimensions, three distinct types of ADHD are recognised, known as "Combined Type", "Predominantly Inattentive Type", and "Predominantly hyperactive impulsive type"(American Psychiatric Association, 1994) (see table 2.I).

In addition to the DSM-IV description of ADHD, the ICD-I0 (World Health Organisation, 1993) used the term of "Hyperkinetic Disorder". The term DAMP (Deficiency of Attention, Motor control, and Perception) has been used in Scandinavian countries since the mid-1980. In this thesis, the term ADHD is used, as given in the DSM-IV definition. 
Table 2.I Diagnostic criteria for Attention-Deficit/Hyperactivity Disorder

A. Either (I) or (2):

(I) six (or more) of the following symptoms of inattention have persisted for at least 6 months to a degree that is maladaptive and inconsistent with developmental level:

\section{Inattention}

(a) often fails to give close attention to details or makes careless mistakes in schoolwork, work, or other activities

(b) often has difficulty sustaining attention in tasks or play activities

(c) often does not seem to listen when spoken to directly

(d) often does not follow through on instructions and fails to finish schoolwork, chores, or duties in the workplace (not due to oppositional behavior or failure to understand instructions)

(e) often has difficulty organizing tasks and activities

(f) often avoids, dislikes, or is reluctant to engage in tasks that require sustained mental effort (such as schoolwork and homework)

(g) often loses things necessary for task or activities (e.g., toys, school assignment, pencils, books, or tools)

(h) is often easily distracted by extraneous stimuli

(i) is often forgetful in daily activities

(2) six (or more) of the following symptoms of hyperactivity-impulsivity have persisted for at least 6 month to a degree that is maladaptive and inconsistent with developmental level:

Hyperactivity

(a) often fidgets with hands or feet or squirms in seat

(b) often leaves seat in classroom or in other situation in which remaining seated is expected

(c) often runs about or climbs excessively in situations in which it is inappropriate (in adolescents or adults, may be limited to subjective feelings of restlessness)

(d) often has difficulty playing or engaging in leisure activities quietly

(e) is often "on the go" or often acts as if "driven by a motor"

(f) often talks excessively

Impulsivity

(g) often blurt out answers before questions have been completed

(h) often has difficulty awaiting turn

(i) often interrupts or intrudes on others (eg. butts into conversation or games)

B. Some hyperactive-impulsive or inattentive symptoms that causes impairment were present before age 7 years.

C. Some impairment from the symptoms is present in two or more settings (e.g., at school [or work] and at home).

D. There must be clear evidence of clinically significant impairment in social, academic, or occupational functioning.

E. The symptoms do not occur exclusively during the course of a Pervasive Developmental Disorder, Schizophrenia, or Psychotic Disorder and are not better accounted for by another mental disorder (e.g., Mood Disorder, Anxiety Disorder, Dissociative Disorder, or a personality Disorder)

Code based on type:

3 I4.0I Attention-Deficit/Hyperactivity Disorder, Combined Type: (ADHD-C) If both Criteria $\mathrm{Al}$ and $\mathrm{A} 2$ are met for the past 6 months

314.02 Attention-Deficit/Hyperactivity Disorder, Predominantly Inattentive Type: (ADHD-PI)

If Criterion $\mathrm{A}$ l is met but Criterion $\mathrm{A} 2$ is not met for the past 6 months

314.0I Attention-Deficit/Hyperactivity Disorder, Predominantly HyperactiveImpulsive Type: (ADHD-PHI)

If Criterion $A 2$ is met but Criterion $A 1$ is not met for the past 6 months

Coding note: For individuals (especially adolescents and adults) who currently have symptoms that no longer meet full criteria, "In partial Remission" should be specified. 


\section{Attention-Deficit / Hyperactivity Disorder: prevalence rates}

Attention-Deficit / Hyperactivity Disorder (ADHD) is considered the most common chronic behaviour disorder observed in the pre-adolescent population. Although prevalence rates range from $1 \%$ to $24 \%$ (Swanson et al., 1998), most studies report a prevalence of 3-5\% (American Psychiatric Association, 1994). Indeed, children with ADHD make up as much as $50 \%$ of clinical child psychiatry populations (Cantwell, 1996). Furthermore, it is known that in about $66 \%$ of children with ADHD, symptoms will persist into adulthood. The male-tofemale ratio varies from $4: 1$ in the general population to 9:1 in clinical settings (American Psychiatric Association, 1994; Gomes et al., 1999).

Although several studies investigated the prevalence of ADHD, there are some issues that deserve extra attention. Firstly, current prevalence rates are mainly for children older than 9 years (Lavigne et al., 1998; Roberts et al., 1998). This might be due to the lack of consensus on appropriate assessment tools for measuring psychopathology, and especially ADHD, in younger children (Keenan et al., 1997). To gain insight into prevalence rates in younger children, structured interview procedures should be applied to the general population of children younger than 9 years. Secondly, the under-representation of girls in referred samples and the probable differences in the characteristics of these children may give rise to results which are not representative of the nature of the disorder (Carlson et al., 1997; Gaub and Carlson, 1997; Barkley, 1998). For these reasons, population-based research is of great importance when investigating the prevalence of ADHD.

\section{Attention-Deficit / Hyperactivity Disorder: aetiology}

Although ADHD has multifactorial aetiology, evidence points to neurological and genetic factors as being the most important contributors to this disorder (see for review: Barkley, 1998). Since the 90 s both neuropsychological and neuro-imaging studies have demonstrated an underlying neurological substrate, implicating a dysfunction of frontosubcortical structures in the pathophysiology of ADHD (Faraone and Biederman, 1998).

However, neuro-imaging results are not consistent and implicate a variety of loci in ADHD. Research has tended to focus on the pre-frontal cortex, the basal ganglia (especially the caudate nucleus) and the cerebellum. Results suggest that these structures are smaller in children and adults with ADHD (Castellanos et al., 1996; Hynd et al., 1993; Semrud-clikeman et al., 2000).

Genetic studies suggest a polygenetic inheritance which may lead to a hypofunctional dopamine system in ADHD (Sagvolden and Sergeant, 1998; Solanto, 1998). The association of the dopamine transporter gene (DATI) with ADHD is of particular importance (Dougherty et al., 1999). Over-expression of DAT results in lower concentrations of dopamine in the synaptic cleft. This relative dopamine deficiency is postulated to be one of the causes of ADHD and is a main target for medication; both D-amphetamine and methylphenidate inhibit dopamine reuptake by binding to the dopamine transporter (Solanto, 1998). 
The dopamine system consists of two primary ascending subsystems: (a) the nigrostriatal system originating in the substantia nigra and terminating in the striatum, which consists of the caudate nucleus and putamen; and (b) the mesocorticolimbic pathway in which several limbic structures receive their dopaminergic input from the midbrain (Martin, 1989; Swanson et al., 200I). Both systems are thought to play an important role in the two main characteristics of ADHD, namely, attention and motor behaviour (Swanson et al., 200I).

Although several psychosocial studies have suggested causes of ADHD, these results should be interpreted with caution. Measures of adversity, such as low social class, family conflict, and maternal depression, may reflect effects of the same genes that cause ADHD, rather than independent causes of the disorder (Faraone and Biederman, 1998). Although these factors are not thought to play an important primary aetiological role, they may function as exacerbating factors, determinants of comorbidity, and contributors to the persistence of the disorder (Barkley, 1998).

\section{Attention-Deficit / Hyperactivity Disorder: motor performance}

ADHD commonly occurs with other conditions such as psychiatric disorders (e.g. oppositional, conduct, anxiety and mood disorders), cognitive problems, emotional problem, learning disabilities, and problems with motor development. Knowledge of comorbidity of ADHD in community-derived samples is important to increase our understanding of the aetiology and course of the disorder to develop appropriate treatments (Angold et al., 1999). The association between ADHD and motor performance is a main theme in this thesis.

This interest is fed by the science behavioural neurology, a field of neurology that focuses on the relation between behaviour and neurological functions and substrates (Farber and Njiokiktjien, 1993). It is known that dopaminergic neurotransmission may be involved in both ADHD and sensorimotor integration (Koepp et al., 1998). For this reason, Sagvolden and Sergeant (1998) suggested that future research should investigate more closely the extent to which motor problems are associated with ADHD. Some issues concerning motor control are discussed below.

\section{Motor control : neuro anatomical background}

The nervous system as a whole is considered to contribute to each motor act (Brooks, 1986). Before a movement is made, the activity of different organic structures in the central nervous system has to be integrated. A three-level system is used to describe the organisation of motor behaviour. The highest level (association cortex and limbic system) plays an important role in the strategy of a movement; the middle level (sensori-motor cortex, cerebellum, basal ganglia, and brain stem) controls the movement, such as its fluency and co-ordination; and the lowest level (spinal cord) translates commands into muscle activity (Brooks, 1986).

Two brain structures play a key role in motor control, namely, the cerebellum and the basal ganglia. The cerebellum plays a major role in the coordination of movement. It receives input 
from virtually the entire central nervous system, including all of the sensory systems and cortical association areas, as well as diverse areas of the brain stem. Its output is focused on specific components of the motor system, such as the primary cortex and the premotor cortex.

The basal ganglia are currently considered part of a distributive system involved in many functions. The 'cortex-basal ganglia-thalamus-cortex loops' provide the anatomo-functional basis for motor, cognitive, and associative functions. Disruption of one of these circuits can give rise to problems ranging from the more common parkinsonian syndrome to complex neuropsychological disorders. On the basis of their connections, the different basal ganglia nuclei can be divided into three categories: (I) input nuclei, (2) output nuclei, and (3) intrinsic nuclei. Of all circuits passing through the basal ganglia, the motor circuit is the most relevant to the pathophysiology of movement disorders. The putamen (input nucleus) receives afferent connections from the cerebral cortex. The globus pallidus and substantia nigra pars reticulata (output nuclei) have projections that leave the basal ganglia. The substantia nigra par compacta (intrinsic nucleus) receives input from, and projects to, the input and output nuclei. The last nucleus provides the dopaminergic input to the caudate nucleus and putamen. A lack of dopamine is a known cause of movement problems. The pathways of motor control are shown in figure 2.I, which is based on Martin's textbook (1989), entitled "Neuroanatomy".

Figure 2.I Pathways in motor control, adapted from "Neuroanatomy" by Martin

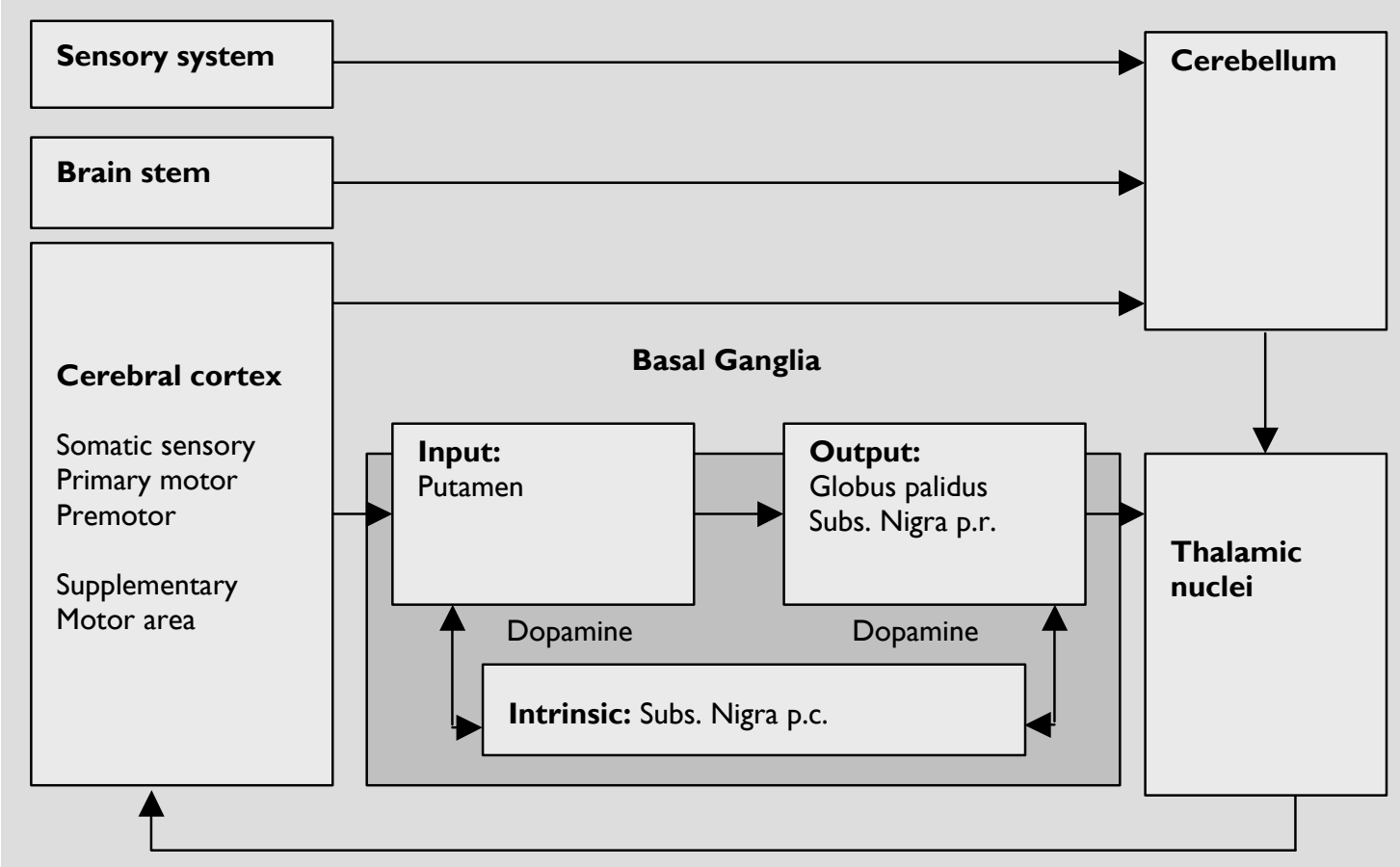




\section{Motor control: theoretical background}

Integrative brain activity, its maturation and normal development, is poorly understood (Farber and Njiokiktjien, 1993). During the last century, several theories on motor development were formulated. In the mid-1900s, Gesell's 'maturation theory' played a significant role (Gesell, 1945). According to this theory, motor development is the result of an increasing cortical control over lower reflexes based on genetic information. The neurological maturational state of the nervous system is considered as the main constraint for developmental progress. As a counterpart of the 'Maturation Theory', the 'Dynamic System Theory' emphasises the role of the environment in addition to the maturational level of the central nervous system (Bernstein, 1967; Lockman and Thelen, 1993). The most recent theory of motor development is the 'Neuronal Group Selection Theory (NGST)' (Sporns and Edelman, 1993), which combines the 'nature' part of the 'Maturation Theory' with the 'nurture' part of the 'Dynamic System Theory' (Haddes-Algra, 2000). According to this theory, brain function is subject to Darwin's principles, thus making adaptive processes and learning and creative processes possible. Variation is the key word for normal development. This variation in motor behaviour knows two forms: primary variability, which is not geared to external conditions, and secondary variability, in which motor performance can be adapted to specific situations. In both cases, selection on the basis of afferent information plays a significant role (Hadders-Algra, 2000). The more limited the variability in motor performance, the worse is the motor performance.

\section{Measuring motor performance}

The knowledge that clumsiness in early school years is strongly related to subsequent academic difficulties and psychological problems is consistent with the idea that early screening and intervention strategies are of utmost importance (Wiart and Darrah, 200I). For this reason, in the Netherlands all 5 to-6-year-old children are examined by the Youth Health Care organisation (YHC). This organisation provides periodic systemic health examinations for children, and assessment of motor performance is an important component of this health check-up.

Studying motor performance, two aspects can be scored: quantity and quality. Where the quantitative aspects of a movement reflects the milestones of development, qualitative aspects describe movement patterns (Boyce et al., 1995). From a neurological point of view the qualitative aspects of different movements are considered to reflect the maturity and integrity of the brain (Gabbard, 1996; Hempel, 1993; Hadders-Algra and Groothuis, 1999; Prechtl et al., 1997). Children with developmental disorders often are characterised by impaired qualitative motor acts, such as a lack of motor persistence (sustained attention during motor task), variability, gracefulness and precision (Farber and Njiokiktjien, 1993). Remarkably, most of the tests developed to assess motor activity in 5 to 6-year-old children measure only quantitative aspects of a movement. The assessment of qualitative aspects of motor behaviour is mostly subjective and relies on the experience of the physician (Smyth, 
1992). Two important exceptions in this field, however, are the neurological examinations of Touwen (1979) and Hempel (1993) which, among others, will be discussed below.

\section{Short review of current motor tests for 5-6 year old children}

In the first few years of life, developmental milestones reflect maturation of the nervous and musculoskeletal systems and thus can be used to detect developmental problems. After 3 years of age, it is especially the way a movement is executed (quality) that reflects variations in motor development. When reviewing current motor tests, it is important to focus not only on the need for norm-referenced, observational, age-adequate measures, but also on the reliability and validity of the tests. With regard to quantitative measures, we will focus on the Bruininks-Oseretsky Test of Motor Proficiency (BOTMP; Bruininks, 1978), the Test of Motor Impairment (TOMI; Stott et al., 1984), and the Movement ABC (M-ABC; Henderson and Sugden, 1992). Although the BOTMP is a well-established test to measure motor function and has been used extensively in physical education, there are some concerns regarding the reliability, validity, and clinical utility of some of the test items (Wiart and Darrah, 200I). The M-ABC was developed from the TOMI and is composed of two components: a performance test and a checklist. Information concerning the psychometric properties of both these components is very limited and further evaluation is required (Wiart and Darrah, 200I).

Of the qualitative motor scores, Touwen's examination (1979) is one of the most widely used tests for detecting soft neurological signs in children aged 3-12 years. This test, however, has not been validated and its reliability is weak, especially with regard to the nine separate categories used (Kakebeeke et al., 1993). A second qualitative motor score is the neurological examination for toddler-age which focuses on qualitative motor performance during spontaneous play between the examiner and the child (aged I.5-4 years) (Hempel, 1993). A third, recently developed, test is the Zürich Neuromotor Assessment (ZMA; Largo et al., 200I). It focuses on time performance and associated movements in children aged 5 to 18. Although reliability and norm reference scores are reported, results concerning validation are not. Finally the Gross Motor Performance Measure (GMPM; Boyce et al., 1995) is a qualitative motor score which was especially developed for children with cerebral palsy. However, this instrument can not be used for normal children because its degree of difficulty is too low.

In summary, there is a lack of appropriate tools especially developed to measure qualitative aspects of several movements for the children aged 5-6. The Youth Health Care organisation (YHC) in the Netherlands, which examines all children of this age, is especially in need of such a tool. To meet this need, we developed a new motor test ('the Maastricht Motor Test') that is able to objectify both quantitative and qualitative aspects of several movements. Moreover the relation between ADHD and motor performance is investigated in this thesis. Because its known that dopaminergic neurotransmission is involved in both ADHD and sensorimotor integration (Koepp et al., 1998), our hypothesis is that analysis of especially the qualitative aspects of a movement can help in early diagnosis of ADHD. 


\section{REFERENCES}

Angold A, Costello EJ, Erkanli A (1999), Comorbidity. Journal of Child Psychology and Psychiatry and Allied Disciplines 40: 57-87

American Psychiatric Association (1968), Diagnostic and statistical manual of mental disorders. 2nd edition Washington, DC: American Psychiatric Association

American Psychiatric Association (1980), Diagnostic and statistical manual of mental disorders. 3rd edition Washington D.C.: American Psychiatric Association

American Psychiatric Association (1987), Diagnostic and statistical manual of mental disorders. 3rd, rev edition Washington D.C.: American Psychiatric Association

American Psychiatric Association (1994), Diagnostic and statistical manual of mental disorders. 4th edition Washington D.C.: American Psychiatric Association

Barkley RA (1998), Attention Deficit Hyperactivity Disorder, A handdbook for diagnosis and treatment. 2nd edition London: The Guilford Press

Bernstein N (1967), Co-ordination and regulation of movements. New York: Bantam press

Boyce WF, Gowland C, Rosenbaum PL, Lane M, Plews N, Goldsmith CH, Russell DJ, Wright V, Potter S, Harding D (1995), The Gross Motor Performance Measure: validity and responsiveness of a measure of quality of movement. Physical Therapy 75: 603-13

Brooks VB (1986), The neural basis of motor control. New York: Oxford university press

Bruininks RH (1978), Bruininks-Oseretsky Test of Motor Proficiency, Examiners Manual. Circle Pines, MN: American Guidance Service

Cantwell DP (1996), Attention Deficit Disorder: A review of the past 10 years. Journal of American Academy of Child and Adolescent Psychiatry 35: 978-87

Carlson CL, Tamm L, Gaub M (1997), Gender differences in children with ADHD, ODD, and co-occurring ADHD/ODD identified in a school population. Journal of American Academy of Child and Adolescent Psychiatry 36: 1706-14

Castellanos FX, Giedd JN, Marsh WL, Hamburger SD, Vaituzis AC, Dickstein DP, Sarfatti SE, Vauss YC, Snell JW, Lange N, Kaysen D, Krain AL, Ritchhie GF, Rajapakse JC, Rapoport JL (1996), Quantitative brain magnetic resonance imaging in attention-deficit hyperactivity disorder. Archives of general psychiatry 53 : 607-616

Chess S (1960), Diagnosis and treatment of the hyperactive child. New York State Journal of Medicine 60: 23792385

Dougherty DD, Bonab AA, Spencer TJ, Rauch SL, Madras BK, Fischman AJ (1999), Dopamine transporter density in patients with attention deficit hyperactivity disorder. The Lancet 354: 21 32-2 133

Faraone SV, Biederman J (1998), Neurobiology of Attention-Deficit Hyperactivity Disorder. Biological Psychiatry 44: $951-958$

Farber D, Njiokiktjien C (1993), Developing brain and cognition. Ist edition, Vol. 4 Amsterdam: Suyi Publications

Gabbard CP (1996), Livelong Motor Development. second edition Boston: McGraw-Hill

Gaub M, Carlson CL (1997), Gender differences in ADHD: a meta-analysis and critical review. Journal of American Academy of Child and Adolescent Psychiatry 36: 1036-45 
Gesell A (1945), The Embriology of behaviour. New York: Harper \& Row

Gomes R, Harvey J, Quick C, Scharer I, Harris G (1999), DSM-4 AD/HD: Confirmatory Factor Models, Prevalence and Gender and Age Differences Based on Parent and teacher Ratings of Australian Primary School Children. Journal of Child Psychology and Psychiatry and Allied Disciplines 40: 265-274

Hadders-Algra M (2000), The neuronal group selection theory: a framework to explain variation in normal development. Developmental Medicine \& Child Neurology 42: 566-572

Hadders-Algra M, Groothuis AMC (1999), Quality of general movements in infancy is related to neurological dysfunction, ADHD, and aggressive behaviour. Developmental Medicine\& Child Neurology 4I: 38I-39I

Hempel MS (1993), The neurological examination for toddler-age. Groningen, The Netherlands: thesis.

Henderson SE, Sugden DA (1992), Movement Assessment Battery for Children London: The Psychological Corporation

Hynd GW, Hern KL, Novey ES, Eliopulos D, Marshall R, Gonzalez JJ, Voeller KK (1993), Attention-deficit hyperactivity disorder and asymmetry of the caudate nucleus. Journal of child Neurology 8: 339-347

Kakebeeke TH, Jongmans MJ, Dubowitz LM, Schoemaker MM, Henderson SE (1993), Some aspects of the reliability of Touwen's examination of the child with minor neurological dysfunction. Developmental Medicine \& Child Neurology 35: 1097-105

Keenan K, Shaw DS, Walsh B, Delliquadri E, Giovannelli J (1997), DSM-III-R disorders in preschool children from low-income families. Journal of American Academy of Child and Adolescent Psychiatry 36: 620-627

Koepp MJ, Gunn RN, Lawrence AD, Cunningham VJ, Dagher A, Jones T, Brooks DJ, Bench CJ, Grasby PM (1998), Evidence for striatal dopamine release during a video game. Nature 393: 266-268

Lavigne JV, Arend R, Rosenbaum D, Binns HJ, Christoffel KK, Gibbons RD (1998), Psychiatric Disorders with onset in the preschool years: I. Stability of Diagnoses. Journal of American Academy of Child and Adolescent Psychiatry 37: 1247-1254

Largo RH, Caflisch JA, Hug F, Muggli K, Molnar K, Molinari M, Sheehy A, Gasser T (200I), Neuromotor development from 5 to 18 years. Part I: timed performance. Developmental Medicine \& Child Neurology 43: 436-443

Largo RH, Caflisch JA, Hug F, Muggli K, Molnar K, Molinari M (200I), Neuromotor development from 5 to I8 years. Part 2: associated movements. Developmental Medicine \& Child Neurology 43: 436-443

Lockman JJ, Thelen E (1993), Developmental biodynamics: Brain, body, behavioral connections (Special section introduction). Child Development 64: 953-959

Martin JH (1989), Neuroanatomy, text and atlas. New York: Appleton \& Lange

World Health Organisation (1993), The ICD-IO Classification of mental and behavioural Disorders: Diagnostic Criteria for Research. Geneva: World Health Organization

Prechtl HF, Einspieler C, Cioni G, Bos AF, Ferrari F, Sontheimer D (1997), An early marker for neurological deficits after perinatal brain lesions. The Lancet 349: 136I-3

Roberts RE, Attkisson CC, Rosenblatt A (1998), Prevalence of psychopathology among children and adolescents. American Journal of Psychiatry 155: 715-25

Sagvolden T, Sergeant JA (1998), Attention deficit/ hyperactivity disorder-from brain dysfunctions to behaviour. Behavioural Brain Research 94: 1-10 
Swanson JM, Flodman P, Kennedy J, Spence MA, Moyzis R, SChuck S, Murias M, Moriarity J, Barr C, Smith M, Posner M (200I) Dopamine genes and ADHD. Neuroscience and Biobehavioral Reviews 24: 2 I-25

Semrud-clikeman M, Steingard RJ, Filipek P, Biederman J, Bekken K, Renshaw PF (2000), Using MRI to examine brain-behavior relationships in males with attention deficit disorder with hyperactivity. Journal of American Academy of Child and Adolescent Psychiatry 39: 477-484

Smyth TR (1992), Impaired motor skill (clumsiness) in otherwise normal children: a review. Child: care, health and development 18: 283-300

Solanto MV (1998), Neuropsychopharmacological mechanisms of stimulant drug action in attention-deficit hyperactivity disorder: a review and integration. Behavioural Brain Research 94: I27-I52

Sporns O, Edelman GM (1993), Solving Bernstein's problem: A proposal for the development of coordinated movement by selection. Child Development 64: 960-98I

Still GF (1902), Some abnormal psychical conditions in children. The Lancet I: 1008-1012, 1077-1082, II631168

Stott DH, Moyes FA, Henderson SE (1984), The Henderson Revision of the Test of Motor Impairment. San Antonio: Psychological Corporation

Swanson JM, Sergeant JA, Taylor E, Sonuga Barke EJ, Jensen PS, Cantwell DP (1998), Attention-deficit hyperactivity disorder and hyperkinetic disorder. The Lancet 35I: 429-33

Touwen BCL (1979), Examination of the Child with Minor Neurological Dysfunction, 2nd ed. London: S.I.M.P.

Wiart L, Darrah J (200I), Review of four tests of gross motor development. Developmental Medicine \& Child Neurology 43: 279-285 


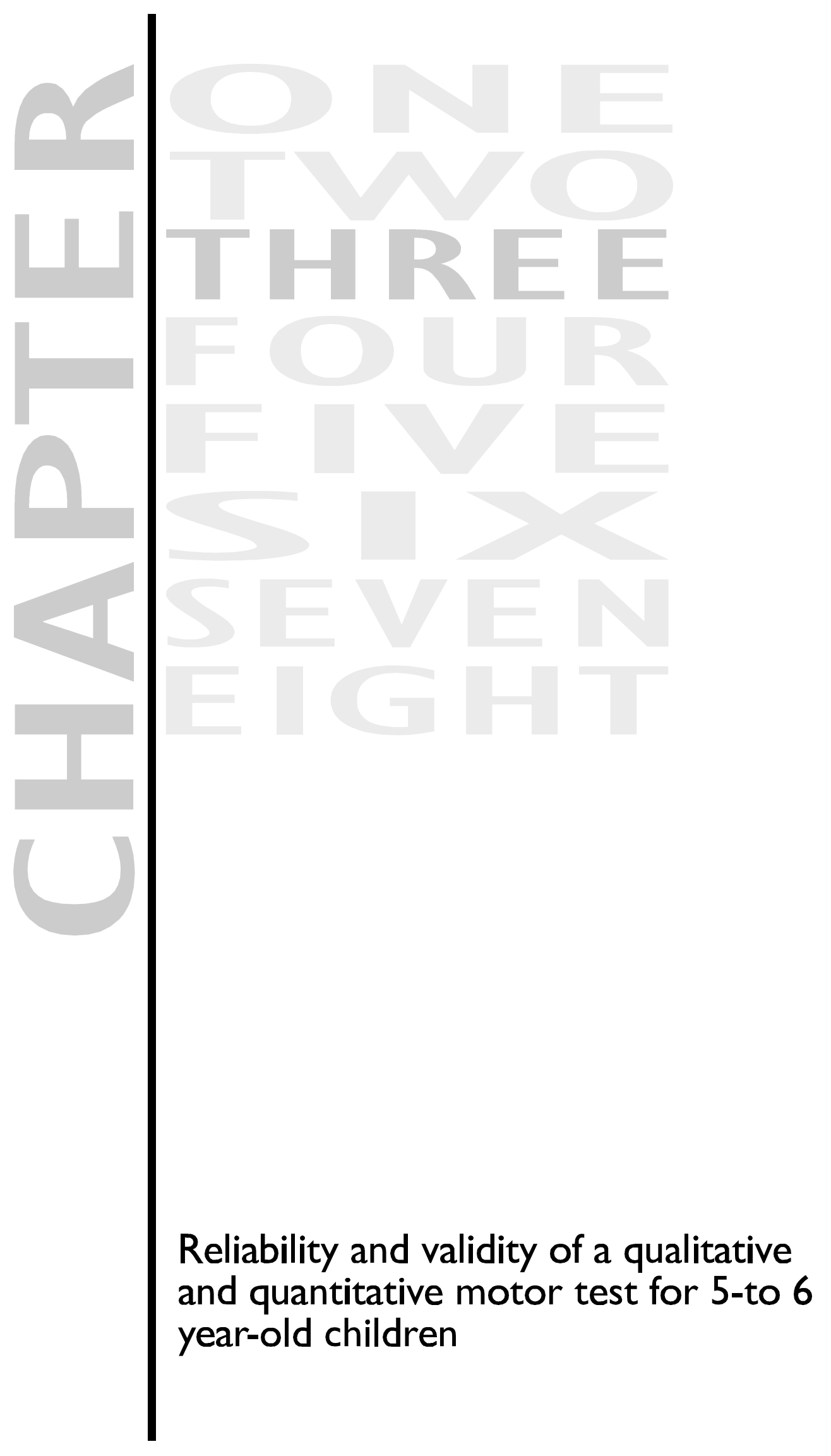





\begin{abstract}
Clumsiness in preschool children is generally assumed to be a precursor of impaired academic performance and psychological and developmental problems. It is assumed that in this age group the qualitative aspects (= pattern) of a movement reflect variation in motor development. Currently available motor tests for this age group, however, only objectify quantitative aspects of a movement. The aim of this study was to develop a new, valid, and reliable tool (Maastricht's Motor Test) to objectify qualitative and quantitative aspects of movement in 5 to-6 year-old children. The test covers Static Balance (14 items), Dynamic Balance (20 items), Ball Skills (8 items), and Diadochokinesis and Manual Dexterity (28 items). About $50 \%$ of the items measure qualitative aspects and $50 \%$ quantitative aspects of movements. In total 487 subjects were recruited from the first year of primary school. To validate the test, the school doctor's global judgement was used as a form of expert validity. Sensitivity and specificity were calculated for different cut-off points. Intraclass correlation coefficients (ICC) of inter-rater $(\mathrm{N}=42)$, intra-rater $(\mathrm{N}=24)$, and test-retest $(\mathrm{N}=43)$ agreement were determined. ICCs of the qualitative total score ranged from $0.6 \mathrm{I}$ to 0.95 and were comparable with those of the total quantitative score. Thus the Maastricht's Motor Test can be used to objectify both qualitative and quantitative aspects of movements. The additional value of the qualitative observations has to be determined in children with various developmental problems.
\end{abstract}

\title{
INTRODUCTION
}

The knowledge that clumsiness in early school years is strongly related to subsequent academic difficulties and psychological problems makes it imperative to screen children early and to implement intervention strategies (Schuil, 2000; Wiart and Darrah, 200I). This is why evaluation of the motor performance of 5 to- 6 year-old children is an important element of the child neurological examination of the Youth Health Care (YHC) organisation. This organisation provides periodic systemic health examinations for all children of this age. Although integrative brain activity and maturation are poorly understood (Farber and Njiokiktjien, 1993), it is assumed that especially qualitative aspects of a movement reflect the maturity and integrity of the brain (Haddes-Algra and Groothuis, 1999; Touwen, 1979; Hempel, 1993; Prechtl et al., 1997) and may therefore be more relevant than quantitative aspects in predicting developmental problems.

Most of the motor tests developed to date only measure quantitative aspects of a movement (Bruininks, 1978; Scot et al., 1984; Henderson and Sugden, 1992) . Qualitative aspects are mostly subjective and based on the experience of the physician (Smyth, 1992). Although some tests do focus on qualitative aspects (Touwen, 1979; Hempel, 1993; Largo et al., 200 I), they were not specifically developed for kindergarten children. Moreover, their reliability and validity are often not sufficient (Kakebeeke et al., 1993; Boyce et al., I99I). 
To prove the assumption that qualitative aspects of a movement can help in the early diagnosis of developmental problems, there is a need for an instrument that scores both quantitative and qualitative aspects of movements in 5-to-6 year-old children. To this end, we developed the Maastricht Motor Test, which objectifies quantitative and qualitative aspects of motor performance in this age group. The aim of the present study is to evaluate the validity, reliability, and normative values of this new test. In a preliminary study of 390 children, the sensitivity and specificity of this test were $80 \%$, with an inter-rater reliability (kappa) of $>0,6$ for all different items (Kroes et al., 1997). These results were used to adapt the test and this adapted Maastricht's Motor Test (MMT) was evaluated in this paper.

\section{METHODS}

\section{Subjects and Procedure}

Subjects were recruited from the first year of normal primary schools in Maastricht (capital of Limburg, province of the Netherlands) and surrounding villages. Some subjects were selected at random and some were originally selected for the Study of Attention disorders in Maastricht (SAM study) (see Kroes et al., 200I; Kalff et al., 200I). The SAM study used a two-stage design and selected children on the basis of the Child Behavior Checklist (CBCL) results (Verhulst at al., 1996). Parents gave consent for their children to participate in the study, which was approved by the Medical Ethics Committee of the University Hospital in Maastricht. A total of 487 children ( 284 boys (mean age=6.2; SD=0.4), 203 girls (mean age=6.0; $S D=0.4)$ ) were enrolled in the study. Their aged showed a Gaussian distribution and ranged from 5.I to 7.0 years. Children with frank neurological problems were excluded. The motor performance of the children was tested during school times at school. The school doctor assessed each child during routine screening. He was unaware of the MMT results (see validity). The interval time between test and screening was maximally 3 months. To minimise sources of variance two precautions were taken: (I) Care was taken to ensure that the testing environment, a quiet room of at least 15 square meters, was similar as possible in all schools. And (2) the examiners were two skilled research assistants trained to use the MMT.

\section{Measures}

\section{Maastricht's Motor Test}

As recommended by Streiner and Norman, a panel of experts co-operated closely in the development of the Maastricht's Motor Test (1995). This panel (two child physiotherapists and two child neurologists) generated motor items that are of relevance in the examination of 5-to 6-year-old children on the basis of their clinical experience, using the available items of existing motor tests as frame of reference. All items were given a qualitative and a quantitative score. This version of the MMT was then adapted on the basis of the results of a preliminary study to form the MMT used in this study (see introduction). According to 
Gabbard (1996), fundamental movement behaviour can be classified into three general motor skill groups: non-locomotion, locomotion, and manipulative skills. Manipulative skills include fine motor manual movements and ball skills. On the basis of this concept, the MMT is organised into four sections: 14 items deal with Static Balance, 20 deal with Dynamic Balance, 8 with Ball Skills, and 28 with Diadochokinesis and Manual Dexterity. Of these, 36 items deal with qualitative and 34 with quantitative aspects of the movement. Items concerning quantity are those that can be counted or measured, e.g. a distance a child can walk on his heels, the velocity of tapping the hand on the table, the number of times a child can hop on one leg. Items concerning quality reflect the pattern of a movement and the ability of the child to perform isolated movements (198I). Because associated movements are the most frequently assessed parameters of movement quality (Largo et al., 200I), the qualitative items focussed on associated movements but also included co-ordination and stability. The 70 items were scored on a 3-point scale from 0 to 2 (See Appendix). The test was performed and scored in 20 to 25 minutes. The examiners were blind to the judgement of the school doctor.

\section{School doctor}

In the Netherlands, it is customary that the school doctor assesses the motor behaviour of the children during health screening by the municipal health service. This 'routine motor function assessment' is used to judge motor performance in these children. The doctor evaluates both the quantitative and qualitative aspects of several movements according to his experience, largely based on "Gestalt perception". He decides whether the child needs an extra training or exercise program (locomotion judged "disturbed"). In this study the same school doctor assessed all children to determine the final motor outcome.

\section{Validity}

To validate the MMT, the school doctor's judgement was used as a form of expert validity. The aim was to determine whether qualitative aspects of motor behaviour could help in distinguishing between children with and without disturbed motor performance as judged by the school doctor. Furthermore, the results were compared with the sensitivity and specificity values of the quantitative score. In this study, the validity of the MMT was calculated with the 'sampling weight option' in STATA for the 487 children (see statistics).

\section{Reliability}

To investigate the reliability of the MMT, the inter-rater, the intra-rater, and test-retest reliability were determined. For inter-rater reliability two raters scored 42 children, independently, at the same time. To investigate intra-rater reliability videotapes were made of 24 children being tested. With an interval of I month, these videotapes were scored twice by the same examiner. To obtain test-retest reliability, 43 children were tested twice by the same examiner, with an interval of I month. 


\section{Statistics}

Because the study population was partly selected at random and partly from participants in the SAM study, the group as a whole cannot be considered as a random sample of the entire population. For this reason, it was necessary to weight the analyses using the 'sampling weight option' of STATA (Statacorp, 200I), which permits adjustment for design characteristics such as 2-stage sampling. The weights were consistent with the inverse of the probability of selection.

To determine whether there was a difference between girls and boys, median scores and ranges were calculated for each of the test categories. The significance of differences between boys and girls was calculated by using the Mann-Whitney $U$ Test. Results were considered significant at $\mathrm{p}<0.05$ (two-tailed). Weighted median motor scores were calculated for the group with and without disturbed motor performance as determined by the school doctor. In addition, percentile scales were calculated for boys and girls separately. The validity of the MMT was calculated by using the Receiver Operating Characteristic Curve (ROC), with the school doctor's judgement being used as final outcome. A ROC curve is a graph of pairs of true-positives (sensitivity) and of false-positives (I-specificity) corresponding to each possible cut-off point of the diagnostic test result (Wiart and Darrah, 200I; Farber and Njiokiktjien, 1993). The sensitivity and specificity of the test change, depending on the chosen cut-off-point chosen. ROC-curves were made for the qualitative, quantitative and total scores of the Maastricht's Motor Test. By plotting the curves, the curve with the largest area underneath represents the most accurate test. Comparison of the areas below the ROC curves made it possible to compare the discriminative ability of the quantitative and qualitative aspects of the MMT (Hanley and Mc. Neill, 1983).

To determine inter-rater, intra-rater and, test-retest reliability, intraclass correlation coefficients were used according to Shrout and Fleiss' formula (Shrout and Fleiss, 1979). Reliability coefficients were computed for each single category, the sum of all qualitative items, all quantitative items and, the total score. 


\section{RESULTS}

\section{Descriptive Statistics}

Weighted descriptive statistics for each of the test categories for boys and girls separately, and for children with and without motor problems are given in Table 3.I.

Table 3.I Descriptive statistics of the Maastricht's Motor Test

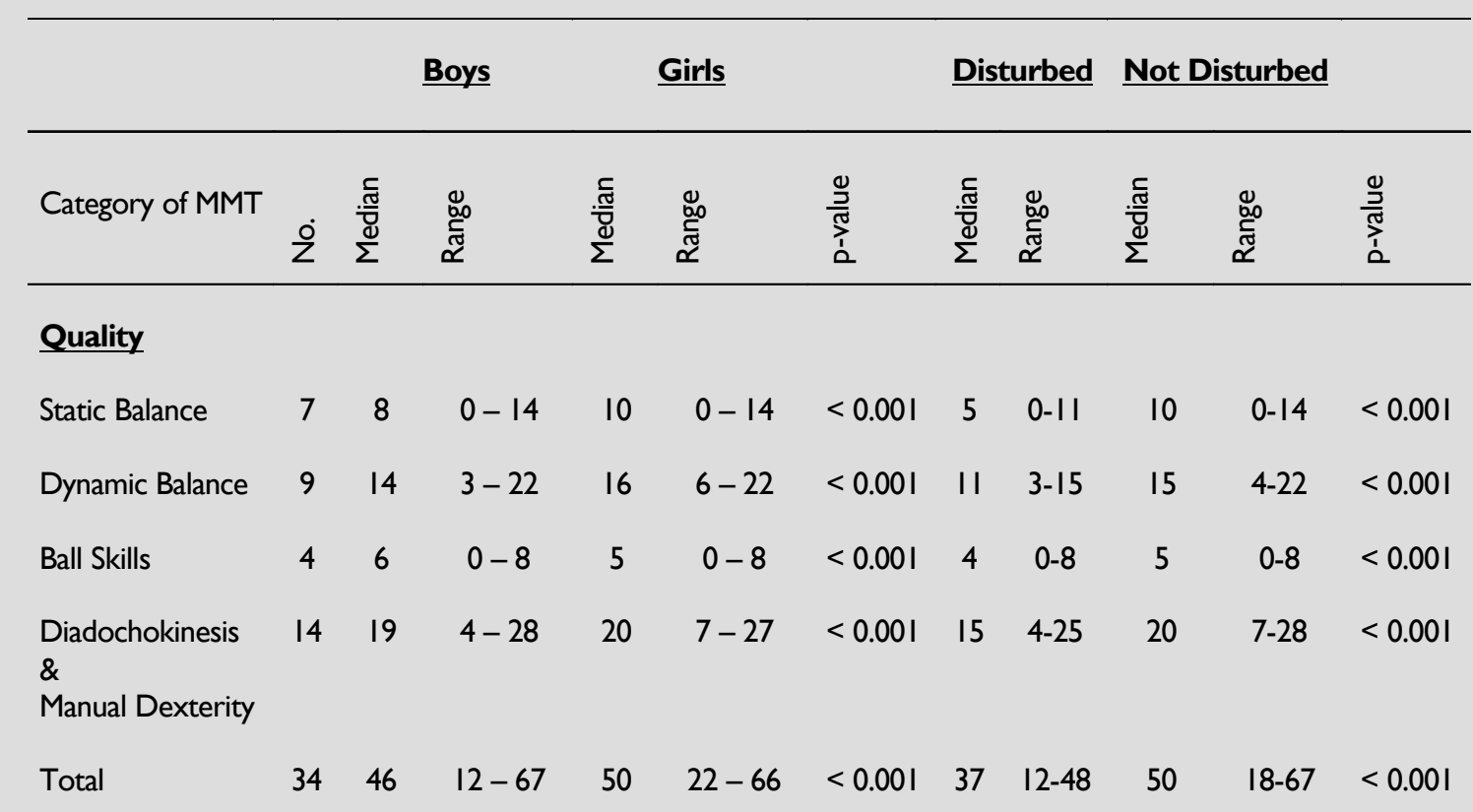

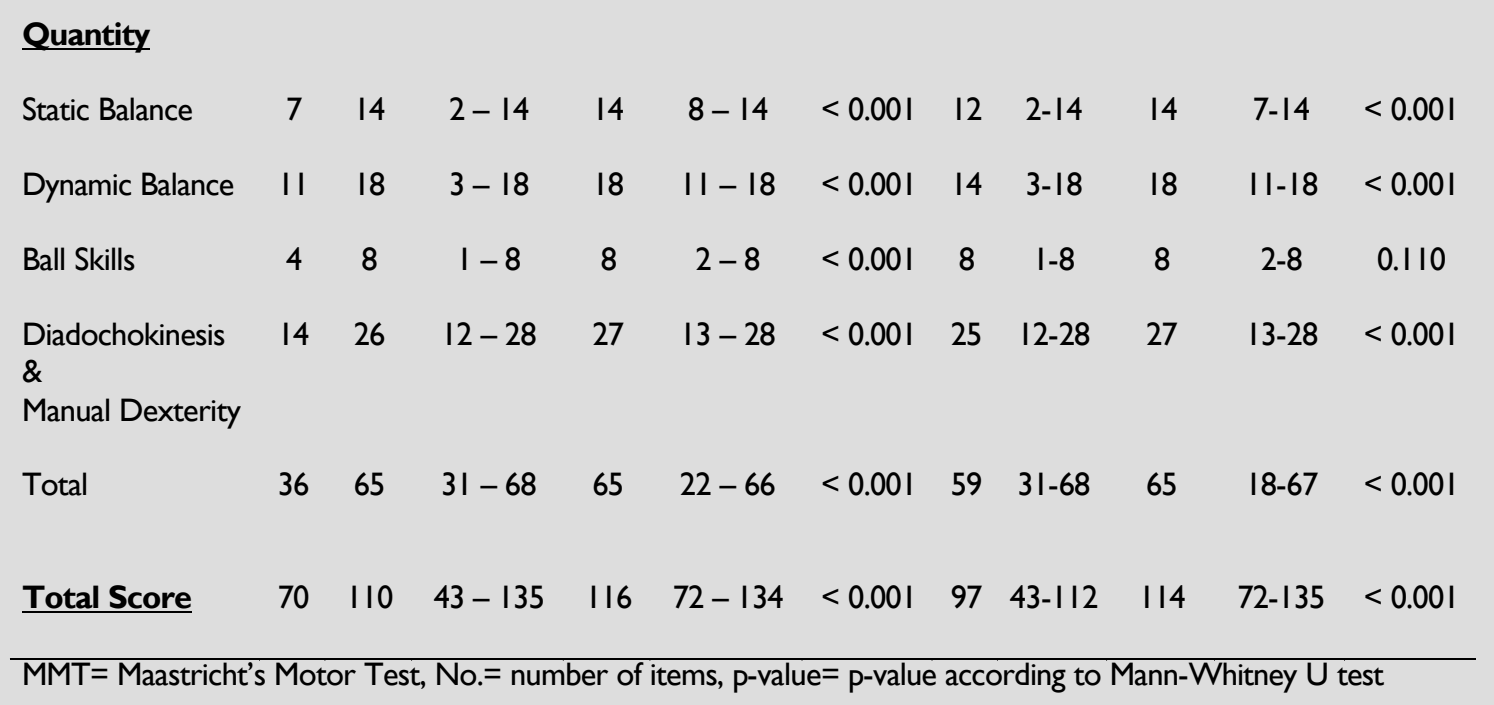

Boys had significantly better ball skills than girls did. For all other categories, girls scored significantly better than boys. According to the school doctor's judgement, 30 out the 487 participants had a disturbed motor performance. After weighting these results $7 \%$ of the weighted population can be considered as 'disturbed'. Of this group 93,5 percent were boys and 6.5 percent were girls. 
With the exception of quantitative ball skills, the non-disturbed group scored significantly better in all categories than the problem group did. Table 3.2 provides normative scores for boys and girls separately. To give some insight into the age differences, information is given for 5-to 6- and 6-to 7-year-old children.

\begin{tabular}{|c|c|c|c|c|c|c|c|c|c|c|c|c|}
\hline \multirow[t]{3}{*}{ Percentiles } & \multicolumn{6}{|c|}{ Boys } & \multicolumn{6}{|c|}{ Girls } \\
\hline & $<=6$ yec & & & $>6$ yea & & & $<=6$ ye & & & $>6$ year & & \\
\hline & Quality & Quantity & Total & Quality & Quantity & Total & Quality & Quantity & Total & Quality & Quantity & Total \\
\hline 5 & 26 & 45 & 64 & 31 & 57 & 89 & 33 & 58 & 93 & 37 & 58 & 102 \\
\hline 10 & 30 & 55 & 89 & 36 & 59 & 97 & 38 & 60 & 98 & 41 & 62 & 104 \\
\hline 25 & 37 & 59 & 96 & 41 & 63 & 105 & 45 & 63 & 110 & 45 & 64 & 108 \\
\hline 50 & 43 & 63 & 106 & 49 & 65 & 113 & 50 & 65 & 114 & 51 & 65 & 117 \\
\hline 75 & 50 & 66 & 113 & 54 & 67 & 120 & 56 & 67 & $|2|$ & 56 & 68 & 122 \\
\hline 90 & 56 & 67 & 123 & 59 & 68 & 125 & 61 & 68 & 126 & 59 & 68 & 126 \\
\hline 95 & 61 & 68 & 126 & 60 & 68 & 126 & 64 & 68 & 130 & 60 & 68 & 128 \\
\hline
\end{tabular}

\section{Validity}

ROC curves of the total, qualitative, and quantitative scores of the Maastricht's Motor Test are plotted in figure 3.I.

\section{Figure 3.I Roc curves}

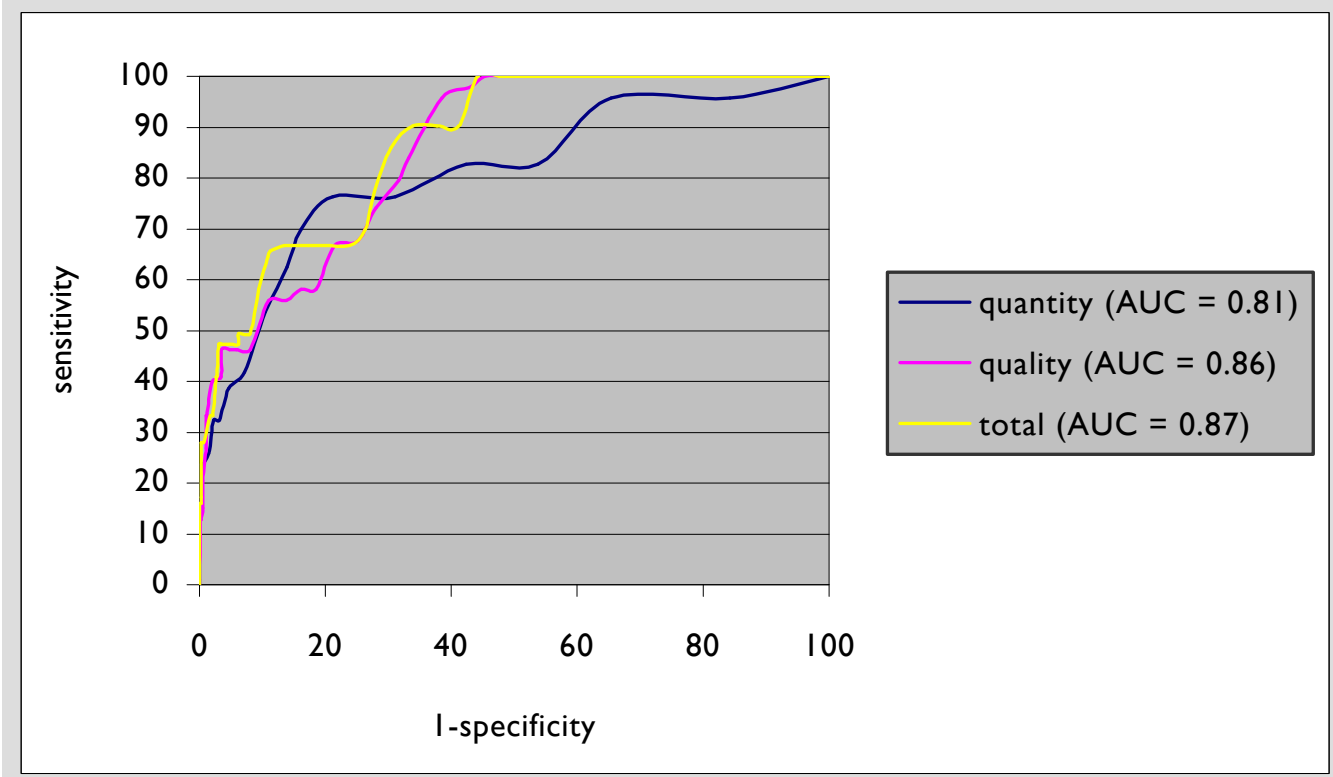

$\mathrm{AUC}=$ area under the curve 
Areas under the curve (AUC) varied from 0.81 for the quantitative score, 0.86 for the qualitative score, and 0.87 for the total score of the MMT. The AUC of the quantitative score was significantly smaller $(<0.00 \mathrm{I}$ and 0.04$)$ than that of the AUC for the total and qualitative scores. The AUCs for the qualitative and total scores were not significantly different.

Table 3.3 gives the validity parameters for different cut-off points for the categories mentioned above. Children with a score equal to or less than a cut-off point were identified as having disturbed motor performance. For example, the specificity and sensitivity of a total MMT score of 108 points was $70 \%$ and $86 \%$, respectively.

Table 3.3 Sensitivity and specificity values for the different cut-off point

\begin{tabular}{llcccc}
\hline $\begin{array}{l}\text { Category of } \\
\text { Maastricht's Motor Test }\end{array}$ & $\begin{array}{l}\text { Cut-off } \\
\text { Point }\end{array}$ & $\begin{array}{c}\text { Specificity } \\
(\%)\end{array}$ & $\begin{array}{c}\text { Sensitivity } \\
\text { (\%) }\end{array}$ & $\begin{array}{c}\text { False pos. } \\
\text { (\%) }\end{array}$ & $\begin{array}{c}\text { False neg. } \\
\text { (\%) }\end{array}$ \\
\hline \multirow{3}{*}{ Quality } & $<=26$ & 99.5 & 20.4 & 0.5 & 79.6 \\
& $<=40$ & 81.4 & 58.1 & 18.6 & 41.9 \\
& $<=43$ & 71.9 & 74.2 & 28.1 & 25.8 \\
& $<=45$ & 66.8 & 83.9 & 33.2 & 16.1 \\
& $<=46$ & 61.4 & 95.7 & 38.6 & 4.3 \\
& & & & & \\
Quantity & $<=49$ & 99.9 & 16.1 & 0.1 & 83.9 \\
& $<=59$ & 89.5 & 53.8 & 10.5 & 46.2 \\
& $<=62$ & 78.8 & 76.3 & 21.2 & 23.7 \\
& $<=64$ & 57.6 & 82.8 & 42.4 & 17.2 \\
& $<=66$ & 34.6 & 95.7 & 65.4 & 4.3 \\
Total & $<=88$ & 97.7 & 33.3 & & \\
& $<=97$ & 90.6 & 58.1 & 0.3 & 66.7 \\
& $<=107$ & 72.2 & 77.4 & 27.8 & 21.9 \\
& $<=108$ & 69.6 & 86.0 & 30.4 & 14.0 \\
& $<=112$ & 55.7 & 100.0 & 44.3 & 0.0 \\
\hline False pos. \%= percentage of false positives, False neg. \%= percentage of false negatives.
\end{tabular}




\section{Intra-class correlation coefficient}

Intra-class correlation coefficients (ICC) for inter-rater, intra-rater and retest reliability are shown in table 3.4. Intra-class correlations of the inter-rater reliability varied from 0.92 for the qualitative score, 0.97 for the quantitative score, to 0.96 for the total score. Individual attribute reliability coefficients were all $>0.80$, with values varying from 0.83 to 0.97 . These values are more or less comparable with those of the intra-rater reliability, except for the quantitative scores of Ball Skills and Diadochokinesis and Manual Dexterity ( 0.73 and 0.72 respectively). The test-retest reliability was considerably lower: the children performed slightly (but not significantly) better when tested for a second time.

\begin{tabular}{lccc} 
Table 3. 4 & & \\
Intra-class Correlation Coefficients & & \\
\hline Category of Maastricht's Motor Test & $\begin{array}{c}\text { Inter-rater } \\
\mathbf{N = 4 2}\end{array}$ & $\begin{array}{c}\text { Intra-rater } \\
\mathbf{N = 2 4}\end{array}$ & $\begin{array}{c}\text { test-retest } \\
\mathbf{N}=\mathbf{4 3}\end{array}$ \\
\hline Quality & & & \\
Static Balance & 0.87 & 0.92 & 0.43 \\
Dynamic Balance & 0.87 & 0.85 & 0.48 \\
Ball Skills & 0.88 & 0.82 & 0.62 \\
Diadochokinesis \& Manual Dexterity & 0.83 & 0.89 & 0.93 \\
Total & 0.92 & 0.95 & 0.61 \\
Quantity & & & \\
Static Balance & & 0.98 & 0.48 \\
Dynamic Balance & 0.95 & 0.98 \\
Ball Skills & 0.97 & 0.90 & 0.55 \\
Diadochokinesis \& Manual Dexterity & 0.90 & 0.73 & 0.62 \\
Total & 0.95 & 0.72 & 0.74 \\
Total Score & 0.97 & 0.93 & 0.74 \\
\hline
\end{tabular}

\section{DISCUSSION}

Motor performance is an important element of the neurological examination of children. It is suggested that especially the qualitative aspects of several movements reflect the maturity and integrity of the brain, and can probably play an important role in the early diagnosis of developmental disorders. The MMT was developed because of the lack of qualitative motor tests. Results show that the MMT is a valid and reliable tool for scoring the qualitative aspects of motor performance in children and for distinguishing between children with and without disturbed motor behaviour.

Girls scored significantly better than boys in almost all MTT categories. This is consistent with the observation that the school doctor described more boys than girls as having 'disturbed' motor behaviour ( $93.5 \%$ boys; $6.5 \%$ girls). Henderson and Sugden (1992) did not find significant differences between boys and girls in the normative scores of the Movement $A B C$. However, their findings are inconsistent with the literature, in which most studies 
report a difference in locomotion in favour of girls (Henderson and Hall, 1982; Johnston et al., 1987; Kaplan et al., 1994). Seven percent of the weighted population were identified as having disturbed motor behaviour. This percentage is comparable to the prevalence of disturbed motor performance, mentioned in the literature (Henderson and Hall, 1982; Johnston et al., 1987). As mentioned in the methods section, the school doctor's judgement was used as a form of expert validity. Using "Gestalt perception", his final judgement probably reflected both quantitative and qualitative aspects. Comparison of the qualitative results of the MMT with the quantitative scores showed that the AUCs of the qualitative and total scores were significantly larger than that of the quantitative score. This indicates that the qualitative and total scores were more accurate than the quantitative score. Cut-off scores can be set depending on the purpose of the study. The higher the sensitivity and specificity values are, the better. But high sensitivity scores may lead to many false positives; on the other hand, high specificity scores are accompanied with many false negatives. A compromise between these two parameters should be made depending on the purpose of the instrument. For example, if the test is used as a screening instrument, high sensitivity rates are important whereas high specificity rates are of interest if the test is used as a diagnostic tool (Statacorp, 200I).

The reliability provides information about the consistency and stability of measurements (Atwater et al., 1990). To evaluate the reliability of the test, intraclass correlations were calculated to investigate inter-rater, intra-rater, and test-retest reliability. When the ICC is high, a large fraction of the variance of observations is associated with variation between subjects rather than between raters (Shrout and Fleiss, 1979). Although there is not a universally accepted minimum value for reliability coefficients, Shrout and Fleiss (1979) used a value of 0.75 or 0.80 as a minimum acceptable value. Assuming this, inter-rater and intrarater reliability values were very good for all individual categories. Reliability scores for all categories were much lower for test-retest reliability. This may be due to practice effects and to "natural" variability in the child's motor behaviour.

In conclusion, the MMT is a reliable and valid instrument to measure qualitative as well as quantitative aspects of a movement. The validity of the qualitative MMT was higher than that of the quantitative MMT. This instrument makes it possible to translate "Gestalt perception" into an objective score, which may be of great relevance for scientific purposes. The high prevalence rates and possible consequences of disturbed motor performance justify the screening of developmental co-ordination disorders in second grade (Wiart and Darrah, 200I; Bouter and van Dongen, 1995). Because the MMT is non-invasive, easy to use, and has a clear protocol, we recommend that this instrument could be used by school-doctors to objectify findings and for research and health care purposes. However, the results of the MMT should always be interpreted in the context of further examination, the opinion of the parents, the child, and eventually the teacher.

We believe that the qualitative items of the MMT will be useful when motor performance is used to differentiate between developmental problems such as attention deficit hyperactivity disorder and learning disorders. The MMT is the first motor test to objectify qualitative 
aspects of several important motor domains in a reliable and valid way. This test can make an important contribution to the evaluation of qualitative motor behaviour in groups of children with and without these developmental problems. 


\section{REFERENCES}

Atwater SW, Crowe TK, Deitz JC, Richardson PK (1990), Inter-rater and test-retest reliability of two pediatric balance tests. Physical Therapy 70: 79-87

Bouter LM, Dongen vMCJM (1995), Diagnostiek. In: Epidemiologisch onderzoek Houten/ Diegem: Bohn Stafleu Van Loghum

Boyce WF, Gowland C, Hardy S, Rosenbaum PL, Lane M, Plews N, Goldsmith C, Russell DJ (I99|), Measuring Quality of Movement in Cerebral Palsy: A review of Instruments. Physical Therapy 7I: 820-8

Bruininks RH (1978), Bruininks-Oseretsky Test of Motor Proficiency, Examiners Manual. Circle Pines, MN: American Guidance Service

Farber D, Njiokiktjien C (1993), Developing brain and cognition. Ist edition, Vol. 4 Amsterdam: Suyi Publications

Gabbard CP (1996), Livelong Motor Development. second edition. Boston.

Haddes-Algra M, Groothuis AMC (1999), Quality of general movements in infancy is related to neurological dysfunction, ADHD, and aggressive behaviour. Developmental Medicine \& Child Neurology 4I: 38I-39I

Hanley JA, Mc.Neill BJ (1983), A Method of Comparing the Area under Receiver Operating Characteristic Curves from the Same Cases. Radiology 148: 893-843

Hempel MS (1993), The neurological examination for toddler-age. Groningen, The Netherlands:

Henderson SE, Hall D (1982), Concomitants of clumsiness in young schoolchildren. Developmental Medicine \& Child Neurology 24: 448-60

Johnston O, Short H, Crawford J (1987), Poorly coordinated children: a survey of 95 cases. Child: Care Health and Development 13: 361-76

Kakebeeke TH, Jongmans MJ, Dubowitz LM, Schoemaker MM, Henderson SE (1993), Some aspects of the reliability of Touwen's examination of the child with minor neurological dysfunction. Developmental Medicine \& Child Neurology 35: 1097-105

Kalff A, Kroes M, Vles J, Bosma H, Feron F, Hendriksen J, Steyeart J, Zeben T, Crolla I, Jolles J (200I), Factors affecting the relation between parental education as well as occupation and problem behaviour in Dutch kindergarten children. Social Psychiatry and Psychiatric Epidemiology 36:324-33I

Kaplan HI, Sadock BJ, Grebb JA (1994), Kaplan and Sadock's Synopsis of Psychiatry. 7th edition, Retford DC ed. Baltimore, Maryland: Williams \& Winkins

Kroes M, Kalff AC, Steyaert J, Kessels AGH, Feron FJM, v.Someren AJWGM, Hurks PPM, Hendriksen JGM, v.Zeben TMCB, Rozendaal N, Crolla IFMA, Jolles J, Troost J, Vles JSH (200I), Child psychiatric diagnoses in a population of Dutch schoolchildren aged 6 to 8 years. Journal of American Academy of Child and Adolescent Psychiatry 40: I40I-1409

Kroes M, Vles J, Vissers Y, Feron F, Sleypen F, Roosendaal N, Troost J (I997), A quantitative and qualitative score for pre-school children. European Journal of Paediatric Neurology I: A20, IIIB8

Largo RH, Caflisch JA, Hug F, Muggli K, Molnar AA, Molinari L (200I), Neuromotor development from 5 to I8 years. Part 2: associated movements. Developmental Medicine \& Child Neurology 43: 444-453

Njiokiktjien C, Gobin A (I98I), Kinderen met leerstoornissen, handleiding bij het klinisch neurologisch onderzoek Utrecht: Wetenschappelijke uitgeverij Bunge

Prechtl HF, Einspieler C, Cioni G, Bos AF, Ferrari F, Sontheimer D (1997), An early marker for neurological 
deficits after perinatal brain lesions. The Lancet 349: I36I-3

Scott DH, Moyes FA, Henderson SE. The Henderson Revision of the Test of Motor Impairment. San Antonio: Psychological Corporation, 1984

Schuil P (2000), Nederlands Leerboek Jeugdgezondheidszorg, 4th ed. Assen: van Gorcum

Shrout PE, Fleiss JL (1979), Intraclass Correlations: Uses in Assessing Rater Reliablity. Psychological Bulletin. 83: 420-428

Smyth TR (1992), Impaired motor skill (clumsiness) in otherwise normal children: a review. Child: care, health and development 18: 283-300

StataCorp (200I), Stata, software for statistical analyses: release 7., College Station, TX: Stata Corporation

Stott DH, Moyes FA, Henderson SE (1984), The Henderson Revision of the Test of Motor Impairment. San Antonio: Psychological Corporation

Streiner DL, Norman GR (1995), Health Measurement Scales. A Practical guide to their development and use. 2nd edition Oxford: Oxford University Press

Touwen BCL (1979), Examination of the Child with Minor Neurological Dysfunction, 2nd ed. London: S.I.M.P.

Verhulst FC, Ende van der J, Koot HM (1996), Handleiding voor de CBCL 4-I8 Rotterdam: Afdeling Kinder en jeugdpsychiatrie, Sophia Kinderziekenhuis/ Academisch Ziekenhuis Rotterdam/ Erasmus Universiteit Rotterdam

Wiart L, Darrah J (200I), Review of four tests of gross motor development. Developmental Medicine \& Child Neurology 43: 279-285

Zweig MH, Campbell G (1993), Receiver-operating characteristic (ROC) plots: a fundamental evaluation tool in clinical medicine. Clinical Chemistry 39: 561-577 


\section{General rules}

The MMT contains quantitative and qualitative items. Every task should be explained and demonstrated by the examiner. The child may not practice; only when he/she shows by the performance of the movement that he/she didn't understand what to do, the examiner explains the task again and the child may have another attempt. About the qualitative part of the test; the examiner scores what he/ she saw the most, unless otherwise mentioned in the text. Quantitative scores are calculated for all separate (left/ right/ dominant/ non-dominant) parts of the test, based on percentiles.

\section{Static Balance:}

I. Stand, with feet next to each other, eyes closed, arms and hands relaxed next to the body.

la: $\quad$ Score 0: 0-19 sec.

Score 2: $20 \mathrm{sec}$.

Ib: $\quad$ Score 0: co-movements (as soon as seen):

- associated facial mimic,

- wrist/finger extension or fist (left/right)

- elbow flexion (left/right), shoulder abduction (left/right)

Score I: a lot of balance/ correction movements present

Score 2: good (few balance/ correction

movements are allowed)

2.

Stand, with feet next to each other, eyes closed,

2a:

Score 0: 0-19 sec.

Score 2: $20 \mathrm{sec}$.

2b: $\quad$ Score 0: co-movements (as soon as seen):

- a step forward

- associated facial mimic,

- finger movements,

- deviation of arms (left/right)

Score I: a lot of balance/ correction movements

Score 2: good (few balance/ correction

movements are allowed)

3/ 4. Stand on one leg, eyes open, flex other leg backwards (extension hip, flexion knee) arms relaxed next to the body

3a:

"RIGHT"

Score 0: 0-3 sec.

Score I: 4-6 sec.

Score 2: 7-10 sec.

3b: $\quad$ Score 0: co-movements:

- elbow flexion (left/right)

- shoulder abduction (left/right) $\left(>45^{\circ}\right)$

Score I: a lot of balance/ correction movements trunk/ wrist and finger extension or fist (left/right)

Score 2: good, no co-movements

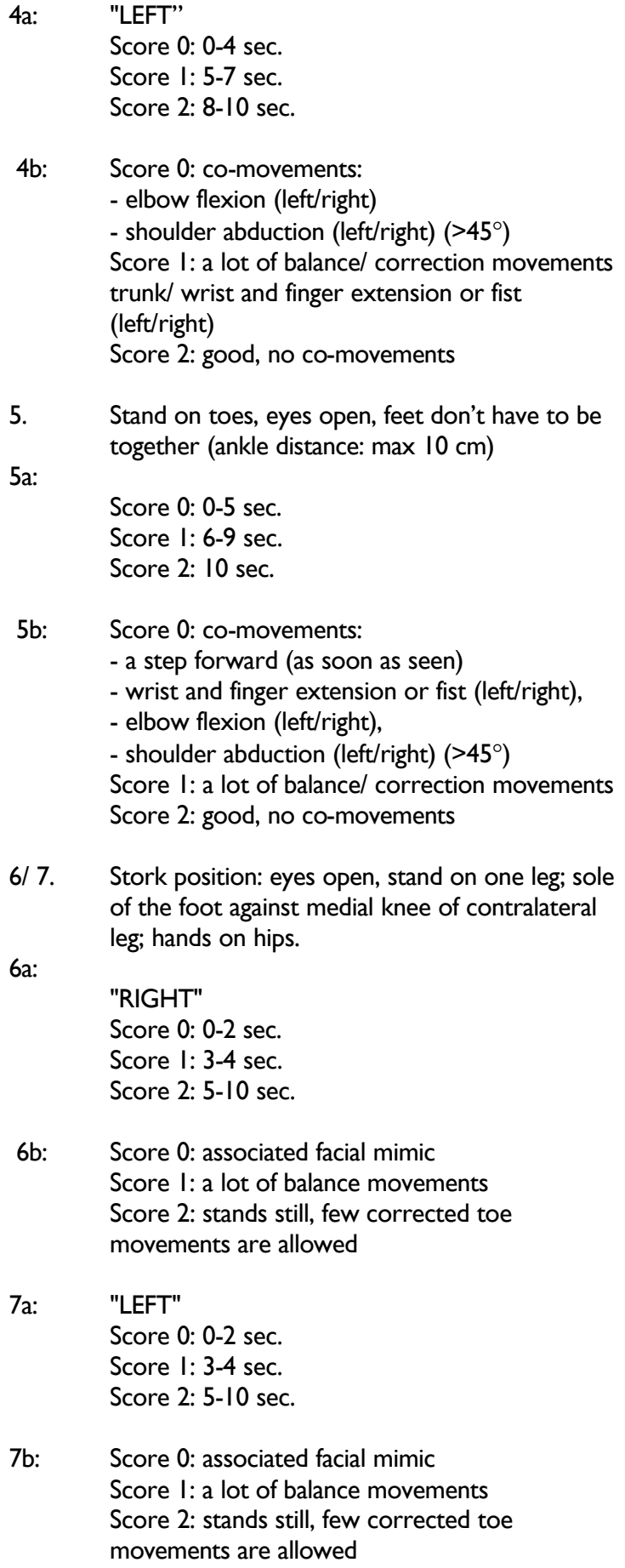

5. Stand on toes, eyes open, feet don't have to be 5a: together (ankle distance: $\max 10 \mathrm{~cm}$ )

Score 0: 0-5 sec.

Score 1: 6-9 sec.

Score 2: $10 \mathrm{sec}$.

5b: $\quad$ Score 0: co-movements:

- a step forward (as soon as seen)

- wrist and finger extension or fist (left/right),

- elbow flexion (left/right),

- shoulder abduction (left/right) $\left(>45^{\circ}\right)$

Score I: a lot of balance/ correction movements

Score 2: good, no co-movements

6/ 7. Stork position: eyes open, stand on one leg; sole of the foot against medial knee of contralateral leg; hands on hips.

6a:

"RIGHT"

Score 0: 0-2 sec.

Score I: 3-4 sec.

Score 2: 5- $10 \mathrm{sec}$.

6b: Score 0: associated facial mimic

Score I: a lot of balance movements

Score 2: stands still, few corrected toe movements are allowed

7a: $\quad$ "LEFT"

Score 0: 0-2 sec.

Score I: $3-4$ sec.

Score 2: 5-10 sec.

7b: $\quad$ Score 0: associated facial mimic

Score I: a lot of balance movements

Score 2: stands still, few corrected toe movements are allowed 


\section{Dynamic Balance:}

I. Walking on heels: 4.5 meters, in a straight line

la: $\quad$ Score 0: 0- $4.4 \mathrm{~m}$

Score 2: $4.5 \mathrm{~m}$

Ib: Score 0: only toes are extended (rest remains on the ground)

Score I: walks on heels but touches ground now and then

Score 2: walking on heels

Ic: Score 0: elbow flexion (left/right)

Score I: wrist and finger flexion/extension (left/right) or fist

Score 2: good, a few balance movements are allowed

2. Tiptoe, $\mathbf{4 . 5}$ meters in a straight line

2a:

Score 0: 0-4.4 m

Score 2: $4.5 \mathrm{~m}$

2b: $\quad$ Score 0: heels are barely raised

Score I: heel drops down now and then

Score 2: heels are raised

2c: $\quad$ Score 0: arms in abduction, endorotation and extension

Score I: wrist flexion/extension or fist (left/right)

Score 2: good, a few balance movements are allowed

3/ 4. Hopping on one leg: within $(50 \times 50 \mathrm{~cm})$ : 10 times

3a:

"RIGHT"

Score 0: 0-3

Score I: 4-9

Score 2: 10

3b: $\quad$ Score 0: movement is supported by arm movements above the umbilicus

Score I: hopping on flat foot

Score 2: hopping on forefoot, arm movements below umbilicus

4a: $\quad$ "LEFT"

Score 0: 0-3

Score 1: 4-8

Score 2: 9-10

4b: $\quad$ Score 0: movement is supported by arm movements above the umbilicus

Score I: hopping on flat foot

Score 2: hopping on forefoot, arm movements below umbilicus

5/ 6. Hopping forward on straight line: 10 times

5a:

"RIGHT"

Score 0: 0-3
Score I: 4-9

Score 2: 10

5b: $\quad$ Score 0: movement is supported by arm movements above the umbilicus

Score I: hopping on flat foot

Score 2: hopping on forefoot, arm movements below umbilicus

6a:

"LEFT"

Score 0: 0-I

Score I: 2-6

Score 2: 7-10

6b:

Score 0: movement is supported by arm movements above the umbilicus

Score I: hopping on flat foot

Score 2: hopping on forefoot, arm movements below umbilicus

7. Jumping with both feet, within margin $(50 \times 50 \mathrm{~cm})$, without intervals, 10 times

7a:

Score 0: 0-9

Score 2: 10

7b:

Score 0: movement is supported by arm movements above the umbilicus

Score I: hopping on flat foot

Score 2: hopping on forefoot, arm movements below umbilicus

8. Jumping: as far as possible. Jumps with both feet at the same time. Touches ground with both feet and stands still directly.

8a:

Score 0: 0 - $49 \mathrm{~cm}$.

Score I: $50-59 \mathrm{~cm}$.

Score 2: $60-300 \mathrm{~cm}$.

8b: $\quad$ Score 0: jumps with asymmetric take off or touch down

Score I: touches down with both feet at the same time, but does not stand still directly/ a lot of balance movements/steps forward

Score 2: performance according to assignment

9. Walk a wire: foot for foot in a straight line, heels against toes, 10 times

9a:

Score 0: 7-10 missteps (heels not against toes/ deviation from line)

Score I: 4-6 missteps

Score 2: 0-3 missteps

9b: Score 0: balance movements of trunk (as soon as seen)

Score I: balance movements of arms (as soon as seen)

Score 2: arms relaxed in adduction 
Illustration item: Dynamic Balance: qualitative aspect "Walking on heels (item Ic)"

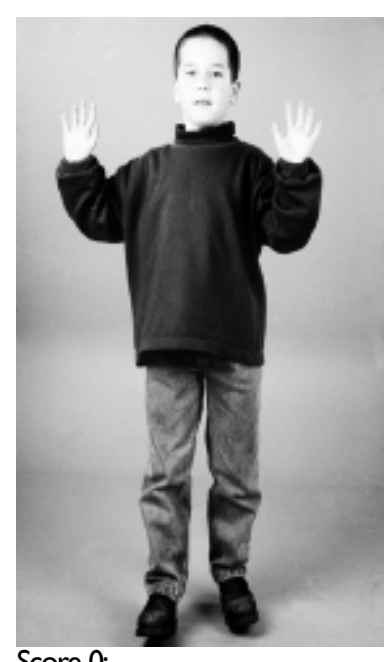

Score 0:

Elbow flexion (left/ right)

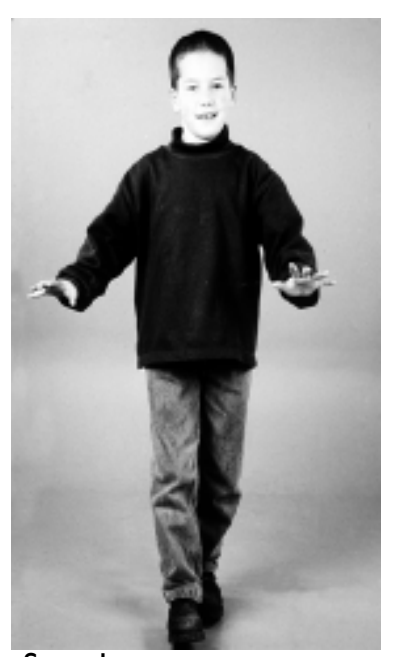

Score I:

wrist and finger flexion/ extension (left/ right) or fist

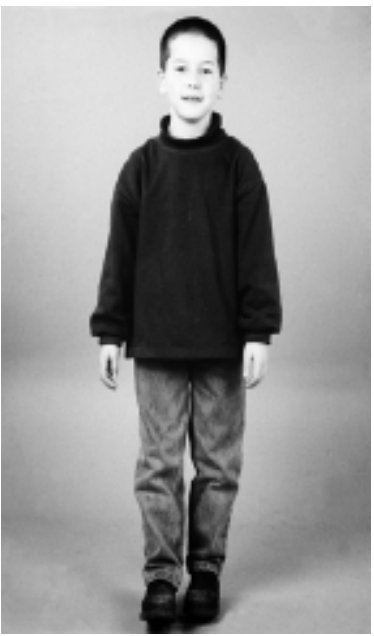

Score 2

good, a few balance movements are allowed

Ball Skills (diameter of ball: $\pm 20 \mathrm{~cm}$ ):

I. Ball catching. Child stands with feet next to each other behind a line. Ball is thrown from a distance of 3 metres, not above shoulder level or below waist of the child. Examiner throws 5 times and the child has to catch the ball with both hands, ball should not touch the body.

la:

Score 0: 0-1

Score I: 2-3

Score 2: $4-5$

Ib: Score 0: no anticipation; head deviates, child leans backward, arms are held forward Score I: child catches the ball, between hands and chest

Score 2: child catches the ball with both hands, ball away from the body, anticipation is good

2. Ball bouncing

Start position: child stands still, feet don't have to be together. Takes the ball between both hands and bounces the ball on the ground. Ball

$2 \mathrm{a}:$ has to be caught between both hands 5 times

Score 0: 0-2

Score 1: 3

Score 2: 45

2b:

Score 0: moves feet and catches the ball, between hands and chest.

Score I: maintains balance, catches the ball, between hands and chest

Score 2: maintains balance, child catches the ball with both hands, ball away from the body
3/ 4. Ball kicking: distance between child and examiner is 3 metres.

Start position, feet don't have to be together. Hands in adduction. The examiner rolls the ball towards the child in a straight line. Child steps forward with $L / R$ leg, using other leg, kicks ball in a straight line (deviation of $50 \mathrm{~cm}$ left/right is allowed) to examiner and lands with this leg behind leg he/she stands on. 5 times

3a:

"RIGHT"

Score 0: 0-1

Score I: 2

Score 2: 3-5

3b: $\quad$ Score 0: loses balance, wrist/ elbow flexion (left/right)

Score I: leg which kicked the ball, lands in front of or next to the leg he/she stands on Score 2: leg which kicked the ball, lands behind the leg he/she stands on

4a: "LEFT"

Score 0: 0

Score I: I

Score 2: 2-5

4b: $\quad$ Score 0: loses balance, wrist/elbow flexion (left/right)

Score I: leg which kicked the ball, lands in front of or next to the leg he/she stands on Score 2: leg which kicked the ball, lands behind the leg he/she stands on 


\section{Diadochokinesis \& Manual Dexterity}

1/ 2/ 3. Diadokinesia: with eyes open

Pronation-suppination

Child sits still, looks forward. Back straight, hips and knees are flexed (90 degree). Arms flexed (90 degree).

Upper arm against trunk, under arm and palm relaxed on upper leg. Contralateral arm hangs next to the body. The examiner sits in same position in front of the child and instructs the child to perform the task as quickly as possible. 10 times (palm 10 times against upper leg)

la:

"DOMINANT HAND"

Score 0: 13-60 sec.

Score I: $11-12 \mathrm{sec}$

Score 0: 0 - $10 \mathrm{sec}$

Ib: Score 0: movement is performed with associated shoulder movements (shoulder $a b$ and adduction)/ associated facial mimic

Score I: associated movements in contralateral hand (tonic/ kinetic)

Score 2: no associative movements

2a: "NON-DOMINANT HAND"

Score 0: $15-60 \mathrm{sec}$.

Score I: $12-14 \mathrm{sec}$

Score 2: 0 - II sec.

2b:

Score 0: movement is performed with associated shoulder movements (shoulder ab and adduction)/ associated facial mimic

Score I: associated movements in contralateral arm (tonic/ kinetic)

Score 2: no associative movements

3a: "USING BOTH HANDS"

Child has to look forward

Score 0: $15-60 \mathrm{sec}$.

Score I: 13-14 sec.

Score 2: 0 - $12 \mathrm{sec}$

3b: $\quad$ Score 0: movement is performed with associated shoulder movements (shoulder $\mathrm{ab}$ and adduction)

Score I: child's eyes are focused on nondominant hand

Score 2: no associative movements

4/ 5/ 6. Finger-thumb opposition: with eyes open The thumb touches tip of the other fingers $(2 \rightarrow 3 \rightarrow 4 \rightarrow 5)$ and this is repeated 3 times. Child sits still, looks forward. Back straight, hips and knees are flexed (90 degree). Arms are kept in abduction and exorotation horizontally; shoulder- and elbow joint are in an angle of 90 degree. Contralateral arm hangs next to the body.Examiner instructs the child to look at the moving fingers and to perform the task as quickly as possible. 4a:

\section{"DOMINANT HAND"}

Score 0: 16-60 sec.

Score I: $13-15 \mathrm{sec}$.

Score 0: 0 - $12 \mathrm{sec}$.

4b: $\quad$ Score 0: associated movements ipsilaterally (e.g. dominant arm moves/ changes position) Score I: child shows associated movements contralatarally (tonic/kinetic)

Score 2: no co-movements

"NON-DOMINANT HAND"

Score 0: $16-60 \mathrm{sec}$.

Score I: $13-15 \mathrm{sec}$.

Score 20 - $12 \mathrm{sec}$

5b: $\quad$ Score 0: associated movements ipsilaterally (e.g. dominant arm moves/ changes position) Score I: child shows associated movements contralatarally (tonic/kinetic)

Score 2: no co-movements

6a:

“USING BOTH HANDS"

Child has to look forward

Score 0: $28-60 \mathrm{sec}$

Score I: $19-27 \mathrm{sec}$.

Score 2: 0-18 sec.

6b: $\quad$ Score 0: child shows associated movements: facial mimic/ arm deviation (left/ right) Score I: child's eyes are focused on nondominant hand

Score 2: no co-movements

7/ 8. Tapping hand: eyes open. Child sits still, looks forward. Back straight, hips and knees are flexed (90 degree). Both palms rest on upper legs. The hand taps from this position as quickly as possible on the upper leg, wrist does not lift. Examiner instructs the child to perform the task 10 times as quickly as possible.

7a:

"DOMINANT HAND"

Score 0: 5-60 sec.

Score 2: 0 - $4 \mathrm{sec}$

7b: $\quad$ Score 0: child shows associated movements on contralateral side (tonic/kinetic)

Score I: associated on ipsilateral side (e.g. movements in dominant foot)

Score 2: no co-movements

8a: "NON-DOMINANT HAND"

Score 0: 6-60 sec

Score I: $5 \mathrm{sec}$.

Score 2: 0 - $4 \mathrm{sec}$.

8b: $\quad$ Score 0: child shows associated movements on contralateral side (tonic/kinetic) Score I: associated on ipsilateral side (e.g. movements in dominant foot) Score 2: no co-movements 
9/ I0. Foot tapping: eyes open

Child sits still, looks forward. Back straight, hips and knees are flexed (90 degree).Both hand palms rest on upper legs

The forefoot taps from this position as quickly as possible on the ground, heel stays on the ground. Examiner instructs the child to perform the task 10 times as quickly as possible.

9a:

"RIGHT FOOT"

Score 0: 8-60 sec.

Score I: 6-7 sec.

Score 2: 0-5 sec.

9b: Score 0: child shows associated movements on contralateral side (tonic/kinetic) Score I: associated on ipsilateral side (e.g. movement in dominant hand) Score 2: no co-movements

\section{0a: "LEFT FOOT"}

Score 0: 9-60 sec.

Score I: 7-8 sec

Score 2: 0-6 sec.

I0b: Score 0: child shows associated movements on contralateral side (tonic/kinetic)

Score I: associated on ipsilateral side

(e.g. movement in dominant hand)

Score 2: no co-movements

II/ I2 Tracking pencil between lines: see bicycle trail. Child sits on chair, picks pencil up

The examiner instructs the child to draw a line between both lines in the picture as quickly and neat as possible. Child may practice once, and

Ila: may pause while drawing an uninterrupted line

\section{"DOMINANT HAND"}

Score 0: $36-60 \mathrm{sec}$.

Score I: $28-35 \mathrm{sec}$.

Score 2: 0-27 sec.
I lb: Score 0: $>4$ times outside the lines Score I: 3-4 times outside the lines Score 2: 0-2 times outside the lines

Ilc: Score 0: elbow and wrist are raised from table Score I: movement in shoulder/elbow joint (no movements in wrist/ fingers)

Score 2: smooth movements

IId: Way child holds pencil Score 0: pencil is held within fist Score I: pencil is held in odd/ immature grip but not in fist

Score 2: pencil is held between thumb and index finger, middle finger may be used

12a: "NON-DOMINANT HAND"

Score 0: 37-60 sec.

Score I: $29-36 \mathrm{sec}$

Score 2: 0-28 sec.

12b: Score 0: $>8$ times outside the lines Score I: 7-8 times outside the lines Score 2: 0-6 times outside the lines

12c: $\quad$ Score 0: elbow and wrist are raised from table Score I: movement in shoulder/ elbow joint (no movements in wrist/ fingers) Score 2: smooth movements

12d: Way child holds pencil Score 0: pencil is held within fist Score I: pencil is held in odd/ immature grip but not in fist

Score 2: pencil is held between thumb and index finger, middle finger may be used 



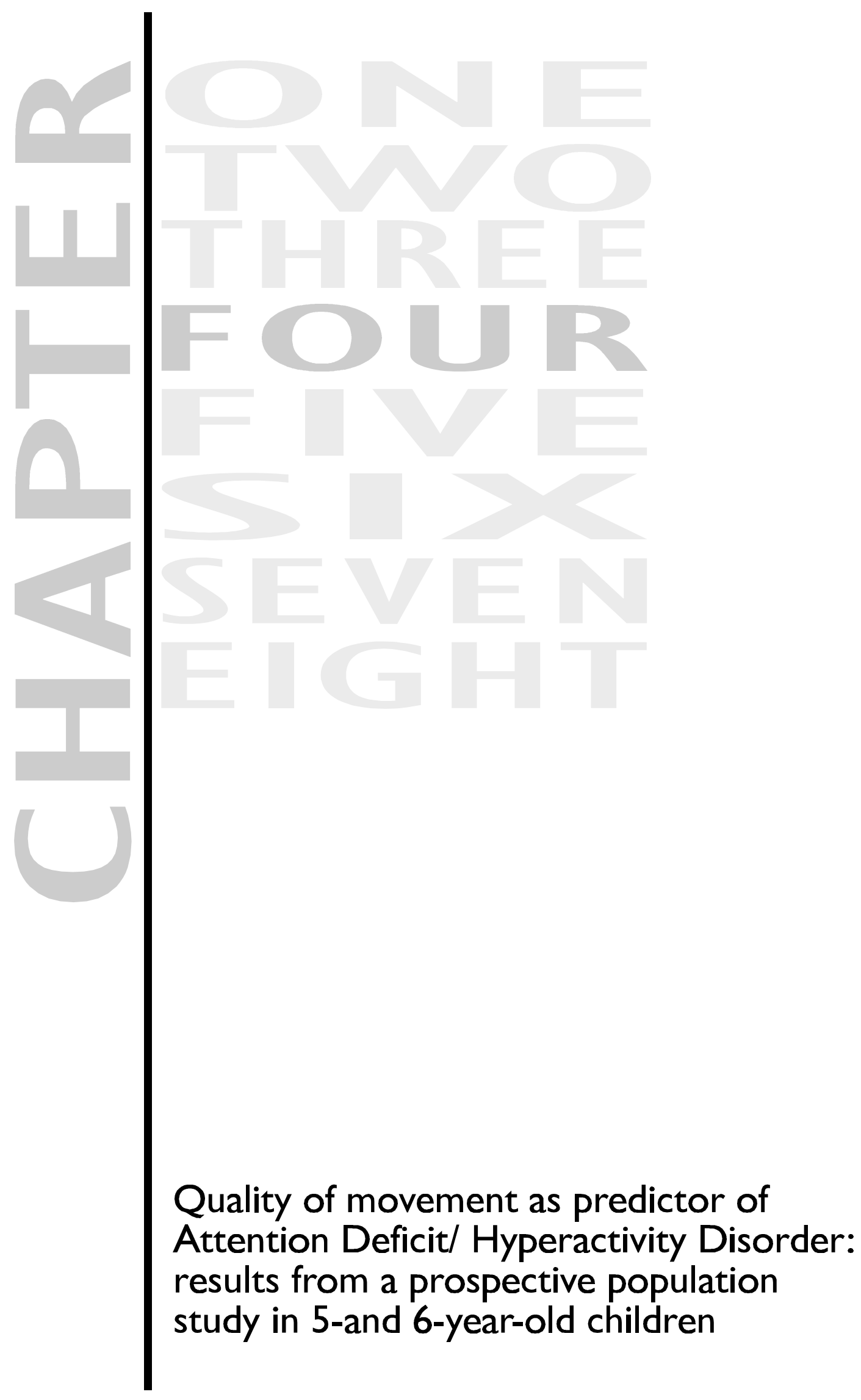





\section{ABSTRACT}

The aims of this prospective study were (I) to examine whether quantitative and / or qualitative aspects of motor performance in 5-to 6-year-old children can predict ADHD at later stage. (2) To investigate whether this relation is also present in conduct disorder (ODD/CD).

Quantitative and qualitative aspects of motor performance were tested in a selected community sample ( $\mathrm{N}=40 \mathrm{I}$; mean age 6.3 , sd 0.5 , range $5.3-7.9$; boys: girls= 232:169) using the Maastricht Motor Test (MMT). One and a half years later, standardized psychiatric information was obtained with the Amsterdam Diagnostic Interview for Children and Adolescents (ADIKA, DSM-IIIR/IV): 35 children were classified as having ADHD, and 92 children as having ODD/CD. Weighted analyses were used in logistic regression analyses to investigate predictive values. Unlike quantitative aspects of motor performance, qualitative aspects were predictive of ADHD. Motor performance was not predictive of ODD/CD.

\section{INTRODUCTION}

Attention-Deficit / Hyperactivity Disorder (ADHD) is currently conceptualised as an early onset, clinically heterogeneous disorder and involves deficits in sustained attention, impulse control, and activity regulation (American Psychiatric Association, 1994; Faraone and Biederman, 1998). Although it is generally assumed that ADHD has its basis in the early years, most children are not clinically diagnosed until later, when they are at elementary school (Mariani and Barkley, 1997). The main reason for this is that although several studies have shown that hyperactivity at pre-school age can predict ADHD at a later stage (Campbell, 1987; McGee et al., 199I; Pierce et al., 1999), it is still unclear in which children these problems persist. A problem with attempting to diagnose ADHD in children at kindergarten age is that much of the behaviour that is considered problematic at an older age falls within the limits of what is normal for these young children (Pierce et al., 1999). In addition, a number of distinctive behaviours in kindergarten children disappear at a later age, to be replaced by other distinctive behaviours. Thus, while behavioural characteristics of ADHD may be present at an early age, their presence does not necessarily mean that the child will develop the disorder. For this reason, other characteristics such as motor problems and neurocognitive dysfunction should be investigated in prospective studies to evaluate whether these characteristics in young children are predictive of a diagnosis of ADHD at a later age. The main aim of the present study is to determine whether or not motor characteristics in 5-to 6-year-old children can predict ADHD at a later stage.

Most studies concerning ADHD and motor performance are cross-sectional studies in elementary school children. Two important exceptions are (I) the study of Hadders-Algra and Groothuis (1999) and (2) those of Kadesjö and co-workers (e.g. Larson et al., 1995; Kadesjö and Gillberg, 1998). The first study investigated movements post-partum and later 
developmental problems, and concluded that abnormal quality of general movements 2 and 4 month post term was associated with ADHD. The second study demonstrate that a combination of attention deficits and clumsiness has a more unfavourable prognosis than each of them separately. Their motor score included both quantitative and qualitative items which were not separately analysed.

Although the relation between ADHD and motor functioning in older children has been studied cross-sectional by several authors, the results are inconsistent. For example, where Hartsough and Lambert (1985) described that $52.3 \%$ of the children with ADHD also had co-morbid co-ordination problems, and Gillberg et al. (1993) even defined a separate diagnostic category for these children (deficit in attention, motor control, and perception; DAMP), Leung and Connolly (1998) suggested that motor processing is typically unaffected in ADHD. These discrepancies might be caused by the use of different assessments and conceptualisations of motor deficits, ADHD, and their combination (Steger et al., 200I).

Two aspects of motor performance can be scored: quantity and quality. Where quantitative aspects of a movement reflect speed or number (countable units), qualitative aspects describe the pattern of a movement. A considerable amount of research in ADHD has focused on the speed (quantity) of pure motor functions, and the assessment battery of Denckla and Rudel (1973; 1974) for repetitive simple movements of the finger, hand, and foot is frequently used for this purpose. Although Denckla et al. (1985) and Carte et al. (1996) found that children with ADHD were significantly slower than their controls, Steger and colleagues (200I) could not replicate this finding. Furthermore, Grodzinsky and Diamont (1992), Leung and Connolly (1998), and Mariani and Barkley (1997) did not find differences between children with and without ADHD when measuring the finger-tapping rate or grooved pegboard scores, which are regarded as simple tests of motor speed. Aspects of movement quality, such as overflow movements and co-ordination problems are also important. Denckla et al. (1985) reported that children with ADHD showed more qualitative signs of dysrhythmia or overflow while making repetitive and alternating movements. In addition, Szatmari and Taylor (1984), using the 'Fogs Test', in which children are asked to walk between two lines in several postures (e.g. heel-to-toe, on their heels or with feet inverted) and overflow movements are scored, found that a severely impaired performance carried an increased risk of behavioural disturbances of all types, especially hyperactive behaviour.

A drawback of recent studies is that most of them measured only a small part of the motor repertoire of the child. Whereas Denckla et al. (1985), for instance, only measured repetitive simple movements in finger, hand and foot (diadochokinesis), Szatmari and Taylor (1984), using the 'Fog Test', only measured dynamic balance. An exception in this field is the study of Piek et al. (1999), in which both fine and gross motor performance was examined, using the Movement Assessment Battery for Children (Henderson and Sugden, 1992). Although this instrument incorporates some qualitative aspects of movements it does not score the movement the pattern separately. To investigate both qualitative and quantitative aspects of several motor domains, we developed the Maastricht Motor Test (Kroes et al., 
submitted), which we used in this prospective study to determine whether aspects of motor performance can predict ADHD.

Another point of interest concerns co-morbidity. As Caron and Rutter (1991) described, it is important to pay attention to co-morbidity because a study of condition $X$ may produce findings that in fact are largely a consequence of the ignored co-morbid condition $\mathrm{Y}$. Because ADHD is known to overlap with oppositional and conduct disorder, we investigated whether motor performance is predictive of ADHD only or whether it is also predictive of oppositional and conduct disorder (ODD/CD).

\begin{tabular}{|c|c|c|}
\hline Figure 4.I & the Study of Attention & ers in Maastricht \\
\hline STAGE I: months I-9 & STAGE 2: months 4-9 & STAGE 3: months I5-25 \\
\hline Responders $(\mathrm{N}=|3| 7)$ & Selected sample $(N=452)$ & Selected sample $(N=452)$ \\
\hline $\begin{array}{l}\text { Behavioural } \\
\text { questionnaire }\end{array}$ & $\begin{array}{l}\text { - } \text { Motor performance } \\
\text { - Cognitive } \\
\text { functioning }\end{array}$ & $\begin{array}{ll}\text { - } & \text { Psychiatric } \\
\text { information }\end{array}$ \\
\hline
\end{tabular}

\section{METHODS}

This report is part of the "Study of Attention disorders in Maastricht (SAM)", a prospective cohort study of the precursors of ADHD in 5-to 6-year-old children in The Netherlands (Kalff et al., 200I; Kroes et al., 200I). In order to maximize our study goals within a reasonable budget, we used a screening-stratified sampling as described by Shrout at al. (1986). In the first stage, the children were selected by means of a behavioural questionnaire at year one of primary school. In the same year (second stage), motor performance was tested in these selected children. One year later, more detailed psychiatric information was collected from the selected children by using a standardised interview (third stage) (see figure 4.I for sampling design).

\section{Subjects}

\section{Stage I: months I-9}

All children in year one of primary school in the south of Limburg (a province in the Netherlands) were approached by the Youth Health Care to participate in the study, in accordance with the guidelines of the Ethics Committee of the University Hospital in Maastricht (the Netherlands). The initial sample comprised 2290 children, of which the parents of 1317 (699 boys and 618 girls, mean age $5.87(S D=0.41))$ granted permission for participation. Responders and non-responders were compared, by randomly sampling 200 subjects from each group, for sex, age and demographic factors such as parental occupation, nationality, family structure, and living area. The information was obtained anonymously from 
the medical records of the Youth Health Care. No significant differences between the nonresponder and responder groups were found.

On the basis of scores for the Child Behaviour Checklist (CBCL; Achenbach and Edelbrock, 1983; Verhulst et al., 1996), which was completed by the parents of the children, three groups of children were selected for the second stage $(\mathrm{N}=452)$. Group $E$ (externalising group) consisted of children with $\mathrm{CBCL}$ externalising-scale scores above the 90th percentile and/or with $C B C L$ attention problem-scale scores exceeding the 95th percentile $(N=173)$. This group contains the children with a putative risk for the development of ADHD (Chen et al., 1994). Group I (internalising group) consisted of children with internalising-scale scores above the 90th percentile and who were not members of the first group $(\mathrm{N}=59)$. This group was included as a pathological control group in order to control for the specificity of the behavioural problems as a possible risk factor. Finally, children out off group $E$ and I were matched for age ( \pm 2 month), sex and school (urban versus non-urban) with children with CBCL total-scores below the 90th percentile. This 'normal group' (group N) consisted of 220 children. As ADHD was of main interest in our study, and former studies showed that especially "attention problem" in the CBCL were predictive for ADHD (see Chen et al., 1994) borderline cut-off were defined for this problem scale. For the externalising and internalising scales clinical cut-off was used. The cut-off values were chosen in consultation with Verhulst, first author of the $\mathrm{CBCL}$ (Verhulst, personal communication).

\section{Stage 2: month 4-9}

The motor performance of 438 (97\%) of the 452 selected children was assessed, using the Maastricht Motor Test (MMT; Kroes et al., submitted). The mean age at the time of assessment was 6.3 years (sd 0.4, range 5.3-7.7); there were 188 girls. The children were tested during school-time at their own schools in a quiet room of at least 15 square metres. The test took about 30 minutes and was administered by two trained examiners who were blind to the $\mathrm{CBCL}$ group assignments. Inter-rater reliability of the total score was 0.96 (see Kroes et al., submitted). Additionally, the cognitive functioning of the children was measured by using two subtests of the Revised Amsterdam Child Intelligence Test (RAKIT; Bleichrodt et al., 1987).

\section{Stage 3: months I5-25}

In the third stage of the study, 18 months after the first stage, the parents of the selected children were interviewed using the Dutch version of the Diagnostic Interview for Children and Adolescents (DICA), renamed ADIKA (Herjanic and Campbell, 1977; Kortenbout van der Sluijs et al., 1993). Three skilled interviewers administered the ADIKAs. They were not aware of the $C B C L$ screening results and were supervised intensively by a senior child psychiatrist. 
Forty-nine (II\%) parents of the 452 selected children refused to allow their children to participate in this last stage, leaving 403 who finally participated. The motor performance of two of these children was not tested in the second stage. Therefore the results for $40 \mathrm{I}$ children (89\% of original selected sample; mean age at time of motor assessment: 6.3 , sd 0.5 , range 5.3-7.9; boys: girls= 232:169) were analysed. Comparison of this final responder group $(\mathrm{N}=40 \mathrm{I})$ with the drop-outs of the original responders $(\mathrm{N}=5 \mathrm{I})$ showed no significant differences in age, sex, and CBCL selection group.

\section{Measures}

\section{Stage I}

The Child Behaviour Checklist was developed by Achenbach and Edelbrock (1983) and was translated and revised by Verhulst et al. (1996) for the Dutch population. It is used as a screening instrument, and previous studies have demonstrated its validity in detecting children with and without behavioural problems according to their parents (Chen et al., 1994; Kasius et al., 1997). Test retest reliability showed significant pearson correlations for all scales (Verhulst et al., 1996)Two broadband-scales can be composed (externalising and internalising problems) and a total problem score. The $C B C L$ also yields several subscales, one of which, the Attention subscale, was used in the present study.

\section{Stage 2}

The Maastricht Motor Test is a test to evaluate quantitative and qualitative motor performance in 5 to 6-year-old children (Kroes et al., submitted). The test includes 70 items and is organised in four domains: 14 items deal with Static Balance (SB), 20 deal with Dynamic Balance (DB), 8 with Ball Skills (BS), and 28 with Diadochokinesia and Manual Dexterity (D\&MD). Of these 70 items, 36 items deal with qualitative and 34 with quantitative aspects of movement. Items concerning movement quantity are compatible with countable units, for example, the number of seconds a child can stand on one leg (SB), the number of times a child can hop on one leg (DB), the number of times the child catches a ball (BS), the speed of tapping the hand (D\&MD). The items concerning movement quality reflect the pattern of a movement, such as associated movements, co-ordination, and stability. The 70 items are scored on a 3-point scale from 0 to 2 . The reliability and validity of the test are acceptable and reported in a separate manuscript (Kroes et al., submitted). To illustrate the difference of quantitative and qualitative aspects as measured in this article we refer to the appendix of the Maastricht Motor Test as entered in this thesis. The intra-class correlation of the interrater reliability varied from 0.92 for the qualitative score, 0.97 for the quantitative score, to 0.96 for the total score. The area under the curve for the total score was 0.87 , which indicated reasonable validity (Kroes et al., submitted).

Cognitive functioning was measured by using two subtests of the RAKIT (Bleichrodt et al., 1987) and used a confounder in the analyses. The 'Vocabulary subtest' measures the verbal 
ability of the child. The raw scores range from I to 60 and were transformed into scaled scores (mean $=15$, sd $=5$, range 1-30) according to Dutch normative data. The 'Embedded Figures subtest' measures the perceptual ability of the child. The raw scores range from I to 45 and were also transformed into scaled scores.

\section{Stage 3}

The Amsterdam Diagnostic Interview for Children and Adolescents (ADIKA; Kortenbout van der Sluijs et al., 1993) is the translation of the Diagnostic Interview for Children and Adolescents (DICA; Herjanic and Campbell, 1977). This is a semi-structured interview that yields scores for several child psychiatric disorders, according to DSM-III-R guidelines (American Psychiatric Association, 1987). The ADIKA was adapted by using the criteria of DSM-IV for diagnosing ADHD (Westereich, 1998). In line with these criteria, children were classified as 'ADHD' if they had ADHD symptoms according to the DSM-IV criteria and if these symptoms were present in at least two situations. The symptoms also had to have persisted for at least 6 months and to have been present before the age of 7 years. The diagnoses of 'Conduct disorder' and 'Oppositional disorder' according to DSM-IIIR were grouped together '(ODD/CD)'. Although the Dutch version of the DICA-IIIR interview has not been separately validated, DICA and DICA-IIIR have been demonstrated to have high test-retest reliability and moderate correlations with clinician based diagnoses (Ezpeleta et al., 1996; Welner et al., 1987). Three skilled interviewers administered the ADIKAs. To optimize the reliability of the interview, the interviewers were trained and supervised intensively by a senior child psychiatrist. The interviewers and the child psychiatrist were blind to the $\mathrm{CBCL}$ screening results.

\section{Data analyses}

Because the selection procedure in stage one was based on the CBCL results, age, sex, and school, the selected group does not represent the entire responder group. For this reason, it was necessary to weight the analyses using the 'sampling weight option' of STATA (StataCorp, 200I), which permits adjustment for design characteristics such as 2-stage sampling. The weights were calculated per $\mathrm{CBCL}$, age, sex, and school stratum, and were consistent with the inverse of the probability of selection.

To examine the predictive value of motor performance at 5 to 6 years of age for the development of ADHD or ODD/CD one and a half years later, logistic regression analyses were used. To determine the cut-off points for the quantitative and qualitative aspects of the different movement domains, the following method was used (Boreas et al., 2002)

I. Children were sorted in ascending order by motor score.

2. For children with the same motor score, the mean chance of ADHD was calculated; this fraction was subsequently assigned to all children with the same motor score.

3. The moving averages of ADHD+ or ADHD- were calculated using a group size of 201 children. 
4. The calculated average could be interpreted as an estimate of the probability of a child having ADHD when it had a certain motor score.

5. These probability rates ( $Y$-axis) were plotted against the motor score (X-axis). The distance on the $\mathrm{X}$-axis between two markers represents a fixed number of children with a certain score. Based upon these plots, cut-off points for different scores were defined.

ADHD or not was used as dependent variable and motor performance for different domains was used as independent variable. Analyses were subsequently performed with and without sex, age, and cognitive functioning as confounders. Main reason to provide both analyses is that on the one hand the co-variates would remove some variance of the disorders of interest (better not to use co-variates) but on the other hand it is known that outcome on motor performance is associated with gender and cognition (better to use co-variates). For the analyses with confounders, the standard scores of the cognitive tests were divided into tertiles. Odds ratios and $95 \%$ confidence intervals were calculated to assess whether performance on each test predicted the subsequent diagnosis of ADHD. In addition to this comparison, ODD/CD was used as dependent variable to investigate whether motor problems are unique to children at risk of developing ADHD, or whether these deficits are also evident in children with ODD/CD. 


\section{RESULTS}

Group characteristics, for the classification assigned in the third stage, are shown in Table 4.I. Thirty-five children were diagnosed with ADHD and 26 of them were also diagnosed with ODD/CD. The total ODD/CD group consisted of 92 children (80 ODD and I2 CD).

\section{Table 4.I Group characteristics.}

\begin{tabular}{lllll}
\hline & $\begin{array}{l}\text { ADHD } \\
(\mathbf{N}=35)\end{array}$ & $\begin{array}{l}\text { Non-ADHD } \\
(\mathbf{N}=366)\end{array}$ & $\begin{array}{l}\text { ODD/CD } \\
(\mathbf{N}=92)\end{array}$ & $\begin{array}{l}\text { Non-ODD/CD } \\
(\mathbf{N}=309)\end{array}$ \\
Characteristics & Mean (sd) & Mean (sd) & Mean (sd) & Mean (sd) \\
\hline Sex (boys/ girls) & $25 / 10$ & $207 / 159$ & $62 / 30$ & $170 / 139$ \\
Age (in years) & $6.1(0.3)$ & $6.2(0.5)$ & $6.2(0.5)$ & $6.2(0.4)$
\end{tabular}

\section{Quality MMT}

$\begin{array}{lllllllll}\text { SB } & 7.2 & (4.1) & 8.8 & (3.7) & 8.7 & (3.2) & 8.6 & (3.9) \\ \text { DB } & 12.9 & (3.7) & 14.6 & (4.0) & 14.1 & (4.1) & 14.6 & (4.0) \\ \text { BS } & 5.3 & (1.7) & 5.4 & (1.6) & 5.5 & (1.5) & 5.3 & (1.6) \\ \text { D\&MD } & 17.5(3.2) & 19.2 & (4.0) & 19.2 & (3.6) & 19.0 & (4.0) \\ \text { TS } & 43.0(9.1) & 47.9 & (9.6) & 47.4 & (8.7) & 47.5 & (10.0)\end{array}$

\section{Quantity of MMT}

$\begin{array}{llllllll}\text { SB } & 13.1(1.4) & 13.3(1.5) & 13.5(1.1) & 13.2(1.6) \\ \text { DB } & 17.2(1.6) & 17.2(1.6) & 17.4(1.3) & 17.1(1.7) \\ \text { BS } & 7.3(1.1) & 7.4(1.1) & 7.4 & (1.1) & 7.4 & (1.1) \\ \text { D\&MD } & 25.7(2.4) & 26.1(2.4) & 26.1(2.0) & 26.0(2.5) \\ \text { TS } & 63.3(3.8) & 64.0(4.6) & 64.4(3.4) & 63.8(4.9)\end{array}$

\section{Cognitive functioning}

$\begin{array}{llllllll}\text { Vocabulary } & 13.0(4.0) & 13.9(5.1) & 13.2(5.1) & 14.0(5.0) \\ \text { Embedded figures } & 13.7(4.6) & 15.5(5.3) & 14.1(5.3) & 15.7(5.2)\end{array}$

SB = Static Balance, DB = Dynamic Balance, BS = Ball Skills, D\&MD = Diadochokinesia and Manual Dexterity, $\mathrm{TS}=$ Total Score. $\mathrm{ADHD}=$ Attention Deficit/ Hyperactivity Disorder, $\mathrm{ODD} / \mathrm{CD}=$ Oppositional and Conduct Disorder, MMT = Maastricht Motor Test.

The moving average scores were plotted for both quantitative and qualitative aspects of the four movement domains. In general, the better a child performed, the lower the chance of it developing ADHD, with the exception of ball skills (figure 4.2). This figure presents that children with higher scores (until 6) have a higher risk for ADHD with exception for the relatively small group of children with scores $>6$, that have a lower risk for ADHD. It is important to realise that while these plots of moving average scores give insight into the relation between movement problems and likelihood of developing ADHD, the curves do not have to show a significant result. 


\section{Figure 4.2 Chance of developing ADHD depending on the qualitative score for ball skills.}

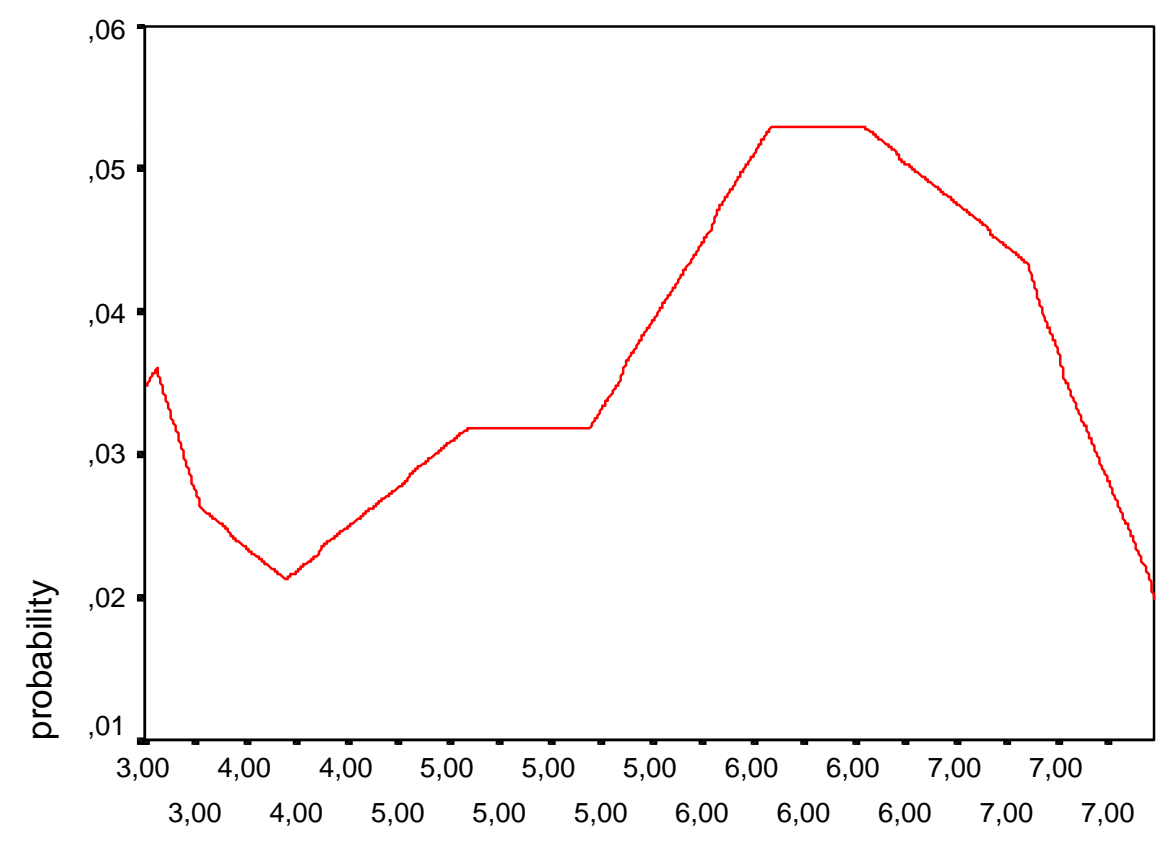

qualitative score for ball skills*.

* distance between two markers represents a fixed number of children

Table 4.2 shows the results of weighted logistic regression analyses for both ADHD and ODD/CD with and without adjustment for confounders. High scores on the MMT were used as reference. Regarding ADHD, the qualitative domains of DB, D\&MD, and the Total Qualitative Score showed significant odds ratios; the odds ratio for SB tended to be associated with ADHD $(p=0.08)$. When age, sex and cognitive functions were combined in the analyses, the results hardly changed. None of the quantitative domains, however, showed significant results. Concerning the predictive value of the MMT for ODD/CD, only the qualitative domain of BS yielded significant odds ratis, which indicates that a better performance increased the risk of ODD/CD. 
Table 4.2 Logistic regression analyses of quantitative and qualitative movement domains in relation to a diagnosis of ADHD in later years, with and without adjustment for sex, age and cognitive functioning

\begin{tabular}{|c|c|c|c|c|c|}
\hline \multirow[t]{2}{*}{ Domain } & \multirow[t]{2}{*}{ Cut-off } & \multicolumn{2}{|c|}{ ADHD } & \multicolumn{2}{|c|}{ ODD/CD } \\
\hline & & OR & $95 \% \mathrm{Cl}$ & OR & $95 \% \mathrm{Cl}$ \\
\hline \multicolumn{6}{|l|}{ Quality } \\
\hline SB & $0-6,7-14$ & $\begin{array}{l}2.1 \\
1.9\end{array}$ & $\begin{array}{l}0.9-4.7 \\
0.8-4.1\end{array}$ & $\begin{array}{l}0.8 \\
0.5\end{array}$ & $\begin{array}{l}0.4-1.4 \\
0.3-1.1\end{array}$ \\
\hline $\mathrm{DB}$ & $0-14,15-22$ & $\begin{array}{l}3.6^{* *} \\
3.9^{1 * *}\end{array}$ & $\begin{array}{l}1.6-8.1 \\
1.5-10.3\end{array}$ & $\begin{array}{l}1.5 \\
1.2\end{array}$ & $\begin{array}{l}0.8-2.7 \\
0.6-2.3\end{array}$ \\
\hline BS & $0-5,6-8$ & $\begin{array}{l}0.7 \\
0.8\end{array}$ & $\begin{array}{l}0.3-1.7 \\
0.3-1.8\end{array}$ & $\begin{array}{l}0.5^{*} \\
0.5^{1 *}\end{array}$ & $\begin{array}{l}0.3-0.9 \\
0.3-1.0\end{array}$ \\
\hline$D \& M D$ & $0-17,18-28$ & $\begin{array}{l}4.7^{* *} \\
4.2^{1 * *}\end{array}$ & $\begin{array}{l}2.1-10.5 \\
1.8-9.8\end{array}$ & $\begin{array}{l}1.0 \\
0.9\end{array}$ & $\begin{array}{l}0.6-1.8 \\
0.5-1.7\end{array}$ \\
\hline TS & $0-48,49-72$ & $\begin{array}{l}5.0^{* * *} \\
4.6^{1 * *}\end{array}$ & $\begin{array}{l}2.1-12.1 \\
1.9-11.3\end{array}$ & $\begin{array}{l}1.0 \\
0.9\end{array}$ & $\begin{array}{l}0.6-1.8 \\
0.5-1.6\end{array}$ \\
\hline \multicolumn{6}{|c|}{ Quantity } \\
\hline SB & $0-13,14$ & $\begin{array}{l}1.9 \\
1.8\end{array}$ & $\begin{array}{l}0.8-4.5 \\
0.7-4.8\end{array}$ & $\begin{array}{l}0.7 \\
0.6\end{array}$ & $\begin{array}{l}0.4-1.4 \\
0.3-1.0\end{array}$ \\
\hline DB & $0-17,18$ & $\begin{array}{l}1.4 \\
1.4^{1}\end{array}$ & $\begin{array}{l}0.6-3.5 \\
0.6-3.7\end{array}$ & $\begin{array}{l}0.6 \\
0.5^{1}\end{array}$ & $\begin{array}{l}0.3-1.1 \\
0.3-0.9\end{array}$ \\
\hline BS & $0-7,8$ & $\begin{array}{l}1.7 \\
1.7^{1}\end{array}$ & $\begin{array}{l}0.7-4.2 \\
0.7-4.4\end{array}$ & $\begin{array}{l}0.8 \\
0.8^{1}\end{array}$ & $\begin{array}{l}0.4-1.5 \\
0.4-1.5\end{array}$ \\
\hline $\mathrm{D} \& \mathrm{MD}$ & $0-26,27-28$ & $\begin{array}{l}1.2 \\
1.0^{1}\end{array}$ & $\begin{array}{l}0.5-2.9 \\
0.4-2.6\end{array}$ & $\begin{array}{l}1.2 \\
1.1^{1}\end{array}$ & $\begin{array}{l}0.7-2.2 \\
0.6-2.0\end{array}$ \\
\hline TS & $0-65,66-68$ & $\begin{array}{l}1.7 \\
1.5^{1}\end{array}$ & $\begin{array}{l}0.7-4.2 \\
0.6-3.9\end{array}$ & $\begin{array}{l}0.8 \\
0.7^{1}\end{array}$ & $\begin{array}{l}0.4-1.4 \\
0.4-1.3\end{array}$ \\
\hline
\end{tabular}

\section{DISCUSSION}

We examined the predictive value of quantitative and qualitative aspects of several movement domains at the age of 5-6 years for the development of ADHD at a later stage. Furthermore, we investigated whether motor problems are unique to children at risk of ADHD or whether these deficits are also evident in children with ODD/CD. In contrast to some other authors who investigated risk factors in a screening-stratified sampling, we weighted our analyses. The advantage of doing this is that calculated odds ratios can be 
interpreted as applying to children in a community population, which in general will differ from odds ratios corresponding to the same predictors in a selected population.

The study had several limitations. Firstly, the diagnosis ADHD was based on the ADIKA scores alone, using information provided by the parents. Although information provided by multiple informants is the best way to diagnose ADHD (Bird et al., 1992), it was not practically possible to the teachers or the children. Furthermore, we did not study different subtypes of ADHD or sex differences. These limitations arose because we used a longitudinal community design, which always results in a relatively small number of 'cases'. For this reason, a larger sample should be studied. Another limitation is that the ADHD and ODD/CD groups of children were not "pure" groups because both groups contained children with co-morbid disorders. Although, based on this design, we cannot draw conclusions concerning the 'pure ADHD group', the ADHD group in this study is representative of ADHD children in a general population, in whom a 'pure diagnosis' is rarely made (Kadesjo and Gillberg, 200I). Last point to pay attention at is the fact that presented odds ratios were not controlled for type I errors (which could be done by using more strict significance levels) because we consider this study as an explorative one. On the other hand this may introduce significant associations which occur by chance due to the number of analyses. Despite these limitations, the findings of our longitudinal community study are of significance because this is the first study to investigate the predictive value of quantitative and qualitative motor performance for the development of ADHD in this young age group. Moreover, the community-based results can be generalised to the population as a whole.

The most salient finding was that two of the four (Dynamic Balance and Diadochokinesia \& Manual Dexterity) qualitative domains and the total qualitative score at 5 to 6 years of age are predictive for the diagnosis ADHD I year later. Moreover, these motor problems were associated with ADHD and not with ODD/CD. None of the quantitative domains contributed significantly to ADHD or CD. In contrast with the assumption that children with ADHD may be more likely to have fine rather than gross motor difficulties (Whitmont and Clark, 1996), we found that both aspects of motor performance were affected. This finding is consistent with that of Piek et al. (1999), with the distinction that we showed that only qualitative aspects of gross and fine motor performance can be used as predictors of the development of ADHD. In both our study and the study of Piek et al. (1999), ball skills were not significantly associated with ADHD.

The quantitative part of the fourth domain (Diadochokinesia and Manual Dexterity) of the MMT is quite similar to the assessment battery of Denckla and Rudel (1973; 1974) and also focuses on the speed of repetitive motor movements. Although Denckla et al. (1985) and Carte et al. (1996) found that children with ADHD were significantly slower than their controls, our findings support these of Steger et al. (200I), Grodzinsky and Diamont (1992), Leung and Connolly (1998), and Mariani and Barkley (1997), who did not find differences in motor speed between children with and without ADHD. 
Our results can be interpreted by using different theories on the aetiology of ADHD. Genetic studies have suggested a polygenetic inheritance, which may lead to a genetically based hypofunctional dopamine system in ADHD (Sagvolden and Sergeant, 1998; Solanto, 1998). The association of the dopamine transporter gene (DATI) with ADHD is of particular importance (Dougherty et al., 1999). Over-expression of DAT causes lower levels of dopamine in the synaptic cleft. This phenomenon is postulated to be a cause of ADHD and is at present the main target for medication: both D-amphetamine and methylphenidate inhibit the re-uptake of dopamine by binding to the dopamine transporter (Solanto, 1998). Our results are consistent with this theory because dopamine plays an important role in regulating in-and output signals in the basal ganglia (Martin, 1989). The basal ganglia and the cerebellum play an important role in the fluency and co-ordination (qualitative aspects) of a movement. Thus a lack of the neurotransmitter dopamine, as is suggested to occur in ADHD, may cause problems in the qualitative aspects of movements.

Our results can also be interpreted in terms of Barkley's theory (1997) concerning a deficit in response inhibition. He suggested that this deficit leads to an impairment in four different executive functions (working memory, self-regulation, internalisation of speech and reconstruction) which influence the motor system in service of goal-directed behaviour, labelled motor control, fluency, and syntax. Although this theory is especially founded with the behavioural characteristics of ADHD, it may also explain the qualitative impairment of motor control. Deficits in inhibition may result in difficulties with varied, complex, and hierarchically organised patterns of motor responses (Barkley, 1997). As suggested by other authors, qualitative aspects might be a better reflection of higher cortical functions than are quantitative aspects (Weisglas-Kuperus et al., 1994).

Although $A D H D$ and $O D D / C D$ are known to overlap, our findings confirm that motor problems in ADHD are primarily related to the diagnosis of ADHD and are not a characteristic of ODD/CD. As far as we know, none of the other studies of motor problems investigated this issue. However, the children investigated not only had a diagnosis of ADHD or ODD/CD but also had other (co-morbid) problems. Thus while conclusions have to be drawn with caution, the results lend support to the notion that ADHD has a different aetiology from that of ODD/CD. Where the former is considered to arise from a biologically based disorder of temperament or neurocognitive delay, the latter is suggested to be primarily due to external factors (Barkley, 1998).

In conclusion, the results of this longitudinal community study show that qualitative aspects of motor performance in children of 5 to-6-years of age are related to a later diagnosis of ADHD and not to a diagnosis of ODD/CD. Where behavioural characteristics appear not to be sufficient to distinguish between children with ADHD or not at an early age, examining the qualitative aspects of a movement as precursors of ADHD may be of additional value in the early identification of kindergarten children at risk of ADHD. 


\section{Acknowledgements}

The authors thank Dr. Jos G.M. Hendriksen, Dr. Thea M.C.B. v.Zeben, Dr. Jean Steyaert and Prof. Jaap Troost as members of the "Study of Attention disorders in Maastricht (SAM)" for their advice and support throughout this project. 


\section{REFERENCES}

Achenbach TM, Edelbrock C (1983), Manual for the Child Behavior Checklist and Revised Child Behavior Profile. Burlinton: University of Vermont Department of Psychiatry

American Psychiatric Association (1987), Diagnostic and Statistical Manual of Mental Disorders. 3rd revised edition Washington D.C.: American Psychiatric Association

American Psychiatric Association (1994), Diagnostic and Statistical Manual of Mental Disorders. 4th edition Washington D.C.: American Psychiatric Association

Barkley RA (1997), Behavioural inhibition, sustained attention, executive functions-constructing a unifying theory of ADHD. Psychological Bulletin 121: 65-94

Barkley RA (1998), Attention Deficit Hyperactivity Disorder, A handbook for diagnosis and treatment. 2nd edition London: The Guilford Press

Bird HR, Gould MS, Staghezza BMPH (1992), Aggregating Data from Multiple Informants in Child Psychiatry Epidemiological Research. Journal of American Academy of Child and Adolescent Psychiatry 31: 78-85

Bleichrodt N, Drenth PJD, Zaal JN, Resing WCM (I987), RAKIT: Handleiding bij de Revisie Amsterdamse Kinder Intelligentie Test [Manual of the revised Amsterdam intelligence test for children]. Lisse: Swets \& Zeitlinger

Boreas AMHP, Lodder J, Kessels F, de Leeuw PW, Troost J (2002), Prognostic value of blood pressure in acute stroke. Journal of Human Hypertension 16: III-I I6

Campbell SB (1987), Parent-referred problem three-year-olds: developmental changes in symptoms. Journal of Child Psychology and Psychiatry and Allied Disciplines 28: 835-45

Caron C, Rutter M (199I), Comorbidity in child psychopathology: concepts, issues and research strategies. Journal of Child Psychology and Psychiatry and Allied Disciplines 32: 1063-80

Carte ET, Nigg JT, Hinshaw SP (1996), Neuropsychological functioning, motor speed, and language processing in boys with and without ADHD. Journal of Abnormal Child Psychology 24: 48I-498

Chen WJ, Faraone SV, Biederman J, Tsuang MT (1994), Diagnostic accuracy of the Child Behavior Checklist scales for attention-deficit hyperactivity disorder: a receiver-operating characteristic analysis. Journal of Consulting and Clinical Psychology 62: 1017-1025

Denckla MB (1973), Development of speed in repetitive and successive finger-movements in normal children. Developmental Medicine \& Child Neurology I5: 635-645

Denckla MB (1974), Development of motor coordination in normal children. Developmental Medicine \& Child Neurology 16: 729-74I

Denckla MB, Rudel RG, Chapman C, Krieger J (1985), Motor proficiency in dyslectic children with and without attentional disorders. Archives of Neurology 42: 228-23।

Dougherty DD, Bonab AA, Spencer TJ, Rauch SL, Madras BK, Fischman AJ (1999), Dopamine transporter density in patients with attention deficit hyperactivity disorder. The Lancet 354: 21 32-2 133

Ezpeleta L, de la Osa N, Domenech JM, Navarro JB, Losilla JM (1997), Diagnostic agreement between clinicians and the diagnostic interview for children and adolescents-DICA-R in an outpatient sample. Journal of Child Psychology and Psychiatry and Allied Disciplines 38: 431-440

Faraone SV, Biederman J (1998), Neurobiology of Attention-Deficit Hyperactivity Disorder. Biological Psychiatry 44: 95 I-958 
Gillberg C, Winnergard I, Gillberg C (1993), Screening methods, epidemiology and evaluation of intervention in DAMP in preschool children. European Child and Adolescent Psychiatry 2: 121-135

Grodzinsky GM, Diamont R (1992), Frontal lobe functioning in boys with attention-deficit hyperactivity disorder. Developmental Neuropsychology 8: 427-445

Hadders-Algra M, Groothuis AMC (1999), Quality of general movements in infancy is related to neurological dysfunctions, ADHD, and aggressive behaviour. Developmental Medicine \& Child Neurology 4I: 38I-39I

Hartsough CS, Lambert NM (1985), Medical factors in hyperactive and normal children: prenatal, developmental, and health history findings. American Journal of Orthopsychiatry 55: 190-20I

Henderson SE, Sugden DA (1992), Movement Assessment Battery for Children London: The Psychological Corporation

Herjanic B, Campbell W (1977), Differentiating psychiatric disturbed children on the basis of a structured interview. Journal of Abnormal Child Psychology 5: 127-134

Kadesjo B, Gillberg C (1998), Attention deficit and clumsiness in Swedish 7-year-old children. Developmental Medicine \& Child Neurology 40: 796-804

Kadesjo B, Gillberg C (200I), The comorbidity of ADHD in the general population of swedich school-age children. Journal of Child Psychology and Psychiatry and Allied Disciplines 42: 487-492

Kalff A, Kroes M, Vles J, Bosma H, Feron F, Hendriksen J, Steyeart J, Zeben T, Crolla I, Jolles J (200I), Factors affecting the relation between parental education as well as occupation and problem behaviour in Dutch kindergarten children. Social Psychiatry and Psychiatric Epidemiology 36: 324-33I

Kasius MC, Ferdinand RF, van den Berg H, Verhulst FC (1997), Associations between different diagnostic approaches for child and adolescent psychopathology. Journal of Child Psychology and Psychiatry and Allied Disciplines 38: 625-632

Kortenbout van der Sluijs MJ, Levita MJ, Manen de R, Defares BP (I993), ADIKA, Amsterdams diagnostisch interview voor kinderen en adolescenten. Handleiding vragenlijst, vragenlijst ouder/verzorger. Lisse: Swets \& Zeitlinger

Kroes M, Kalff AC, Kessels AGH, Steyaert J, Kessels AGH, Feron FJM, v.Someren AJWGM, Hurks PPM, Hendriksen JGM, v.Zeben TMCB, Rozendaal N, Crolla IFMA, Troost J, Jolles J, Vles JSH (200I), Child Psychiatric diagnoses generalized to a population of Dutch school children aged 6 to 8 years. Journal of American Academy of Child and Adolescent Psychiatry 40: I40I-I409

Kroes M, Vissers YLJ, Sleypen FAM, Feron F, Kessels AGH, Bakker E, Kalff AC, Hendriksen JGM, Steyaert J, van Zeben TMCB, Jolles J, Troost J, Vles JSH (submitted), Reliability and validity of a qualitative and quantitative motor test for kindergarten children.

Larsson JO, Aurelius G, Norberg L, Rydelius PA, Zetterström R (1995) Screening for minimal brain dysfunction (MBD/DAMP) at six years of age: results of motor test in relation to perinatal conditions, development and family situation. Acta Paediatry 84: 30-36

Leung PWL, Connolly KJ (1998), Do hyperactive children have motor organization and/or execution deficits? Developmental Medicine \& Child Neurology 40: 600-607

Mariani MA, Barkley RA (1997), Neuropsychological and academic functioning in preschool boys with attention deficit hyperactivity disorder. Developmental Neuropsychology 13: I I I- 129

Martin JH (1989), Neuroanatomy, text and atlas. New York: Appleton \& Lange 
McGee R, Partridge F, Williams S, Silva PA (199I), A twelve-year follow-up of preschool hyperactive children. Journal of American Academy of Child and Adolescent Psychiatry 30: 224-32

Piek JP, Pitcher TM, Hay DA (1999), Motor coordination and kinaesthesis in boys with attention deficithyperactivity disorder. Developmental Medicine \& Child Neurology 4I: 159-65

Pierce EW, Ewing LJ, Campbell SB (1999), Diagnostic status and symptomatic behavior of hard-to-manage preschool children in middle childhood and early adolescence. Journal of Clinical Child Psychology 28: 4457

Sagvolden T, Sergeant JA (1998), Attention deficit/ hyperactivity disorder-from brain dysfunctions to behaviour. Behavioural Brain Research 94: I-10

Shrout PE, Skodol AE, Dohrenwend BP (1986), A two-stage approach for case identification and diagnosis: firststage instruments, in Mental disorders in the community, $42^{\text {nd }}$ edition New York: Guildford Press

Solanto MV (1998), Neuropsychopharmacological mechanisms of stimulant drug action in attention-deficit hyperactivity disorder: a review and integration. Behavioural Brain Research 94: 127-152

StataCorp (200I), Stata, software for statistical analyses: release 7., College Station, TX: Stata Corporation

Steger J, Imhof K, Coutt E, Grundelfinger HC, Brandeis D (200I), Attentional and neuromotor deficits in ADHD. Developmental Medicine \& Child Neurology 43: I72- 179

Szatmari P, Taylor DC (1984), Overflow movements and behaviour problems: scoring and using a modification of fogs' test. Developmental Medicine \& Child Neurology 26: 297-310

Verhulst FC, Ende van der J, Koot HM (1996), Handleiding voor de CBCL 4-I8 Rotterdam: Afdeling Kinder en jeugdpsychiatrie, Sophia Kinderziekenhuis/ Academisch Ziekenhuis Rotterdam/ Erasmus Universiteit Rotterdam

Weisglas-Kuperus N, Baerts W, Fetter WPF, Hempel MS, Mulder PGH, Touwen BCL, Sauer PJJ (I994), Minor Neurological Dysfunction and Quality of movement in relation to neonatal cerebral damage and subsequent development. Developmental Medicine \& Child Neurology 36: 727-735

Welner Z, Reich W, Herjanic B, Jung KG, Amado H (1987), Reliability, validity, and parent-child agreement studies of the diagnostic interview for children and adolescents (DICA). Journal of American Academy of Child and Adolescent Psychiatry 26: 649-653

Westereich (1998), Amsterdams Diagnostisch Interview voor Kinderen en Adolescenten, ADHD-deel o.b.v. DSM-IV [Amsterdam Diagnostic Interview for Children and Adolescents, ADHD-part of DSMIV criteria]. Brussels: Vrije Universiteit

Whitmont S, Clark C (1996), Kinaesthetic acuity and fine motor skills in children with attention deficit hyperactivity disorder: a preliminary report. Developmental Medicine \& Child Neurology 38: 109I-1098 


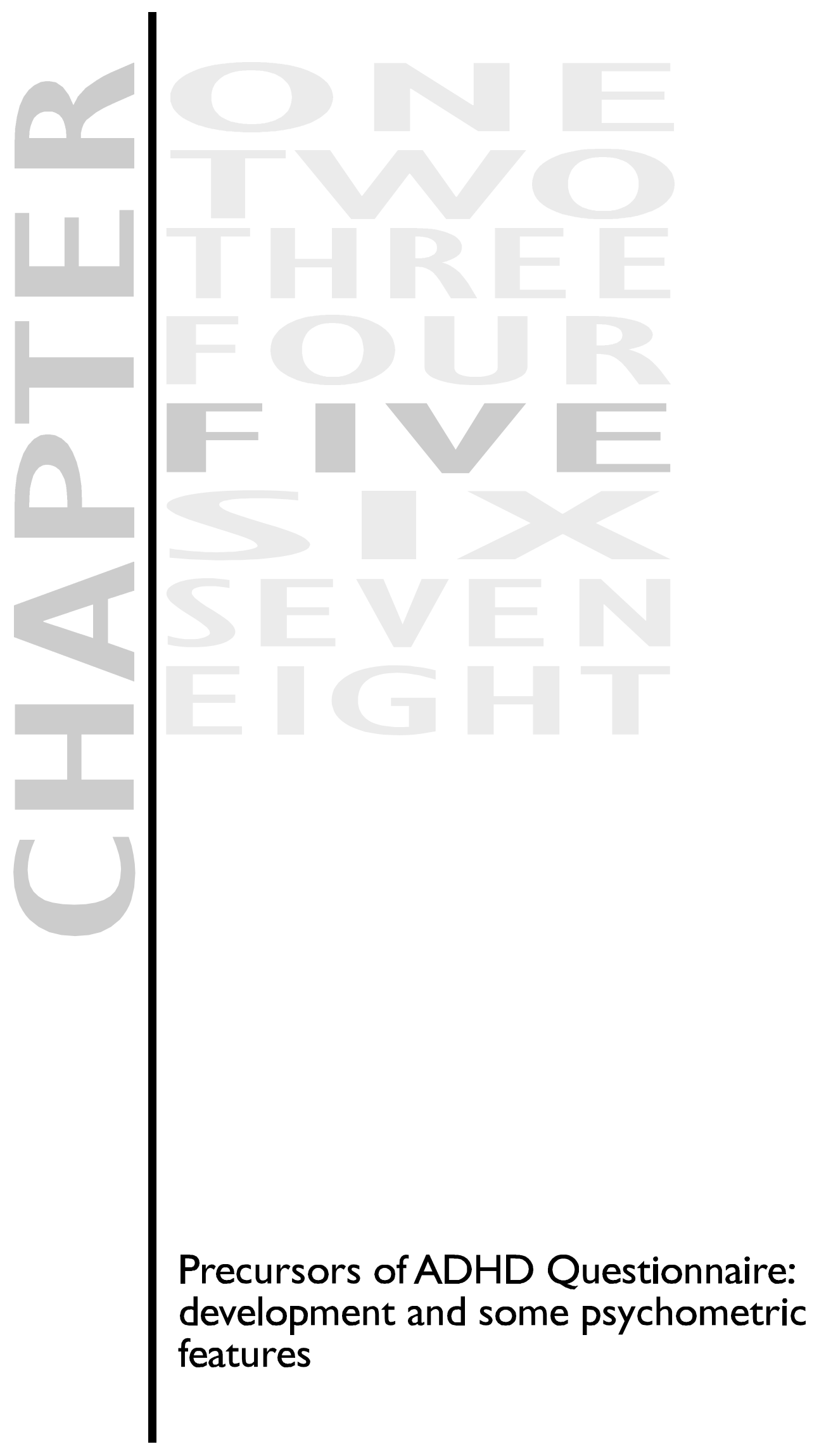





\begin{abstract}
Some of the key symptoms of Attention Deficit / Hyperactivity Disorder (ADHD) pertain to normal behaviour at pre-school age. This phenomenon complicates the identification of preschool children at risk of ADHD. For this reason we developed a questionnaire for kindergarten children in order to identify those children at risk of ADHD. Factor analysis, in a group of 1317 pre-school children, reduced the questionnaire to 16 questions divided in four domains: "socially inadequate behaviour", "impulsivity", "hyperactivity", and "inattention". The instrument proved to be a reliable and valid test for the early detection of pre-school children at risk of ADHD.
\end{abstract}

\title{
INTRODUCTION
}

Since the first description of "attention problems with hyperactivity" by Still in 1902, Attention Deficit/Hyperactivity Disorder (ADHD; DSM-IV; American Psychiatric Association, 1994) is one of the most studied and reported developmental disorders of children (Cantwell, 1996). Its impact on society is enormous in terms of its financial cost, stress to families, adverse academic and vocational outcomes, and negative effects on selfesteem (Faraone and Biederman, 1998). For this reason early identification of children at risk of developing ADHD is important because it could lead to early intervention and thus to an improved prognosis.

\section{ADHD in the pre-school period}

Although according to the DSM-IV criteria, at least some of the symptoms should be present before the seventh year, the disorder is often diagnosed only after 6 years of age (Applegate, 1997). While several studies showed that hyperactivity at kindergarten age can predict ADHD in later stage (Campbell, 1987; McGee, Partridge, Williams, \& Silva, 199I; Pierce, Ewing, \& Campbell, 1999), it is still unclear in which of the children the problems persist. A problem with attempting to diagnose ADHD in children younger than 6 years is that much of the behaviour that is considered problematic at an older age falls within the limits of what is normal for toddlers or kindergarten children. To illustrate this; in a pilot study of the Precursors of ADHD Questionnaire (PAQ) (Hendriksen \& Steyaert, 1999) we found that several items are reported very frequently in 5 to- 6 years old children. Sixty per cent of parents reported that their child was untidy, 50 per cent that the child had difficulty sitting still, and 47 per cent that the child was easily distracted. These are all symptoms of ADHD and illustrate the meaning of the term "symptom specificity", or rather the lack of it.

In addition, a number of distinctive behaviours in kindergarten children, for example, "not able to remain sitting down" disappear at a later age, to be replaced by other distinctive behaviours, such as "does not finish doing things" (Palfrey, Levine, Walker, \& Sullivan, 1985; Marakovitz \& Campbell, 1998). This illustrates the problem of "symptom instability". Thus, 
the same disease manifests itself in different symptoms at different ages in the same child. The duration, severity, and persistence of symptoms and the child's temperament appear to be important predictors of whether problems persist (Marakovitz \& Campbell, 1998; Campbell, 1987; Pierce, Ewing, \& Campbell, 1999; Sonuga Barke, Stevenson, \& Thompson, 1996; Lambert \& Hartsough, 1984).

\section{Early diagnosis}

From the above, it can be seen that while behaviours characteristic of ADHD may be present at an early age, their presence does not necessarily mean that the child will develop the disorder. Instruments that are often used in the Netherlands to screen children for ADHD are questionnaires such as the Conners Rating Scale (Conners, 1973), the Child Behavior Checklist (CBCL) (Verhulst, van der Ende, \& Koot, 1996a), or the recently developed ADHD questionnaire (Scholte \& van der Ploeg, 1999). However, none of these questionnaires was specially developed and validated for kindergarten children. Goal of this study, therefore is to describe the new questionnaire 'Precursors of ADHD Questionnaire (PAQ)' which could be helpful in detecting early signs of ADHD.

\section{Precursors of ADHD Questionnaire (PAQ)}

On the basis of their experience, five specialists (child and youth psychiatrists) prepared a list of behaviours (items) shown by kindergarten children that they considered predictive of ADHD. They identified 42 items, but this number was reduced to 31 after a pilot study involving 120 children (Hendriksen \& Steyaert, 1999). Items were re-formulated if an item was not ticked, apparently because it was not understood by the parents. In the study, described in this paper, the abridged questionnaire was administered to the parents of 1317 kindergarten children and the reliability and validity of the instrument were evaluated.

\section{METHODS}

This report is part of the "Study of Attention Disorders in Maastricht (SAM)", which is a prospective population study of the precursors of ADHD (Kalff et al., 200I), and was performed in accordance with the guidelines of the local ethics committee. The study used a two-phase design: in the first stage the children were screened with the Child Behavior Checklist (Verhulst et al., 1996) at kindergarten age. In the second stage, one and a half years later, more detailed psychiatric information was collected for selected children by using a standardised interview.

\section{Subjects and procedures}

The parents of all kindergarten children in the south of Limburg (county of The Netherlands) were approached by the Youth Health Care to participate in the study. The initial sample comprised 2290 children, of which the parents of 1317 (699 boys and 618 girls, mean age $5.87(\mathrm{SD}=0.4 \mathrm{I}))$ gave their permission for participation. These parents completed the $\mathrm{CBCL}$ 
(Verhulst et al, 1996a) as well the PAQ (see measures). Responders and non-responders were compared by randomly sampling 200 subjects from both groups. Information was obtained anonymously from the medical records of the Youth Health Care. No significant differences between the non-responder and responder groups were found with regard to sex, age, and demographic factors.

The $C B C L$ was used as screening instrument to select children at risk for ADHD and their controls for the second stage. The cut-off value was chosen in consultation with those who made the Dutch version of the CBCL (Verhulst, 1996b). The first group consisted of children with $C B C L$ externalizing-scale scores above the 90th percentile and/or with $C B C L$ inattention scale scores exceeding the 95 th percentile $(n=173)$. The second group consisted of children with internalizing-scale scores above the 90th percentile and who were not members of the first group $(n=59)$. Finally, the control group, matched on age $( \pm 2$ months), sex, and school (urban versus non-urban), consisted of children $(n=220)$ with $C B C L$ total scores below the 90th percentile $(T<63)$.

In the second stage of the study, the parents of the selected children were interviewed using the Dutch version of the Diagnostic Interview for Children and Adolescents (ADIKA) (Kortenbout van der Sluijs et al., 1993). Based on this interview, the diagnoses ADHD or no ADHD were made (see measures). Eleven per cent of the parents of the originally selected children $(n=452)$ refused to participate in this last stage, leaving 403 who finally participated (233 boys, 170 girls). At the time of the interview, the ages of the children ranged from 6.4 to 8.6 (mean=7.I, SD=0.4) years. A number of 35 children turned out to have ADHD according to the ADIKA, 368 did not. In $89.6 \%$ of the cases the mother of the child was interviewed, in $6.4 \%$ of the cases the father, and in $4.0 \%$ of the cases another caretaker.

\section{Measures}

The Child Behavior Checklist (CBCL) was developed by Achenbach (1983) and translated and revised by Verhulst (1996a) for the Dutch population. Two broadband scales can be composed (externalizing and internalizing problems) and a total problem score. The CBCL also yields several subscales, one of which (Attention subscale) was used in the present study.

The Amsterdam Diagnostic Interview for Children and Adolescents (ADIKA) (Kortenbout van der Sluijs et al., 1993) is the translation of the Diagnostic Interview for Children and Adolescents (ADIKA) (Herjanic \& Campbell, 1977), which is based on the DSM-IIIR criteria (American Psychiatric Association, 1987). The Dutch version of the DICA was adapted by using the DSM-IV criteria for ADHD (Westereich, 1998).

Although no reliability and validity studies of the Dutch version of the interview have been performed (Vandermeulen, 1997), the reliability and validity of the DICA are reported to be good (Reich, 2000). Three skilled interviewers administered the ADIKA. To optimize the reliability of the interview, the interviewers were supervised intensively by the child 
psychiatrist. The interviewers and the child psychiatrist were not aware of the $C B C L$ screening results.

The Precursors of ADHD Questionnaire (PAQ) (3I items) should be completed by the parents. All questions are scored on an ordinal scale from 0 to $2(0=$ not applicable; $I=$ slightly $/$ sometimes applicable; 2 = definitely / often applicable).

\section{Analysis}

The number of missing items was determined for the PAQ in order to get an impression of the extent to which parents did not answer specific questions. The frequency distribution of the scores for each item is given. Principal components analysis was used to reduce and cluster the questions (de Heus, van der Leeden, \& Gazendam, 1995). In addition to this "algebraic" method, we also used a graphic method, PRINCALS (de Heus et al., 1995). This analysis is more suited for applications on ordinal scales. Relevant subscales were formed on the basis of the two analyses. The internal consistency of the abridged questionnaire was calculated using Chronbach's alpha (Cronbach, 195I). The quartile scores of the different subscales were also calculated.

Receiver operator characteristic (ROC) curves were used to evaluate the predictive validity of the PAQ, with the classification of ADHD according to the ADIKA being used as reference diagnosis. A ROC curve is a graph of the pairs true-positives (sensitivity) and falsepositives (I-specificity) corresponding to each possible cut-off point of the diagnostic test result. Depending on the chosen cut-off-point of the test, the sensitivity and specificity of the test change. The area under the curve is calculated for the different subscales of the PAQ and represent the discriminative ability and comparison of the area under the curve made it possible to compare the discriminative ability of the different subscales of the PAQ (Hanley \& McNeil, 1983).

Because ADHD information was only present for the selected children in the second stage $(\mathrm{N}=403)$, the cut-off points and corresponding sensitivity and specificity values of this selected group is not applicable to the entire responder group $(\mathrm{N}=1317)$. Because of this it was necessary to weight the ROC analyses. When calculating the weights CBCL-group, age, gender and type of school were included because the control group in our study was matched on these variables. These weights are consistent with the inverse of the probability that the observation is included in the sample due to the sample design (see procedure).

\section{RESULTS}

\section{Descriptive statistics}

For all items of the PAQ, the number of "missing answers per item" turned out to be $0.8 \%$ or less, which is equivalent to the answers for 10 children. A short description of the different items and their percentage scores are given in Table 5.I. The frequency of positive answers varied. For example, the item "is excluded by others" was answered positively the 
least often (II.4\%), whereas the item "gives up quickly if something fails" was answered positively the most often (52.8\%).

\section{Table 5.I Short item description with frequency distribution of scores and weighting of the four component ( $F I$ to $F 4$ ) solution after varimax rotation. (Only weightings higher than 0.30 are given; $n=1247$ )}

\begin{tabular}{|c|c|c|c|c|c|c|c|}
\hline \multirow[t]{2}{*}{ Short description of item } & \multicolumn{3}{|c|}{ Score in \% } & \multicolumn{4}{|c|}{ Weighting of the component } \\
\hline & 0 & I & 2 & $\mathrm{FI}$ & $\mathrm{F} 2$ & $\mathrm{~F} 3$ & $\mathrm{~F} 4$ \\
\hline PAQ 0I: Leaves parents in shops & 64.2 & 30.8 & 4.9 & & $0.52 *$ & & \\
\hline PAQ 02: Immature speech & 82.1 & 12.9 & 4.5 & & & & 0.40 \\
\hline PAQ 03: Correction is ineffective & 60.9 & 32.4 & 5.7 & 0.34 & 0.37 & 0.34 & \\
\hline PAQ 04: Makes a mess at table & 67.7 & 27.6 & 4.6 & & 0.44 & & \\
\hline PAQ 05: Has difficulty playing alone & 78.0 & 18.1 & 3.7 & & & 0.31 & 0.39 \\
\hline PAQ 06: Has difficulty falling asleep & 83.3 & 12.2 & 4.3 & & & & \\
\hline PAQ 07: Easily aggressive towards other children & 84.1 & 13.9 & 2.1 & $0.65^{*}$ & & & \\
\hline PAQ 08: Gives up easily & 46.9 & 43.8 & 9.0 & & & & $0.66^{*}$ \\
\hline PAQ 09: Causes problems on outings & 83.7 & 14.3 & 1.8 & 0.48 & & & \\
\hline PAQ 10: Does not seem to listen to parents & 53.5 & 39.9 & 6.5 & 0.48 & 0.38 & & \\
\hline PAQ II: Changes games rapidly & 76.6 & 19.7 & 3.6 & & & & $0.62^{*}$ \\
\hline PAQ I2: Has difficulty in changing activities & 87.2 & 11.9 & 0.8 & & & & 0.34 \\
\hline PAQ 13: Interferes others & 79.3 & 18.5 & 2.0 & $0.69 *$ & & & \\
\hline PAQ 14: Rarely finishes something & 65.8 & 30.4 & 3.7 & 0.33 & & & $0.68^{*}$ \\
\hline PAQ 15: Fidgets & 86.4 & 10.3 & 3.2 & & & $0.66^{*}$ & \\
\hline PAQ 16: Does not recognize danger on the street & 54.9 & 40.4 & 4.7 & & $0.66 *$ & & \\
\hline PAQ 17: Learns little from comments & 64.8 & 28.0 & 6.7 & 0.42 & 0.43 & & \\
\hline PAQ 18: Is isolated by others & 88.2 & 10.5 & 0.9 & 0.38 & & & 0.32 \\
\hline PAQ 19: Destroys thing if something fails & 78.1 & 18.8 & 2.8 & 0.45 & & & \\
\hline PAQ 20: Takes risks without thinking & 76.1 & 21.3 & 2.2 & & $0.63^{*}$ & & \\
\hline PAQ 21: Disrupts other children in their play & 73.8 & 24.4 & 1.3 & 0.60 & & & \\
\hline PAQ 22: Leaves things at school & 73.3 & 24.9 & 1.6 & & 0.38 & & 0.32 \\
\hline PAQ 23: Talks rapidly, stumbling over words & 62.7 & 31.2 & 5.8 & & 0.33 & & 0.41 \\
\hline PAQ 24: Fidgets at the doctor & 75.4 & 20.3 & 3.9 & & 0.31 & $0.50^{*}$ & \\
\hline PAQ 25: Often has minor accidents & 67.4 & 26.8 & 5.6 & & $0.53^{*}$ & & \\
\hline PAQ 26: Playing together often ends in conflict & 62.6 & 34.2 & 3.0 & $0.60^{*}$ & & & \\
\hline PAQ 27: Hardly listens to stories & 84.0 & 13.7 & 2.3 & & 0.35 & 0,35 & $0.42^{*}$ \\
\hline PAQ 28: Snatches toys away from others & 80.6 & 17.8 & 1.4 & $0.61^{*}$ & & & \\
\hline PAQ 29: Runs about excessively & 80.1 & 15.9 & 3.9 & & & $0.7 I^{*}$ & \\
\hline PAQ 30: Allows only very short cuddles & 83.7 & 12.5 & 3.4 & & & 0.42 & \\
\hline PAQ 31: Is restless & 73.9 & 19.7 & 5.8 & & & $0.74^{*}$ & \\
\hline
\end{tabular}

Score $0=$ not applicable; $\mathrm{I}=$ slightly/sometimes applicable; $2=$ definitely/often applicable. $\mathrm{FI}=$ socially inadequate behaviour; F2 = impulsivity; F3 = hyperactivity; F4 = inattention; * = selected items. 


\section{Principal components analysis}

After list-wise deletion $(n=1247)$, the principal components analysis identified seven components with an eigenvalue higher than 1.00. Because this rather large number of components reduces the interpretability of the questionnaire, three, four, and five component solutions were investigated after varimax rotation. The percentage explained variance for the different solutions was 37.4, 40.7, and 44.6, respectively. The fourcomponent solution was chosen (see Table 5.I). This choice was also supported by the scree plot, which showed a bend in the curve at four components. PRINCALS also indicated that the questions could be grouped in four clusters, which confirmed the solution of the principal components analysis.

Item 6 (difficulty falling asleep) had a weighting of less than 0.3 on all components and was thus left out of further analyses. In determining the final composition of the questionnaire, for each component we chose the four items with the highest weightings; other items were discarded. The first component "socially inadequate behaviour (FI)" (eigenvalue 8.3; explained variance $26.8 \%$ ) comprised items $7,13,26$, and 28 . These items refer to interfering behaviour, aggressiveness, and not being able to play with other children. The second component "impulsivity (F2)" (eigenvalue 1.59; explained variation 5.1\%) comprised items I, 16, 20, and 25. These items refer to reckless behaviour, being accident-prone, and leaving parents in shops. The third component "hyperactivity (F3)" (eigenvalue 1.39; explained variance $4.5 \%$ ) comprised items $15,24,29$, and 31 . These items refer to restlessness, fidgeting, and not being able to sit still. The last component "inattention (F4)" (eigenvalue I.34; explained variance 4.3\%) comprised items $8,1 \mathrm{I}, 14$, and 27 . The items refer to the child giving up easily in the face of difficulties, not finishing things, or switching from one game to another when playing. The sum of these 16 items gives the total score for the PAQ, which is 32 points. 


\section{Internal consistency}

Table 5.2 gives an overview of the percentile distribution per subscale, the total score, and Cronbach's alpha (a measure of internal consistency) for each subscale. Problems related to impulsivity and attention were reported more often than problems related to social behaviour or hyperactivity. The internal consistency of the entire scale was 0.86 and can be considered good. The internal consistency of the various subscales ranged from 0.63 to 0.74 and can be considered more than adequate.

Table 5.2 Number of items $(\mathrm{n}), 25^{\text {th }}, 50^{\text {th }}$ and $75^{\text {th }}$ percentiles; Cronbach's alpha (alpha) for the four subscales and the total score of the Precursors of ADHD Questionnaire.

\begin{tabular}{llllll}
\hline Components & $\mathbf{n}$ & $\mathbf{2 5}$ th $\%$ & $\mathbf{5 0 t h} \%$ & $\mathbf{7 5}$ th $\%$ & alpha \\
\hline & & & & & \\
Socially inadequate behaviour & 4 & 0 & 0 & 2 & 0.74 \\
Impulsivity & 4 & 0 & 1 & 2 & 0.63 \\
Hyperactivity & 4 & 0 & 0 & 1 & 0.78 \\
Inattention & 4 & 0 & 1 & 2 & 0.74 \\
Total & 16 & 1 & 4 & 7 & 0.86 \\
\hline
\end{tabular}

\section{Validity: ROC curve}

The degree of sensitivity and specificity of a questionnaire can be altered by using different cut-off values; however, an increase in sensitivity is always gained at the expense of the specificity, and vice versa (Bouter \& van Dongen, 1995). The ROC curve plots the sensitivity of the questionnaire against [I-specificity] for various test scores and gives the sensitivity and specificity of different cut-off values (see table 5.3) (Deyo, Diehr, \& Patrick, I99I).

Figure 5.I ROC curves for the subscales of the Precursors of ADHD Questionnaire versus ADHD according to the ADIKA classification

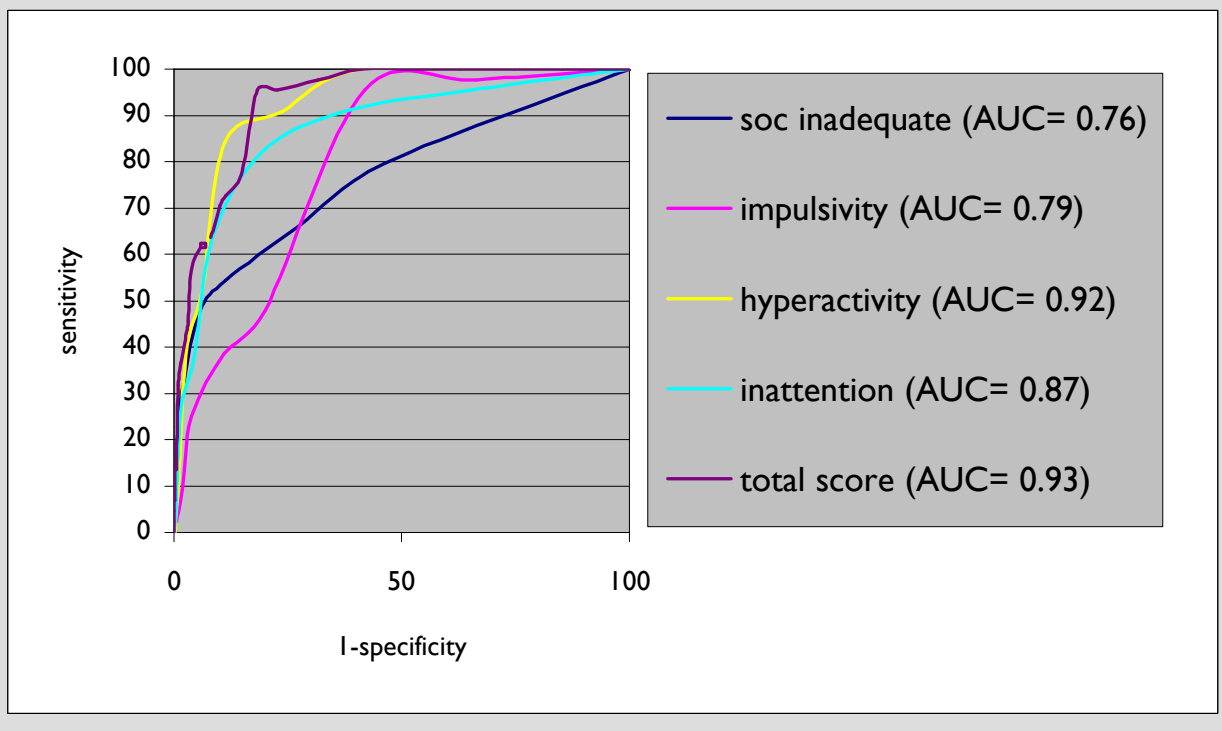


The discriminative power of a test increases as the ROC curve approaches the upper left corner (Bouter \& van Dongen, 1995). In other words, the greater the area under the curve, the greater the discriminative power of the test. To gain an impression of the discriminative power of the various subscales of the PAQ, the ROC curves and associated areas under the curves are given in Figure 5.I. The total PAQ had the greatest discriminative power, followed by the subscale "hyperactivity".

\section{Table 5.3 Sensitivity and specificity for the different cutoff points of the four subscales (FI to F4) and the total scale of the Precursors of ADHD Questionnaire.}

\begin{tabular}{|c|c|c|}
\hline Component & Sensitivity & Specificity \\
\hline \multicolumn{3}{|l|}{$\mathrm{FI}$} \\
\hline$>=0$ & $100(0.92-1.00)$ & $(0.00-0.00)$ \\
\hline$>=1$ & $79.6(0.65-0.90)$ & $53.6(0.51-0.56)$ \\
\hline$>=2$ & $65.9(0.52-0.81)$ & $72.8(0.70-0.75)$ \\
\hline$>=3$ & $54.6(0.39-0.70)$ & $88.6(0.87-0.90)$ \\
\hline$>=4$ & $47.7(0.32-0.63)$ & $94.4(0.93-0.96)$ \\
\hline \multicolumn{3}{|l|}{$\mathrm{F} 2$} \\
\hline$>=0$ & $100(0.92-1.00)$ & $0 \quad(0.00-0.00)$ \\
\hline$>=1$ & 97.7 (0.88-1.00) & $33.5(0.30-0.36)$ \\
\hline$>=2$ & $95.4(0.85-0.99)$ & $58.0(0.55-0.61)$ \\
\hline$>=3$ & $47.7(0.32-0.63)$ & $80.1(0.78-0.82)$ \\
\hline$>=4$ & $38.6(0.24-0.55)$ & 89.1 (0.87-0.91) \\
\hline \multicolumn{3}{|l|}{ F3 } \\
\hline$>=0$ & $100(0.92-1.00)$ & $(0.00-0.00)$ \\
\hline$>=1$ & $100(0.92-1.00)$ & $58.8(0.56-0.62)$ \\
\hline$>=2$ & $90.9(0.78-0.97)$ & $76.1(0.74-0.78)$ \\
\hline$>=3$ & $84.1(0.70-0.93)$ & $88.8(0.87-0.90)$ \\
\hline$>=4$ & $52.3(0.37-0.68)$ & $93.7(0.92-0.95)$ \\
\hline \multicolumn{3}{|l|}{$\mathrm{F} 4$} \\
\hline$>=0$ & $100(0.92-1.00)$ & $(0.00-0.00)$ \\
\hline$>=1$ & $95.4(0.85-0.99)$ & $34.4(0.32-0.37)$ \\
\hline$>=2$ & $90.9(0.78-0.97)$ & $62.8(0.60-0.65)$ \\
\hline$>=3$ & $81.8(0.67-0.92)$ & $81.0(0.79-0.83)$ \\
\hline$>=4$ & $63.6(0.48-0.78)$ & $91.5(0.90-0.93)$ \\
\hline \multicolumn{3}{|l|}{ Tot } \\
\hline$>=5$ & 100 & $58.7(0.56-0.6 I)$ \\
\hline$>=6$ & 97.7 (0.88-1.00) & $68.3(0.66-0.7 I)$ \\
\hline$>=7$ & $95.5(0.85-0.99)$ & $77.2(0.75-0.79)$ \\
\hline$>=8$ & $95.5(0.85-0.99)$ & $81.7(0.79-0.84)$ \\
\hline$>=9$ & $77.3(0.62-0.89)$ & $85.2(0.83-0.87)$ \\
\hline
\end{tabular}


The discriminative power of the PAQ subscales for the prediction of ADHD classification was then compared by comparing the area of the different curves. This showed that the predictive validity of the total PAQ was greater than that of its individual subscales. This difference was statistically significant for the subscales "socially inadequate behaviour", "impulsivity", and "inattention" ( $p<0.5)$ but was not for the subscale "hyperactivity".

\section{DISCUSSION}

Several studies have shown that while hyperactivity at pre-school age can be predictive of later problems (McGee et al., 199I; Pierce et al. 1999), many children get over their problems as they grow up (Campbell, 1987; Marakovitz \& Campbell, 1998; Palfrey et al., 1985). A better insight into which of these children have a high risk of developing ADHD will lead to earlier interventions, which in turn may influence the natural course of the symptoms (Rappaport, Ornoy \& Tenenbaum, 1998). The Precursors of ADHD Questionnaire (PAQ) was developed in order to gain more insight into the behavioural profile of kindergarten children at risk for ADHD.

Principal component analysis indicated that a four-component solution was the best. The most important criterion when making this choice was the interpretability of the questionnaire. Given the aim of the questionnaire, it was important to be able to distinguish between the four behavioural components "socially inadequate behaviour", "impulsivity", "hyperactivity", and "inattention". Even though the DSM-IV combines the subscales "hyperactivity" and "impulsivity", we chose to consider them as distinct subscales. This decision is supported by earlier research into the structure of ADHD (Gomes et al., 1999; Scholte \& Ploeg van der, 1999). Principal component analysis showed that the component "socially inadequate behaviour" had the highest explained variance, which indicates that these items cover an important part of the original questionnaire.

The internal consistency of the PAQ was good, which indicates that the homogeneity of the questionnaire is acceptable. To date, there is no information available about the stability of the test (test-retest data), which is a limitation of this study and needs to be investigated in the future. The validity of the instrument was very high for each of the sub-scales as well for the total scale. It is recommended that the questionnaire has to be used in its entirety to predict which children are at risk. For interpretation of the test, however, the individual subscales are important and they give an indication of the domain in which the child has problems. In future research it is important to investigate the further development of the children that participated in this study, because this will provide information about the longterm predictive validity of the PAQ.

When choosing an appropriate cut-off value for the PAQ, it is important not to forget the purpose of the questionnaire, namely, to facilitate the identification of kindergarten children at increased risk of developing ADHD. Because the questionnaire is intended as a screening instrument, it should have a high sensitivity. In this young age group, it is important to detect as many children at risk of developing ADHD as possible. 
Results showed that the PAQ is a reliable and valid instrument for the early detection of 5 to 6 years old children at increased risk of developing ADHD. However, it is important to appreciate that the questionnaire assesses only precursor symptoms of $\mathrm{AHDH}$. Comorbid signs, if present, cannot be ascertained with the PAQ. It is also possible that the symptoms detected with the PAQ have a cause other than ADHD. For this reason, results should be interpreted with care. A final point is that the validity of the questionnaire was determined on the basis of the ADIKA diagnosis of ADHD. This does not guarantee the final diagnosis of ADHD, which should be made on the basis of multidisciplinary investigations and information from multiple informants.

Despite these shortcomings, the PAQ can have an important function in screening kindergarten children for precursors of ADHD. The instrument could be used during the periodic medical examination of young children by school doctors, to make an inventory of problem behaviour. School doctors can then change their further investigations depending on the results. When determining the policy for individual children, however, it is important to interpret the results of the PAQ in the context of the results found during the examination of the child and the interview with the parents and school teachers. Besides monitoring and supervising children with "worrying" results, school doctors could also consider re-administering the questionnaire after several months, thus enabling the problems to be monitored with time.

The advantage of the questionnaire over an observational instrument is that a large number of children can be screened. In addition, the PAQ makes it possible to evaluate a child's behaviour in its own environment over longer periods of time. The development of the PAQ has enabled investigators to gain a better insight into the predictive validity of different behaviours shown at kindergarten age for the risk of developing ADHD. The use of this questionnaire will facilitate the early detection of kindergarten children at risk of ADHD.

\section{Acknowledgements}

We are grateful to Prof. Dr. R.B. Minderaa, Prof. Dr. B.W. Gunning, Dr. M.J. Langenaken, and Prof. Dr. T. Compernolle for generating the questions. We thank Dr. G. ter Riet and N. Rozendaal for their assistance with the statistical analyses. 


\section{REFERENCES}

Achenbach TM, \& Edelbrock C (1983), Manual for the child Behavior Checklist and Revised Child Behavior Profile. Burlington: University of Vermont Department of Psychiatry.

American Psychiatric Association (1987), Diagnostic and Statistical Manual of Mental Disorders (3rd ed): Washington D.C: American Psychiatric Association.

American Psychiatric Association (1994), Diagnostic and Statistical Manual of Mental Disorders (4th ed): Washington D.C: American Psychiatric Association.

Applegate B, Lahey BB, Hart EL, Biederman J, Hynd GW, Barkley RA, Ollendick T, Frick PJ, Greenhill L, McBurnett K, Newcorn JH, Kerdyk L, Garfinkel B, Waldman I, \& Shaffer D (1997), Validity of age-ofonset criterion for ADHD: A report from the DSM-IV field trials. Journal of American Academy of Child and Adolescent Psychiatry 36: 1211-1221.

Bouter LM \& van Dongen MCJM (1995), Epidemiologisch onderzoek, opzet en interpretatie (3 ${ }^{\text {de }}$ druk): Houten/ Diegem: Bohn Stafleu Van Loghum.

Campbell SB (1987), Parent-referred problem three-year-olds: developmental changes in symptoms. Journal of Child Psychology and Psychiatry and Allied Disciplines 28: 835-845.

Cantwell DP (1996), Attention Deficit Disorder: A review of the past 10 years. Journal of American Academy of Child and Adolescent Psychiatry 35: 978-87.

Conners CK (1973), Rating scales for use in drug studies with children. Psychopharmacology Bulletin: Special Issue, Pharmacotherapie in children, 24-84.

Cronbach, LJ (195I), Coefficient alpha and internal structure of tests. Psychometrika 16: 297-334.

Deyo RA, Diehr P, \& Patrick DL (199I), Reproducibility and responsiveness of health status measures. Statistics and strategies for evaluation. Controlled Clinical Trials I2: I42S-I58S.

Directoraat-Generaal voor de Arbeidsvoorziening (1989), Handleiding voor de functieanalyse. Den Haag: SDU uitgeverij.

Faroane SV, Biederman J (1998), Neurobiology of Attention-Deficit Hyperactivity Disorder. Biological Psychiatry 44: $951-958$.

Gomes R, Harvey J, Quick C, Scharer I, \& Harris G (1999), DSM-4 AD/HD: Confimatory factor models, prevalence and gender and age differences based on parent and teacher ratings of australian primary school children. Journal of Child Psychology and Psychiatry and allied disciplines 40: 265-274.

Hanley JA \& McNeil BJ (1983), A method of comparing the areas under Receiver Operating Characteristic Curve derived from the same case. Radiology 148: 839-843.

Hendriksen JGM \& Steyaert J (1999), Ontwikkeling van de Vragenlijst Voorlopers ADHD. Interne publicatie: Maastricht: Academisch Ziekenhuis Maastricht.

Herjanic B \& Campbell W (1977), Differentiating psychiatric disturbed children on the basis of a structured interview. Journal of Abnormal Child Psychology 5: 127-134.

Heus de P, Leeden van der R \& Gazendam B (1995), Toegepaste data-analyse, Technieken voor niet-experipenteel onderzoek in de sociale wetenschappen. Utrecht: Uitgeverij Lemma BV.

Kortenbout van der Sluijs MJ, de Levita DJ, Manen de R \& Defares BP (I993), ADIKA, Amsterdams diagnostisch interview voor kinderen en adolescenten. Lisse: Swets \& Zeitlinger. 
Lambert NM \& Hartsough CS (1984), Contribution of predispositional factors to the diagnosis of hyperactivity. American Journal of Orthopsychiatry 54: 97-109.

Marakovitz SE \& Campbell SB (1998), Inattention, impulsivity, and hyperactivity from preschool to school age: performance of hard-to-manage boys on laboratory measures. Journal of Child Psychology and Psychiatry and allied disciplines 39: 84I-85I.

McGee R, Partridge F, Williams S \& Silva PA (199I), A twelve-year follow-up of preschool hyperactive children. Journal of American Academy of Child and Adolescent Psychiatry 30: 224-32.

Palfrey JS, Levine MD, Walker DK \& Sullivan M (1985), The emergence of attention deficits in early childhood: a prospective study. Developmental and Behavioral Pediatrics 6: 339-348.

Pierce EW, Ewing LJ \& Campbell SB (1999), Diagnostic status and symptomatic behavior of hard-to-manage preschool children in middle childhood and early adolescence. Journal of Clinical Child Psychology 28: 4457.

Rappaport GC, Ornoy A \& Tenenbaum A (1998), Is early intervention effective in preventing ADHD? The Israel Journal of Psychiatry and Related Sciences 35: 27I-279.

Reich W (2000), Diagnostic Interview for Children and Adolescents (DICA). Journal of the American Academy of Child and Adolescent Psychiatry 39: 59-66.

Scholte EM \& Ploeg van der JD (1999), De ontwikkeling en toetsing van de ADHD-vragenlijst. Kind en Adolescent 20: 76-92.

Sonuga Barke E, Stevenson J \& Thompson MJJ (1996), Mental health of preschool children and their mothers in a mixed urban/ rural population. II. Family and maternal factors and child behaviour. Britisch Journal of Psychiatry 168: 21-25.

Still GF (1902), Some abnormal psychical conditions in children. The Lancet I: 1008-1012, 1077-1082, II63II68.

Vandermeulen JAM (1997), Testbespreking: Amsterdams Diagnostisch Interview voor Kinderen (ADIKA), Nederlands Tijdschrift voor de Psychologie 52: I35-I 38.

Verhulst FC, Ende van der J \& Koot HM (1996a), Handleiding voor de CBCL 4- 18. Rotterdam: Afdeling Kinder en jeugdpsychiatrie, Sophia Kinderziekenhuis/Academisch Ziekenhuis Rotterdam/ Erasmus Universiteit Rotterdam.

Verhulst FC (1996b) Personal, communication.

Westererich S (1998), Amsterdams Diagnostisch Interview voor Kinderen en Adolescenten, ADHD-deel o.b.v. DSM-IV. Interne Publicatie : Brussel : Vrije Universiteit 


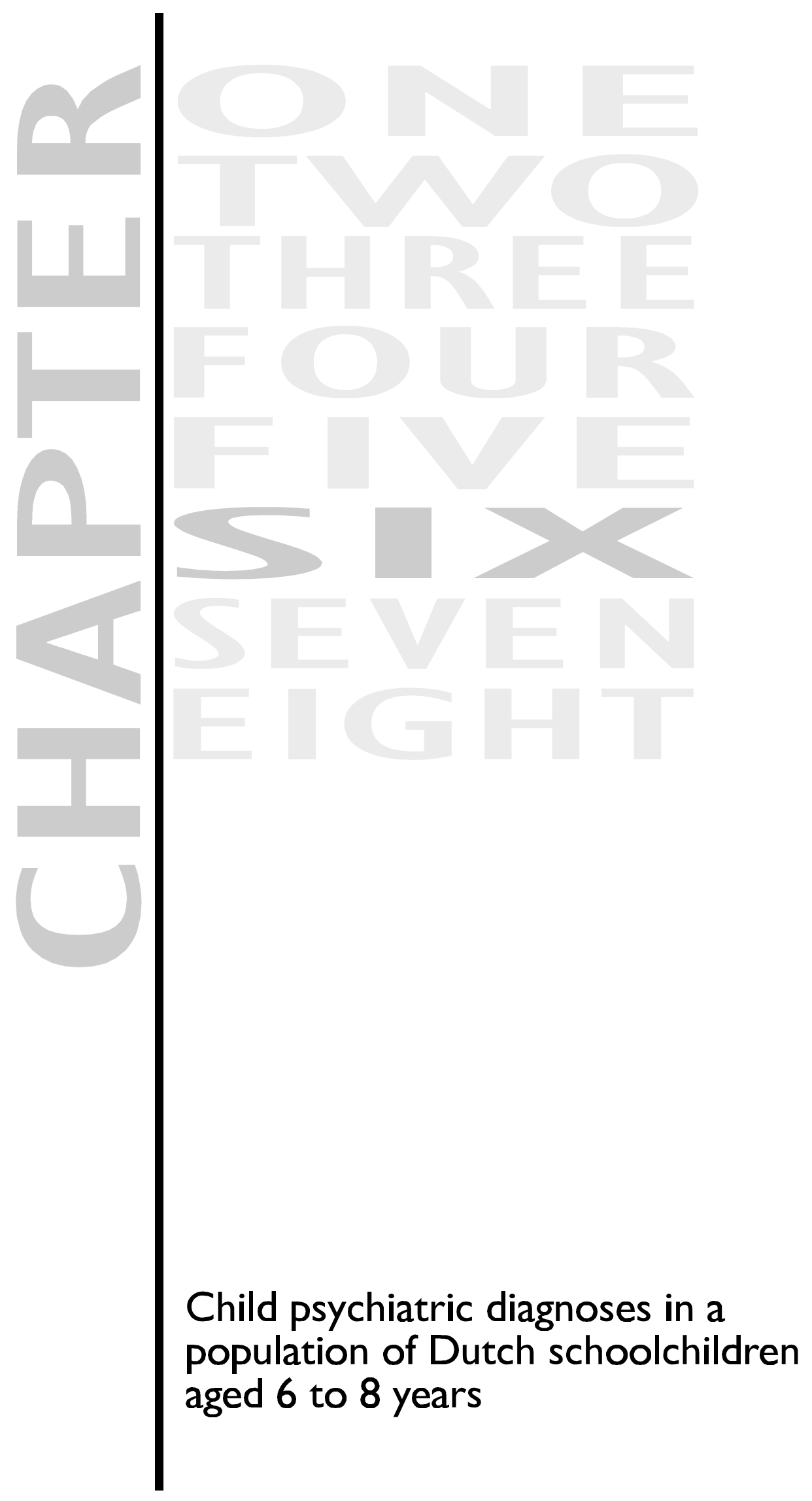





\section{ABSTRACT}

Objective: To determine the prevalence rates of child psychiatric diagnoses in a school-based population of children aged 6 to 8 years in the south of the province of Limburg (The Netherlands).

Method: In a two-stage design 1317 children were screened with the Child Behavior Checklist. From 403 of these children, child psychiatric information was obtained with the Amsterdam Diagnostic Interview for Children and Adolescents (ADIKA, DSM-IIIR/ IV). Data were generalized to the responder group $(N=|3| 7)$ and to the entire cohort $(N=2290)$. For the latter procedure, a prediction model was used to generalize ADIKA results to the nonresponders ( $\mathrm{N}=973)$.

Results: Estimates of the prevalence of different ADIKA diagnoses in the responder group were quite comparable with those for the entire cohort. Twenty-four percent of the entire cohort met criteria for a single disorder and $21.0 \%$ met criteria for two or more disorders. However, in only $5.7 \%$ of the cases parents did report a need for help.

Conclusions: Where other studies generalize psychiatric diagnoses to the responder group only, this report adds new information by generalizing the prevalence to a school-based cohort of children aged 6 to 8 years. These prevalence estimates are of importance with regard to the demand for care for child psychopathology.

\section{INTRODUCTION}

Since 1985 several epidemiological population studies have described the prevalence and comorbidity of psychopathology in school-age children and adolescents (Anderson et al., 1987; Bird et al., 1993; Costello, et al., 1996; Feehan et al., 1994; Fergusson et al., 1993; Verhulst et al., 1985). In these studies the prevalence of DSM-based disorders varied from 17.6\% (Anderson et al., 1987) to 44.7\% (Feehan at al., 1994), with lower rates when impairment was considered. Comorbidity is reported in 40 to $50 \%$ of the cases (Anderson et al., 1987; Bird et al., 1993).

Remarkably, little is known about the prevalence of DSM-based disorders in children younger than 9 (Angold et al., 1999; Lavigne et al., 1996). Of the studies performed, most have concentrated on behaviour problems in general, without focussing on child psychiatric diagnoses. This is mainly because there are few methods developed to evaluate younger children (Costello, et al., 1996) and because the information provided by children is considered unreliable (Edelbrock et al., 1985).

Two important exceptions are The Ontario Child Health Study (Offord et al., 1987) and the study of Lavigne and his colleagues (1996). Offord et al. (1987) used self-completed problem checklists and summed items to form scores that approximate child and adolescent psychiatrists' diagnoses. In the $4-1 \mathrm{I}$ age group, the prevalence of conduct disorder was $6.5 \%$ for boys and $1.8 \%$ for girls. That of hyperactivity was $10.1 \%$ for boys and $3.3 \%$ for girls, and that of emotional disorders was $10.2 \%$ for boys and $10.7 \%$ for girls. However, these data are 
not consistent with DSM-based estimates as used in older children. Lavigne and his colleagues (1996; 1998) monitored a pediatric sample (2-9 years of age) with the aim of identifying risk factors for the development of psychopathology. In the absence of a structured interview for preschool children, diagnoses were based on "best estimates" and varied from less than $1 \%$ for each emotional disorder to $2 \%$ for AttentionDeficit/Hyperactivity Disorder (ADHD) and $16.8 \%$ for oppositional defiant disorder. A limitation of this study was that the children belonged to a pediatric primary care sample, so that results could not be generalized to a community sample.

Another limitation of published studies is that prevalence estimates were generalized to the responder groups only. In most studies (Anderson et al., 1987; Costello et al., 1996; Lavigne, et al., 1998), sex, age, race, social class, and marital status were compared among responder and nonresponder groups to determine the similarity of the groups. Potentially important risk factors, such as parental occupation, however, were not compared and psychopathology in the nonresponder group was usually not estimated.

Many variables seem to be associated with early pathways to problem behaviour (Campbell, 1995). These can be divided into child, family, and environmental risk factors. Concerning the child-related factors, Stevenson and colleagues (1996) showed that it is important to investigate child characteristics. Furthermore, low parental occupation (Campbell, 1995; Kalff et al., 200I), smaller family sizes (Lavigne et al. 1996), single-parent families (Lavigne et al., 1998), low maternal age at delivery (Orlebeke et al., 1998), and cigarette abuse during pregnancy (Weissman et al., 1999) all seem important family-related risk factors. As regards the environment, Offord at al. (1987) reported more problem behaviour in urban versus nonurban areas. In this paper a prediction model used these risk factors to estimate the prevalence of psychopathology and comorbidity in a population of Dutch children (including both responders and nonresponders) aged 6 to 8 years.

\section{METHOD}

This report is part of the "Study of Attention disorders in Maastricht (SAM)" which involves a prospective population study of the precursors of ADHD (Kalff et al., 200I), and was in accordance with the guidelines of the local ethics committee. To maximize our study goals within a reasonable budget, we used a two-stage design as described by Shrout et al. (1986).

\section{Subjects and procedure}

\section{Stage I: Months I-9}

In the first stage of the study, all parents of children in the second grade of normal kindergarten schools in the south of the province of Limburg (The Netherlands) were approached by Youth Health Care (YHC) to participate in the study. This national organization is responsible for performing a periodic systemic health examination for all 
children in the region. The response rate is $98 \%$. School doctors perform this examination and they are allowed, by law, to use the medical information gained anonymously for epidemiological research purposes. The parents of 1317 (57.5\%) of 2290 eligible children agreed to participate in the study and completed the Child Behavior Checklist $(\mathrm{CBCL})$ (Verhulst et al., 1996). Three groups were formed on the basis of the CBCL results. The first group (E, 'externalizing problems') consisted of all children with $C B C L$ Externalizing scale scores above the 90th percentile and/or with $\mathrm{CBCL}$ Attention Problem scores exceeding the 95th percentile $(\mathrm{N}=\mathrm{I73})$. The second group (I, 'internalizing problems') consisted of children with Internalizing-scale scores above the 90th percentile and who were not members of the first group ( $N=59)$. The third group $(N)$ consisted of 1080 'normal' children whose $\mathrm{CBCL}$ total scores were below the 90th percentile and who were not members of group E or I. Only five children could not be categorized because they did not belong to one of the problem groups (groups $E$ and I) and their total scores were above the 90 th percentile. Because of its small size, this latter group was not included in the data analysis.

\section{Stage 2: Months I5-25}

The children of groups E and I were recruited for follow-up. Each of the children in these two groups was matched with one child from the normal group on the basis of sex, age, and school. The parents of these children were invited to attend a structured child psychiatric interview about their child, the Amsterdam Diagnostic Interview for Children and Adolescents (ADIKA) (Kortenbout van der Sluijs et al., 1993), and filled in a questionnaire assessing their need for help. The parents of 403 children (89\%) took part (233 boys, 170 girls): I 50 children from group E, 54 from group I, and 199 from group $N$. At the time of the interview, the children's ages ranged from 6.4 to 8.6 years (mean=7.I, SD=0.4). In $89.6 \%$ of the cases the mother of the child was interviewed, in $6.4 \%$ of the cases the father, and in $4.0 \%$ of the cases another caretaker.

\section{Measures}

\section{Stage I:}

The CBCL was developed by Achenbach in 1983 and translated and revised by Verhulst et al. (1996) for the Dutch population. It is used as a screening instrument and previous studies have demonstrated its usefulness in detecting children with and without behavioural problems according to their parents (Steingard et al., 1992). Two broad-band scales can be composed (Externalizing and Internalizing problems) and a Total problem score. The CBCL also yields several subscales, one of which (Attention subscale) was used in the present study. 
Demographic information

The first set of variables, collected from the medical records of all responders $(N=|3| 7)$ as well as from a random sample of 200 nonresponders, consisted of child characteristics, family variables, and environmental variables. Child characteristics were (I) age; and (2) sex. Family variables were (I) parental occupation, which was scored on a 7-point-scale, ranging from low skilled to scientific labor (DGA, 1989) (For the present study, this scale was reduced to three levels: low [I, 2 and 3], middle [4 and 5] and high [6 and 7]. Housewives and househusbands were coded separately and entered in the low-level occupation category.); (2) country of birth of the parents; (3) number of children; (4) position of the child in sibship; (5) family status; (6) maternal age at delivery and (7) paternal age at delivery. Environment variables were (I) living area (urban area of Maastricht versus surrounding villages) and (2) school the child attended.

In addition, a second set of variables, which were determined for randomly drawn groups of 200 responders and 200 nonresponders, concerned pregnancy-related problems (cigarette abuse during pregnancy and postpartum difficulties of the child), and psychosocial and physical findings reported by the school doctor. These variables were collected anonymously from the medical records at the Youth Health Care. Information about the distribution of both sets of variables is shown in Table 6.I. 
Table 6.I Child, family, and environmental characteristics of the responder sample $(N=1317)$ and a random subgroup of 200 responders and 200 nonresponders.

\begin{tabular}{|c|c|c|c|}
\hline Variable & I 3 I 7 Responders (\%) & $\begin{array}{l}200 \text { Responders } \\
(\%)\end{array}$ & $\begin{array}{l}200 \text { Non-responders } \\
\text { (\%) }\end{array}$ \\
\hline \multicolumn{4}{|l|}{ Sex } \\
\hline Male & 53.1 & 54.0 & 50.0 \\
\hline Female & 46.9 & 46.0 & 50.0 \\
\hline \multicolumn{4}{|l|}{ Attention deficit } \\
\hline Yes & n.a. & 22.0 & 17.0 \\
\hline No & n.a. & 77.5 & 82.5 \\
\hline Missing & n.a. & 0.5 & 0.5 \\
\hline \multicolumn{4}{|l|}{ Parental occupation } \\
\hline High & 33.9 & 35.5 & 26.5 \\
\hline Middle & 29.4 & 26.0 & 28.5 \\
\hline Low & 35.8 & 37.5 & 42.0 \\
\hline Missing & 0.9 & 1.0 & 3.0 \\
\hline \multicolumn{4}{|l|}{ Nationality } \\
\hline Dutch & 87.1 & 89.0 & 84.0 \\
\hline Foreign born & 10.7 & 11.0 & 16.0 \\
\hline Missing & 2.2 & 0 & 0 \\
\hline \multicolumn{4}{|l|}{ Family status } \\
\hline Living with two parent & 88.0 & 87.5 & 84.0 \\
\hline Living with one parents & 10.7 & 12.5 & 16.0 \\
\hline Missing & 1.3 & 0 & 0 \\
\hline \multicolumn{4}{|l|}{ Cigarettes during pregnancy } \\
\hline Yes & n.a. & 17.0 & 20.5 \\
\hline No & n.a. & 83.0 & 79.5 \\
\hline \multicolumn{4}{|l|}{ Living area } \\
\hline Urban & 58.8 & 60.5 & 60.5 \\
\hline Non urban & 41.2 & 39.5 & 39.5 \\
\hline \multicolumn{4}{|l|}{ School } \\
\hline Urban & 61.4 & 63.0 & 63.5 \\
\hline \multirow[t]{2}{*}{ Non urban } & 38.6 & 37.0 & 36.5 \\
\hline & Mean (SD) & Mean (SD) & Mean (SD) \\
\hline \multicolumn{4}{|l|}{ Age } \\
\hline Child (at screening) & $5.87 \quad(0.4 I)$ & $5.92 \quad(0.43)$ & n.a. \\
\hline Mother at delivery & $29.75(4.46)$ & $29.82(4.43)$ & $29.21(4.64)$ \\
\hline Father at delivery & $32.42(5.06)$ & $32.35(5.11)$ & $32.11(5.70)$ \\
\hline Number of children & $2.23(0.87)$ & $2.28(0.92)$ & $2.25(0.97)$ \\
\hline Sibship position & I.7I (0.86) & $1.76(0.89)$ & $1.73(0.86)$ \\
\hline Apgar score (after I minutes) & n.a. & $8.57(1.23)$ & $8.73(1.13)$ \\
\hline Birth weight (in kg) & n.a. & $3.31(0.54)$ & $3.21(0.60)$ \\
\hline
\end{tabular}




\section{Stage 2:}

The ADIKA (Kortenbout van der Sluijs et al., 1993) is the translation of the Diagnostic Interview for Children and Adolescents (DICA) (Herjanic and Campbell, 1977), which is based on the DSM-III-R criteria (American Psychiatric Association, 1987). The reliability and validity of the DICA are reported to be good (Reich, 2000).

DSM-IV criteria (American Psychiatric Association, 1994) were used for diagnosing ADHD (Westereich, 1998). In addition to children with ADHD, children in whom ADHD symptoms were present but in fewer than two situations were considered as 'Borderline ADHD'.

Three skilled interviewers administered the ADIKAs. They were trained and supervised intensively by a senior child and adolescent psychiatrist and were blind to the $\mathrm{CBCL}$ screening results. Diagnoses were generated from the coded ADIKAs by a computer algorithm ignoring hierarchical DSM criteria (Rozendaal, 1998).

The prevalence rate for the different ADIKA diagnoses were calculated separately, as were prevalence rates for combinations of diagnoses that define five major domains of childhood psychopathology. The clustering is based on common sense, namely; (I) 'Attention problems', which includes ADHD, inattentive, hyperactive and combined type, and 'Borderline ADHD'; (2) 'Mood Disorders' including major depression, dysthymia (at present and past, with and without an underlying live event), and bipolar disorders; (3) 'Anxiety disorders', namely, overanxious disorder, avoidant disorder, phobias, and post-traumatic stress disorder; (4) 'Conduct/ Oppositional defiant disorders', which encompasses conduct disorder and oppositional defiant disorder; and (5) 'Disorders of elimination', namely, functional enuresis and functional encopresis. Autism, psychosis, and somatization problems were excluded because they occur too infrequently in the general population to be identified reliable in this study.

As Bird et al. (1990) have suggested that estimates of the prevalence of disorders are more meaningful when they are related to severity criteria, part B of 'The assessment of Family Stress (Wels and Robbroeckx, 1996)' was completed by parents and related to the prevalence of the ADIKA diagnoses. This part of the questionnaire was developed to determine the need for help.

\section{Statistical Analyses}

The estimated prevalence of the different ADIKA diagnoses in the selected sample of the responder group (sample I, $N=403$ ) was extrapolated to the entire cohort $(N=2290)$ for two reasons (Figure 6.I). Sample I was selected on the basis of the outcome of the $\mathrm{CBCL}$ and matched for age, sex, and type of school (see "subjects and procedure"). Because of this selection, the prevalence of the ADIKA diagnoses within this selected group is not applicable to the entire responder group $(\mathrm{N}=1317)$. Moreover, the prevalence of the ADIKA diagnoses in the nonresponder group $(\mathrm{N}=973)$ is not necessarily the same as that in the responder group. To compensate for these biases, the ADIKA diagnoses were calculated in two steps. 
The procedure used is based on the assumption that the outcomes for the nonresponders are "missing at random", given the background characteristics used in the prediction model as suggested by Little and Rubin (1987) and Schafer and Schenker (2000).

\section{Figure 6.I Sampling design for the "Study of Attention disorders in Maastricht"}

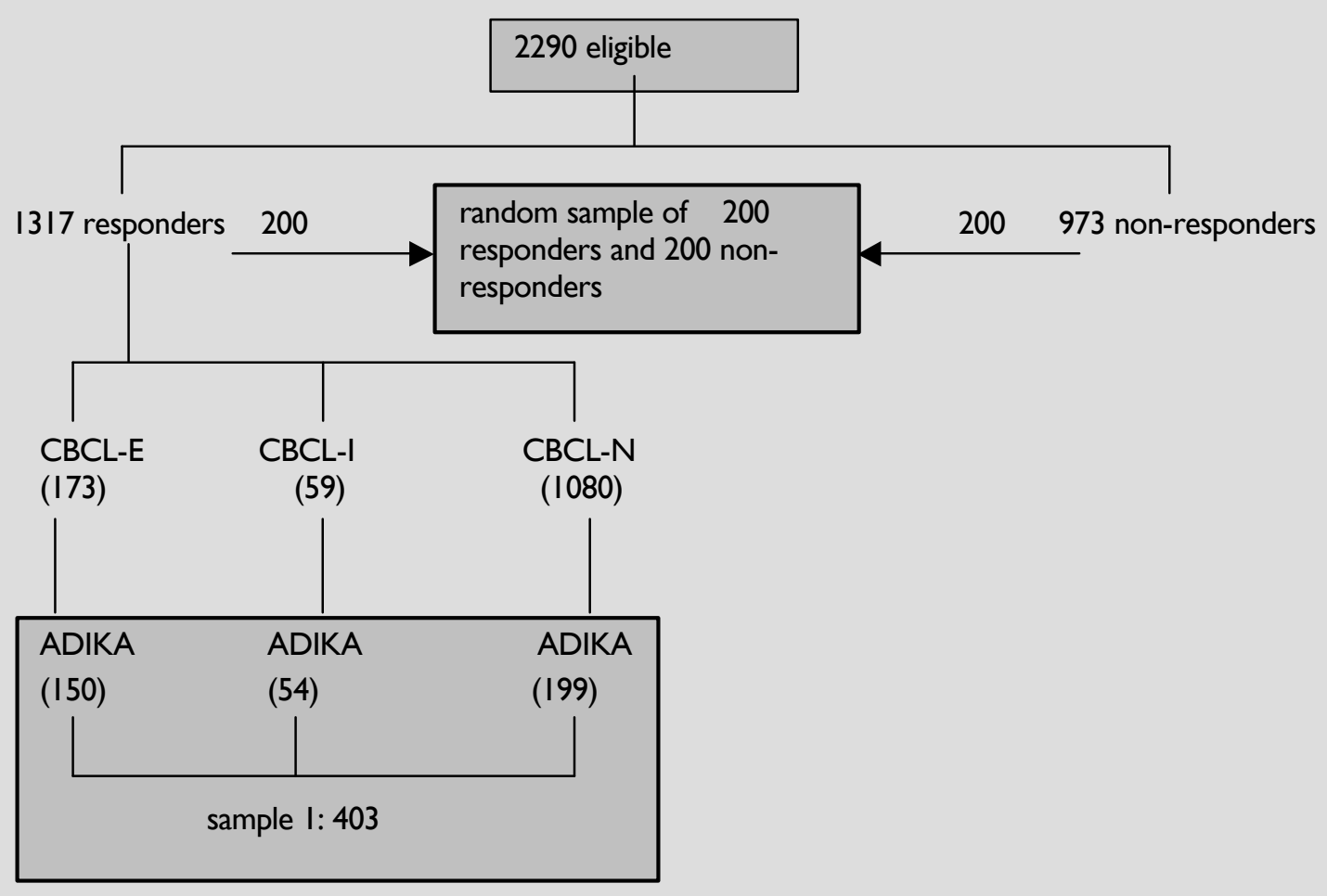

Step I: Estimated prevalence of ADIKA diagnoses in the responder group The probability of different ADIKA diagnoses, given a certain outcome on the CBCL was determined using a logistic regression model. Age, sex, and type of school were taken into account to adjust for the sampling design (see "subjects and procedure"). Because these probabilities were estimated for each child in the responder group, the average of these probabilities is an estimate of the prevalence of the different ADIKA diagnoses within the entire responder group.

Step 2a: Estimated prevalence of $C B C L$ group membership in the non-responder group $(\mathrm{N}=973)$

To estimate the prevalence of ADIKA diagnoses in the nonresponder group ( $N=973)$, the prevalence of $C B C L$ group membership (externalizing, internalizing, and normals) had to be determined. Stepwise logistic regression analyses of the data for the random sample of 200 responders (Figure 6.I) were used to generate two models. For this purpose all variables 
given in Table 6.I were used and Hosmer and Lemershow's goodness of fit was decisive in generating the best fit (Hosmer and Lemershow's, 1989). The first model was used to calculate the probabilities of membership in the problem group (including both the externalizing [E] and internalizing [I] group). Subsequently, the second model was used to calculate the probabilities of membership in group $E$ or group I. Combinations of both models made it possible to calculate the probabilities of membership of the three separate $\mathrm{CBCL}$ groups (externalizing, internalizing, normal), conditional on the set of variables found in the models stated above for the random sample of 200 nonresponders. The product of the mean of these probabilities and the number of children in the nonresponder group $(N=973)$ was used to calculate the $C B C L$ group membership in the entire nonresponder group.

Step 2b: Estimated prevalence of ADIKA diagnoses in the entire cohort $(N=2290)$

The estimated prevalence of different ADIKA diagnosis in the entire nonresponder group was calculated from the estimated $C B C L$ group membership for these children. Finally, the prevalence of the ADIKA diagnoses in the entire cohort was calculated by summing the prevalence in the responder group (step I) and in the nonresponder group (step 2b).

\section{Comorbidity}

We followed the same procedure to estimate the comorbidity rate, concentrating on 'Attention Problems' and 'ADHD' separately, in relation to the other four domains. Both expected and observed comorbidity rates were calculated. Expected comorbidity was calculated as the product of the prevalence of the two disorders in the sample, on the assumption that these types of disorders were statistically independent (Bird et al., 1993).

\section{RESULTS}

Step I: Estimated prevalence of ADIKA diagnoses in the responder group

Table 6.2 shows the estimated prevalence of ADIKA diagnoses in the responder group. Rates will be discussed under step $2 b$.

Step 2a: Estimated prevalence of $C B C L$ group membership in the non-responder group $(\mathrm{N}=973)$

To predict the prevalence of $\mathrm{CBCL}$ group membership in the nonresponder group, logistic regression identified three main predictors that distinguished between the 'problem' (externalizing and internalizing) group and the normal group of the $\mathrm{CBCL}$. These variables were low parental occupation (odds ratio $[\mathrm{OR}]=3.5,95 \%$ confidence interval $[\mathrm{Cl}]=\mathrm{I} .3-9.3$ ), followed by cigarette abuse by the mother during pregnancy $(\mathrm{OR}=4.0,95 \% \mathrm{Cl}=1.4-\mathrm{II} . \mathrm{I})$, and attention deficit according to the school doctor $(\mathrm{OR}=4.2,95 \% \mathrm{Cl}=1.7-10.2)$. Logistic regression identified the school (urban versus nonurban) which the child attended (OR = 
I.9, $95 \% \mathrm{Cl}=1.0 \mathrm{I}-3.58)$ and low parental occupation level $(\mathrm{OR}=2.5,95 \% \mathrm{Cl}=\mathrm{I} .2-5.3)$ as factors that distinguished between the externalizing and internalizing problem groups. On the basis of these variables, there were 142.15 children (76.96 boys, 65.19 girls) in the CBCL externalizing group, 36.25 (19.6I boys, 16.64 girls) in the internalizing group, and 794.55 (389.93 boys, 404.62 girls) in the normal group.

Step 2b: Estimated prevalence of ADIKA diagnoses in the entire cohort $(N=2290)$

In total, $45.2 \%$ of the children in the entire cohort initially met the requisite DSM-III-R (DSM-IV for ADHD) criteria for at least one disorder ('Borderline ADHD' was not considered because it is not a real diagnosis). Twenty-four percent had a single disorder and $21.0 \%$ had two or more. Most parents (93.3\%) did not believe they needed professional help. When considering the need for help, the percentage of $45.2 \%$ decreased to $5.7 \%$. More parents of children with two or more problems reported needing help than did parents of children with a single disorder ( $4.2 \%$ vs. $1.5 \%)$.

Table 6.2 Generalized prevalence rates (\%) derived from ADIKA.

\begin{tabular}{|c|c|c|c|c|c|}
\hline \multirow{2}{*}{$\begin{array}{l}\text { Disorder } \\
\text { Attention problems }\end{array}$} & \multirow[t]{2}{*}{$\begin{array}{l}\text { Entire } \\
\text { sample } \\
(\mathrm{N}=2290)\end{array}$} & \multicolumn{2}{|c|}{$\begin{array}{l}\text { Responder } \\
\text { group } \\
(\mathbf{N}=|3| 7)\end{array}$} & \multicolumn{2}{|c|}{$\begin{array}{l}\text { Responder group } \\
\text { Male/ Female }\end{array}$} \\
\hline & & & & & \\
\hline ADHD & 3.8 & 3.7 & $(1.9)$ & $4.8 / 2.4$ & $(2.6 / 1.0)$ \\
\hline 'Borderline-ADHD' & 15.2 & 14.9 & $(2.9)$ & | 7.7 / | | .8 & $(4.3 / 1.4)$ \\
\hline Any attention problem & 19.0 & 18.6 & $(4.9)$ & $23.1 / 13.5$ & $(7.0 / 2.6)$ \\
\hline \multicolumn{6}{|l|}{ Mood disorder } \\
\hline Major Depression & 4.6 & 4.6 & $(1.2)$ & $4.0 / 5.3$ & $(1.5 / 0.9)$ \\
\hline Dysthemia & 3.6 & 3.6 & $(0.3)$ & $2.6 / 4.7$ & $(0.5 / 0.0)$ \\
\hline Any mood disorder & 6.7 & 6.7 & $(1.3)$ & $5.3 / 8.2$ & $(1.7 / 0.9)$ \\
\hline \multicolumn{6}{|l|}{ Anxiety disorder } \\
\hline Overanxious disorder & 2.9 & 2.9 & $(0.7)$ & $3.6 / 2.1$ & $(0.8 / 0.5)$ \\
\hline Avoidant disorder & 1.7 & 1.7 & $(0.6)$ & $1.3 / 2.2$ & $(0.7 / 0.2)$ \\
\hline Phobia & 21.9 & 21.9 & $(3.0)$ & $20.9 / 22.9$ & $(3.9 / 2.2)$ \\
\hline Any anxiety disorder & 23.8 & 23.9 & (3.3) & $23.4 / 24.4$ & $(4.3 / 2.1)$ \\
\hline \multicolumn{6}{|l|}{ Conduct disorders } \\
\hline Oppositional disorder & 11.8 & 11.5 & $(3.7)$ & $13.3 / 9.4$ & $(5.5 / 1.6)$ \\
\hline Any conduct disorder & 12.8 & 12.4 & $(4.2)$ & $15.2 / 9.3$ & $(6.2 / 1.8)$ \\
\hline \multicolumn{6}{|l|}{ Disorders of elimination } \\
\hline Functional enuresis & 12.8 & 12.7 & $(0.9)$ & $17.8 / 6.9$ & $(1.7 / 0.0)$ \\
\hline Functional encopresis & 2.7 & 2.6 & $(0.2)$ & $3.9 / 1.0$ & $(0.2 / 0.3)$ \\
\hline Any disorder of elimination & 14.4 & 14.2 & $(1.0)$ & $19.9 / 7.8$ & $(1.6 / 0.3)$ \\
\hline \multicolumn{6}{|l|}{ Other disorders } \\
\hline Separation anxiety & 11.0 & 11.0 & $(1.6)$ & $10.8 / 11.3$ & $(1.9 / 1.4)$ \\
\hline Obsessive-compulsive disorder & 4.4 & 4.3 & $(0.6)$ & $4.1 / 4.6$ & $(1.2 / 0.0)$ \\
\hline
\end{tabular}


The estimated prevalence rates of ADIKA diagnoses in the entire cohort were quite similar to those in the responder group (Table 6.2). The most prevalent disorder was phobia, followed by 'Borderline-ADHD'. The male-female ratio was greatest for 'Disorders of elimination', followed by 'Attention problems'. Only a small proportion of parents thought they needed professional help; the discrepancy between the prevalence of a disorder and the reported need for help was greatest for 'Disorders of elimination' and 'Anxiety disorders'.

Table 6.3 shows both expected and observed comorbidity estimates for separate domains combined with 'Attention Problems' and 'ADHD'. 'Attention problems' as well as 'ADHD' were most often associated with 'anxiety and conduct disorders'. 'Disorders of elimination' were observed as often as one would expect when these types of disorders were statistically independent.

\begin{tabular}{|c|c|c|c|c|}
\hline Table 6.3 & $\begin{array}{l}\text { Prevalence (i } \\
\text { 'ADHD' }\end{array}$ & ercentages) of & Torbidity in 'At & tion Problems' and \\
\hline & Mood & Anxiety & Conduct & Disorders of \\
\hline & Disorders & Disorders & Disorders & Elimination \\
\hline & O\%; E\% & O\%; E\% & O\%; E\% & O\%; E\% \\
\hline Attention Problen & & & & \\
\hline In entire sample & $2.4 ; 1.3$ & $8.4 ; 4.5$ & $7.8 ; 2.4$ & $3.2 ; 2.7$ \\
\hline In responder group & $2.4 ; 1.2$ & $8.2 ; 4.4$ & $7.5 ; 2.3$ & $3.1 ; 2.6$ \\
\hline Male/ Female ratio & $2.3 / 2.5 ; 1.2 / 1.1$ & $8.9 / 7.5 ; 5.4 / 3.3$ & $8.8 / 6.0 ; 3.5 / 1.3$ & $4.8 / 1.2 ; 4.6 / 1.1$ \\
\hline$\underline{A D H D}$ & & & & \\
\hline In entire sample & $1.2 ; 0.3$ & $2.2 ; 0.9$ & $2.7 ; 0.5$ & $0.6 ; 0.5$ \\
\hline In responder group & $1.2 ; 0.2$ & $2.1 ; 0.8$ & $2.6 ; 0.5$ & $0.6 ; 0.5$ \\
\hline Male/ Female ratio & I.3/I.I; $0.3 / 0.2$ & 2.4/I.7; I.I/0.6 & $3.4 / 1.6 ; 0.7 / 0.2$ & $1.1 /<0.0 ; 1.0 / 0.2$ \\
\hline
\end{tabular}

\section{DISCUSSION}

This article reports the prevalence and comorbidity of a number of common DSM-based disorders in a population of 6-to 8-year-old children. The study had a prospective design and scores on the $C B C L$ were used to select the children. To generalize the $C B C L$ data to the entire population, a prediction model was used that included the most important child, family, and environmental characteristics. Low parental occupation, attention deficits in the 
child, and cigarette abuse by the mother during pregnancy turned differentiated significantly between the problem group $(\mathrm{E}+\mathrm{l})$ and the 'normal' group. These findings confirm previous findings (Campbell, 1995; Kalff et al., 200 I; Orlebeke et al., 1998; Stevenson et al., 1996) . As found by Offord et al. (1987), also here school type (urban/ nonurban) was identified as significant information for distinguishing between the externalizing (more urban) and the internalizing groups. Attention deficit, as observed by the school doctor, was not an independent variable but was just a symptom of many underlying problems. This report, however, underlines the importance of this symptom in the prediction of problem behaviour.

To date, prevalence studies have included only the variables sex, age, social class, and country of birth of the child to compare responder with nonresponder samples. Other characteristics, such as attention deficits, pregnancy-related problems, and school variables, have not been taken into consideration, probably because it is difficult to obtain this kind of information from the nonresponder group. A major advantage of our research design was that we had the cooperation of the school doctor and were able to use information from the medical records. With this method, however, the prevalence rates in the responder group and the entire sample were very similar.

Although most prevalence estimates were quite comparable with those of other population studies (Anderson, 1987; Bird et al., 1993; Costello et al., 1996; Feehan et al., 1994; Fergusson et al., 1993), there were some important differences. A substantial number of children in this study met criteria for at least one diagnosis. However, a vast majority of the parents reported not needing any help. Also Fergusson et al. (1993) and Jensen et al. (1995) reported important decreases in the prevalence of disorder after investigating the need for help; however our decreases were even higher, which suggests that the parents of younger children are less inclined to ask for help. This raises doubt about the severity of some of the DSM-based diagnoses in this young age group. However, it is important to realize that a parent's judgment of the need for services may be unreliable and affected by many factors which may lead to underestimation of the frequency of some conditions (Jensen et al., 1995). There was a high prevalence of 'Any Anxiety disorders' (23.8\%). Phobia, as major contributor to 'Any Anxiety disorder', had a prevalence of $21.8 \%$. Because of the young age of the children the most important phobia, darkness, probably does not reflect a disorder but can be regarded as a part of normal maturation. Other authors also doubt the validity of DSM in diagnosing clinically relevant 'Anxiety disorders' (Ezpeleta et al., 1997). Thus, it has been suggested that 'Anxiety syndrome' should be redefined to enable a more clinically relevant diagnosis to be made (Steingard et al., 1992).

The prevalence of 'Borderline ADHD', in which affected children had ADHD symptoms but in fewer than two situations, was 19.1\%. Swanson and coworkers (1998) reviewed the literature and reported the prevalence of ADHD to range from I to $24 \%$. The prevalence of ADHD (3.8 \%) in our cohort is in accordance with that mentioned in DSM-IV (American Psychiatric Association, 1994). The relatively high prevalence of 'Borderline ADHD' may explain the high prevalence of ADHD found in earlier studies, because if investigators paid 
insufficient attention to the pervasivity criteria for ADHD, they may have grouped 'ADHD' and 'Borderline ADHD' together. Another point of interest concerning the 'Attention problems' in this study is the male-female ratio. Although population-based studies of 'ADHD' are relatively scarce, the DSM-IV (American Psychiatric Association, 1994) reported a male-female ratio of $4: 1$, whereas we found a ratio of $2: 1$. This is probably because ADHD may be underestimated in girls because 'ADHD girls', in the general population tend to be less impaired than ADHD boys are (Gaub and Carlson, 1997).

The estimates of comorbidity with ADHD were comparable with those in other studies (Angold et al., 1999). 'Anxiety disorders' and 'Conduct disorders' were the most important comorbid diagnoses of both 'Attention problems' and 'ADHD'. Comorbidity concerning 'Disorders of Elimination' was not higher than expected as these types of disorder were statistically independent. Although the current literature is not univocal concerning this point (Barkley, 1998), this population study supports the hypothesis that children with ADHD do not have problems with elimination more often than other children.

With respect to the generalizability of the findings, it is important to remember that this study included only those children who attended normal kindergarten schools in the south of the province of Limburg. Although this part of The Netherlands is quite comparable with the rest of the country, there are some important differences. Compared with the northwest of the country, there are few foreign-born families in the south of Limburg, and, because the capital of Limburg (Maastricht) has a university, inhabitants are relatively welleducated. All schools in The Netherlands are public; private schools do not exist. However, our data do not apply to children who attend schools for special educational needs (about $5 \%$ of all schoolchildren); if these children were to have been included, the estimates probably would have been higher.

\section{Limitations}

A major limitation of the study is the lack of multiple informants. Structured interviews of the children themselves and their teachers were not feasible. The reason for interviewing only the parent of the child, however, is that information provided by young children is considered unreliable (Edelbrock et al., 1985). Previous studies found that parents are better informants for externalizing disorders than for internalizing disorders (Ezpeleta et al., 1997; Fergusson et al., 1993), which means that the prevalence of internalizing disorders may have been underestimated. Furthermore, Gomez and his colleagues (1999) reported that parents tend to diagnose ADHD more often than do teachers, which would imply that the prevalence of ADHD was overestimated in our study.

Although the prediction model was able to estimate the prevalence of ADIKA diagnoses in the nonresponder group, the low response rate $(57.5 \%)$ is still a limitation of the study. Furthermore, some potentially important variables, such as family income and the psychiatric state of the parents, were missing. Although these variables are associated with child 
emotional and behavioural disorders, our study design was limited to information available from the medical records of the children, which did not include these variables.

\section{Clinical implications}

To our knowledge this article is the first to report prevalence estimates according to structured-interview in the age group 6 to 8 years. In comparison with prevalence estimates in older children, the most obvious finding in this study is that the ADIKA seems to overestimate some of the diagnoses in this young age group. On the other hand the major decrease in reported diagnoses after considering the need for help may also indicate that parents of young children with problem behaviour are less likely to seek help. Because of this, the number of young children with psychopathology who visit a clinic may be much lower than the actual number in the general community. School doctors in particular should be aware of this, so that psychopathology can be identified earlier. This, in turn, could lead to subsequent treatment and may prevent further difficulties. 


\section{REFERENCES}

Achenbach TM, Edelbrock C (1983), Manual for the Child Behavior Checklist and Revised Child Behavior Profile. Burlinton: University of Vermont Department of Psychiatry

American Psychiatric Association (1987), Diagnostic and Statistical Manual of Mental Disorders, 3rd edition (DSMIII-R). Washington, DC: American Psychiatric Association

American Psychiatric Association (1994), Diagnostic and Statistical Manual of Mental Disorders, 4th edition (DSMIV). Washington DC: American Psychiatric Association

Anderson JC, Williams S, Mc Gee R, Silva, PA (1987), DSM-III Disorders in preadolescent children, Prevalence in a large sample from the general population. Archives in General Psychiatry 44:69-76

Angold A, Costello E J, Erkanli A (1999), Comorbidity. Journal of Child Psychology and Psychiatry and Allied Disciplines 40:57-87

Barkley RA (1998), Attention Deficit Hyperactivity Disorder, A handbook for diagnosis and treatment, 2nd edition. London: The Guilford Press

Bird HR, Yager TJ, Staghezza BM, Gould MS, Canino G, Rubio-Stipec MA (1990), Impaiment in the epidemiologic measurement of childhood psychopathology in the community. Journal of American Academy of Child and Adolescent Psychiatry 29:796-803

Bird HR, Gould MS, Staghezza BM (1993), Patterns of diagnostic comorbidity in a community sample of children aged 9 through 16 years. Journal of American Academy of Child and Adolescent Psychiatry 32:36I368

Campbell SB (1995), Behavior problems in preschool children: A review of recent research. Journal of Child Psychology and Psychiatry and Allied Disciplines 36:1 13-149

Costello EJ, Angold A, Burns BJ, Stangl, DK, Tweed DL, Erkanli A, Worthman CM (1996), The Great Smoky Mountains Study of Youth. Goals, design, methods, and the prevalence of DSM-III-R disorders. Archives of General Psychiatry 53:I I29-I I36

Directoraat-Generaal voor de Arbeidsvoorziening (DGA) (1989), Handleiding voor de functie analyse [Manual functional analyses] Den Haag: SDU Uitgeverij

Edelbrock C, Costello AJ, Dulcan MK, Kalas R, Conover NC (1985), Age differences in the reliability of the psychiatric interview of the child. Child Development 56:265-275

Ezpeleta L, Osa de la N, Domenech JM, Navarro JB, Losilla JM (1997), Diagnostic agreement between clinicians and the diagnostic interview for children and adolescents-DICA-R-in an outpatient sample. Journal of Child Psychology and Psychiatry and Allied Disciplines 38:431-440

Feehan M, McGee R, Raja SN, Williams SM (1994), DSM-III-R disorders in New Zealand I8-year-olds. Australian and New Zealand Journal of Psychiatry 28:87-99

Fergusson DM, Horwood LJ, Lynskey MT (1993), Prevalence and comorbidity of DSM-III-R diagnoses in a birth cohort of 15 year olds. Journal of American Academy of Child and Adolescent Psychiatry 32:I I 27 - I I 34

Gaub M, Carlson CL (1997), Gender differences in ADHD: a meta-analysis and critical review. Journal of American Academy of Child and Adolescent Psychiatry 36:1036-1045 
Gomez R, Harvey J, Quick C, Scharer I, Harris G (1999), DSM-IV AD/HD: Confirmatory Factor Models, Prevalence, and Gender and age differences based on parent and teacher ratings of Australian primary school children. Journal of Child Psychology and Psychiatry and Allied Disciplines 40:265-274

Herjanic B, Campbell W (1977), Differentiating psychiatric disturbed children on the base of a structured interview. Journal of Abnormal Child psychology 5:127-134

Hosmer DW, Lemeshow S (1989), Applied Logistic Regression. New York: John Wiley \& Sons

Jensen PS, Watanbe HK, Richters JE, Cortes R, Roper M, Liu S (1995), Prevalence of mental disorder in military children and adolescents: Findings from a two-stage community survey. Journal of American Academy of Child and Adolescent Psychiatry 34:1514-1524

Kalff AC, Kroes M, Vles JSH, Bosma H, Feron FJM, Hendriksen JGM, Steyaert J, van Zeben TMCB, Crolla IFAM, Jolles J (200I), Factors affecting the relation between parental education as well as occupation and problem behaviour in Dutch 5-to 6-year-old children. Social Psychiatry and Psychiatric Epidemiology 36: 324-331

Kortenbout van der Sluijs MJ, Levita DJ, Manen R, Defares PB (1993), ADIKA, Amsterdams diagnostisch interview voor kinderen en Adolescenten. Lisse: Swets \& Zeitlinger

Lavigne JV, Gibbons RD, Christoffel KK, Arend R, Rosenbaum D, Binns HJ, Dawson N, Sobel H, Isaacs C (1996), Prevalence rates and correlates of psychiatric disorders among preschool children. Journal of American Academy of Child and Adolescent Psychiatry 35:203-214

Lavigne JV, Arend R, Rosenbaum D, Binns HJ, Christoffel KK, Gibbons RD (1998), Psychiatric disorders with onset in the preschool years: I. Stability of diagnoses. Journal of American Academy of Child and Adolescent Psychiatry 37:1247-1254

Little RJA, Rubin DB (1987), Statistical analysis with missing data (chapter I \& 12). New York: John Wiley \& Sons

Offord DR, Boyle MH, Szatmari P, Rae-Grant N I, Links PS, Cadman DT, Byles JA, Crawford JW, Munroe Blum H, Byrne C, Thomas H, Woodward CA (1987), Ontario Child Health Study II. Six-month prevalence of disorder and rates of service utilization. Archives of General Psychiatry 44:833-836

Orlebeke JF, Knol DL, Boomsma DI (1998), Frequency of parental report of problem behavior in children decreases with maternal age at delivery. Psychological Report 82:395-404

Reich W (2000), Diagnostic Interview for Children and Adolescents (DICA). Journal of American Academy of Child and Adolescent Psychiatry 39:59-66

Rozendaal N (1998), Handleiding Computer Algoritme Amsterdams Diagnostisch Interview voor Kinderen en Adolescenten (ADIKA). Maastricht: Vakgroep Psychiatrie en Neuropsychology, Universiteit Maastricht

Schafer JL, Schenker N (2000), Inference with imputed conditional means. Journal of the American Statistical Association 95: |44-154

Shrout PE, Skodol AE, Dohrenwend BP (1986), A two-stage approach for case identification and diagnosis: firststage instruments, in Mental disorders in the community, 42nd edition New York: Guildford Press

Steingard R, Biederman J, Doyle A, Sprich-Buckminster S (1992), Psychiatric comorbidity in attention deficit disorder: impact on the interpretation of Child Behavior Checklist results. Journal of American Academy of Child and Adolescent Psychiatry 31:449-54

Stevenson J, Thompson MJJ, Sonuga-Barke E (1996), Mental health of preschool children and their mothers in a mixed urban/rural population. III. Latent variable models. British Journal of Psychiatry, I68(I), 26-32 
Swanson JM, Sergeant JA, Taylor E, Sonuga-Barke EJ, Jensen PS, Cantwell DP (1998), Attention-deficit hyperactivity disorder and hyperkinetic disorder. The Lancet 351:429-433

Verhulst FC, Berden GFMG, Sanders-Woudstra, JAR (1985), Mental health in Dutch children: (II) the prevalence of psychiatric disorder and relationship between measures. Acta psychiatrica Scandinavica Supplementum 324, I-45

Verhulst FC, Koot JM, Van der Ende J (1996), Handleiding voor de CBCL 4-I8. Rotterdam: Afdeling Kinder-en jeugdpsychiatrie, Sophia Kinderziekenhuis/ Academisch Ziekenhuis Rotterdam/ Erasmus Universiteit Rotterdam

Weissman MM, Warner V, Wickramaratme PJ, Kandel DB (1999), Maternal smoking During Pregnancy and Psychopathology in Offspring Followed to Adulthood. Journal of American Academy of Child and Adolescent Psychiatry 38:892-899

Wels PMA, Robbroeckx LMH (1996), Nijmeegse vragenlijst voor de opvoedingssituatie (NVOS) Handleiding. [The assessment of Family Stress] Lisse: Swets \& Zeitlinger 


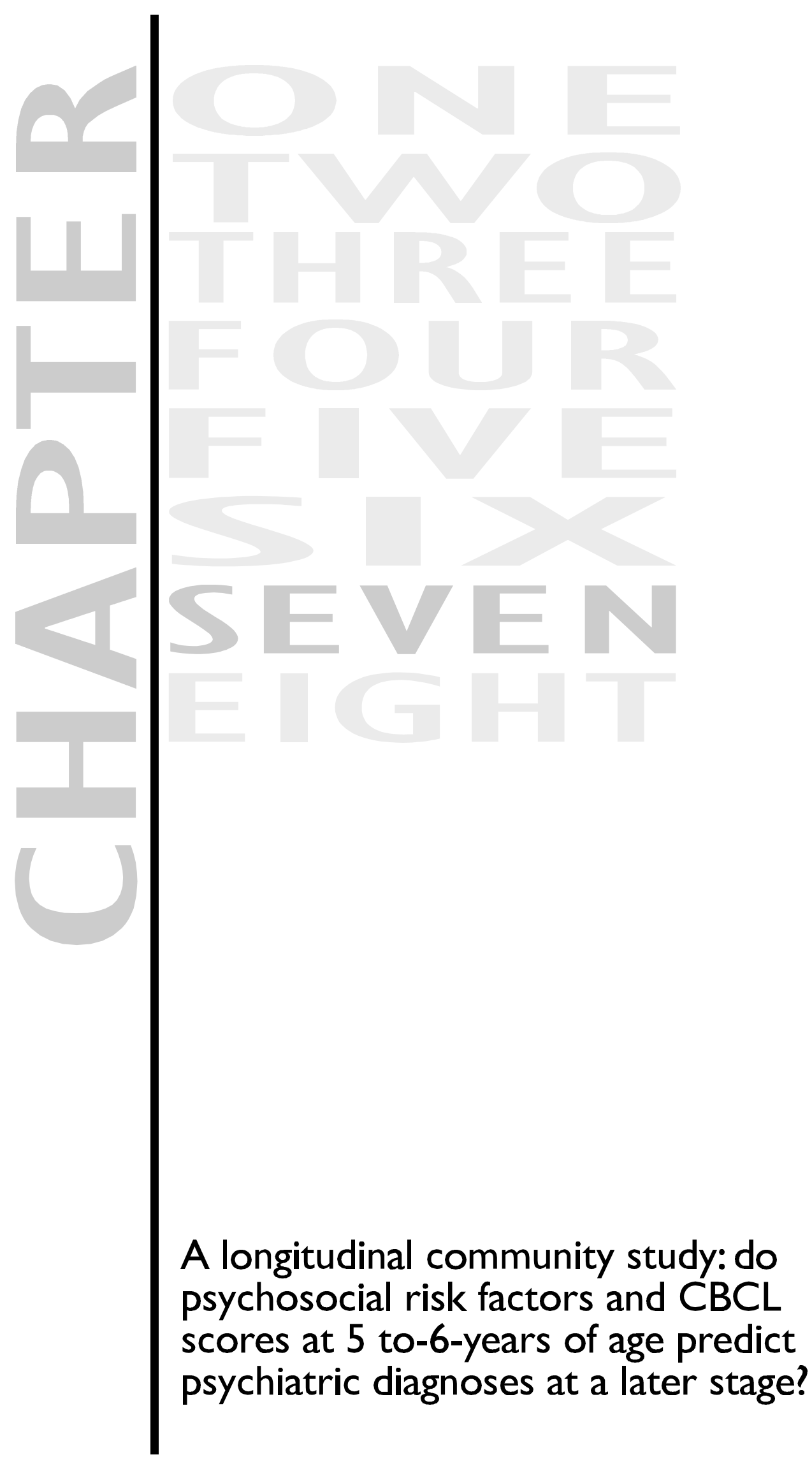





\section{ABSTRACT}

Objective: To examine the extent to which certain risk factors in 5-to 6-year-old children predict later psychopathology in a population-based sample of children from the province of Limburg in the south of the Netherlands.

Method: Of the 2290 children of interest, 1317 children were screened with the Child Behavior Checklist (CBCL). Psychosocial risk factors for these children were collected, and based on the $C B C L$ results three groups were selected for consequent analysis. One and a half years later, standardized child psychiatric information was obtained from 403 children, selected for the second stage. Weighted logistic regression analyses were used to investigate predictors of psychopathology.

Results: In separate analyses of specific types of child psychopathology, different risk factors emerged as significant. Low-level parental occupation and having foreign-born parents were predictive for 'Conduct disorders', while living in a single-parent family and a having a life event were the most important predictors of 'Mood and Anxiety disorders'. Furthermore, CBCL-based ratings at 5-6 years of age corresponded well with interview-defined diagnoses I.5 years later.

Conclusions: Assessment of psychosocial risk factors and $C B C L$ scores at the age of 5-6 is helpful in predicting child psychopathology and can help identify children at risk, in order to provide them with timely attention.

\section{INTRODUCTION}

Research into child development suggests that early recognition of problems and early intervention in families will lead to successful prevention programs (Hermanns and Leu, 1998). For this reason, it is of great interest to investigate the extent to which early psychosocial risk factors predict later psychopathology in a community sample of young children.

Although most community studies of young children have focussed on psychosocial risk factors for behavioural problems in general (Kalff et al., 200la; Campbell, 1995), little is known about psychosocial risk factors for specific DSM-based diagnoses. This is mainly because there are relatively few methods for specifically evaluating younger children (Costello et al., 1996) and the fact that information obtained from children of this age is considered unreliable (Edelbrock et al., 1985). An important exception in this field is the study of Lavigne et al. (1998), in which 2-to 9-year-old children were investigated for predictors of stability and change in psychiatric disorders, based on "best estimates". The authors concluded that family context (especially lower levels of family cohesion, more negative life events and negative affect by mothers) contributed to the onset or maintenance of problems starting in preschool years. A limitation of this study, however, is that it was not based on a community sample. Furthermore, only complex disruptive and emotional 
disorders were investigated and no attention was paid to risk factors for individual DSM diagnoses.

Many of the studies involving older children have focussed on a single diagnosis (e.g. anxiety), rather than multiple diagnoses, or they have used an indicator for case versus non-case as the dependent variable (Lavigne et al., 1998; Manassis and Hood, 1998; Verhulst et al., 1985). Moreover, the studies failed to provide information on the specificity of the identified risk factors. The results of the studies that did focus on separate diagnoses, have not been consistent. For example, Velez et al. (1989) concluded that the risk factors studied were related more to the externalizing than to the internalizing diagnoses, whereas Williams et al. (1990) failed to provide strong support for differences in background characteristics among children with different diagnoses. For this reason, additional research is needed to increase our knowledge of the predictive value of psychosocial risk factors in young children.

The first aim of the present report was to investigate whether various psychosocial risk factors (child, family, and environmental factors) in 5-to 6-year-old children are related to psychopathology in a general population of Dutch school children. Concerning the childrelated factors, Velez et al. (1989) reported that stressful life events are important risk factors for both internalizing and externalizing disorders. Low-level parental occupation (Kalff et al., 200la; Campbell, 1995), family size (Williams et al., 1990), race (Costello et al., 1996), family structure (Velez et al., 1989), low maternal age at delivery (Orlebeke et al., 1998), and maternal depression (Lavigne et al., 1998) are important family-related risk factors. Although the environment in which a child grows up is a potential risk factor for behavioural problems (Kalff et al., 200 lb), little is known about its influence on DSM-based diagnoses (Hermanns and Leu, 1998). Data were collected during a longitudinal population study in the south of the Netherlands, entitled SAM ("Study of Attention disorders in Maastricht "), that used a two-stage design (Kalff et al., 200I; Kroes et al., 200I). In the first stage, the children were screened with the Child Behavior Checklist (Verhulst et al., 1996) and psychosocial risk factors were obtained. In the second stage, I.5 years later, more detailed psychiatric information was collected from selected children by using a standardized interview.

Although several authors have explored the cross-sectional relations between $\mathrm{CBCL}$ dimensions and DSM-based diagnoses (Biederman et al., 1993; Jensen et al., 1993; Kasius et al., 1997), it has been argued that longitudinal studies are needed to clarify the utility of the $\mathrm{CBCL}$ in young children for predicting DSM-based diagnoses at a later age (Keenan et al., 1997). Thus an additional goal of the present study was to examine the predictive value of the different subscales of the CBCL in stage I of the study for individual DSM-based diagnoses in stage 2 of the study. 


\section{METHODS}

\section{Subjects and procedure}

\section{Stage I: Months I-9}

In the first stage of the study, all parents of children in the second grade of normal kindergarten schools in the south of the province Limburg (the Netherlands) were approached by the Youth Health Care (YHC) organization for participation in the study. This included all public schools in this region (private schools do not exist in the Netherlands) excluding those for special educational needs. The national organization is responsible for performing a periodic health examination of all the children. The average response rate is $98 \%$. The school doctors perform this examination, and under Dutch law they are allowed to use medical information anonymously for epidemiological research purposes. The initial sample comprised 2290 children, and the parents of 1317 children (57.5\%; 699 boys and 618 girls; mean age 5.87; SD=0.4I) granted permission for participation. Responders and non-responders were compared for sex, age, and demographic factors such as parental occupation, nationality, family structure, and living area by randomly sampling 200 subjects from both groups. Information was obtained anonymously from the medical records of the Youth Health Care. No significant differences between the groups were found (see also Kroes et al., 200I; table I).

Based on the scores for the CBCL, which was completed by the parents of the children, three groups of children (total $\mathrm{N}=452$ ) were selected for stage 2 of the study. Group $E$ (externalizing group) consisted of children with $\mathrm{CBCL}$ externalizing-scale scores above the 90th percentile and/or with $\mathrm{CBCL}$ attention problem-scale scores exceeding the 95th percentile $(\mathrm{N}=173)$. Group I (internalizing group) consisted of children with internalizingscale scores above the 90th percentile and who were not members of the first group $(\mathrm{N}=59)$. Thus, children with high scores on internalizing and externalizing scales were assigned to group E. Finally, each child in these two groups was matched for sex, age $( \pm 2$ month), and school (urban versus non-urban) with a child whose $C B C L$ total score was below the 90th percentile. This 'normal group' (group $N$ ) consisted of $(N=220)$ children. Psychosocial risk factors were collected for the three selected groups.

\section{Stage 2: Months I5-25}

Of the 452 children, the parents of 403 (89\%; 233 boys and I 70 girls) were interviewed with the Amsterdam Diagnostic Interview for Children and Adolescents, ADIKA (Kortenbout van der Sluijs et al., 1993). Eleven percent $(n=49)$ of the children's parents refused further participation or had moved. Of these 403 children, 150 were originally assigned to group $E$, 54 to group I, and 199 to group N. At the time of the interview, the children's ages ranged from 6.4 to 8.6 (mean=7.I, SD=0.4) years. In $89.6 \%$ of the cases the mother of the child was interviewed, in $6.4 \%$ of the cases the father, and in $4.0 \%$ of the cases another caretaker. 


\section{Measures}

\section{Stage I:}

The Child Behavior Checklist (CBCL) was developed by Achenbach and Edelbrock (I983) and translated and revised by Verhulst et al. (1996) for the Dutch population. The results of the questionnaire give a profile composed of nine problem scales (withdrawn; somatic complaints; anxious/depressed; social problems; thought problems; attention problems; delinquent behaviour; aggressive behaviour; sex problems), two broadband scales (externalizing, consisting of delinquent and aggressive behaviour; and internalizing, consisting of withdrawn, somatic complaints, and anxious/depressed), and the total problem score. Verhulst et al. (1996) defined both clinical and borderline cut-off values for the problem scales (clinical: T >70 (98th percentile), borderline T: 67-70 (95th-98th percentile)) as well for the total scores (clinical: $T>63$ (90th percentile), borderline T: 60-63 (82nd-90th percentile)).

Child characteristics, family variables, and environmental variables were recorded as psychosocial risk factors. There were three child characteristics: (I) sex; (2) age; and (3) life events as elicited by means of an open-ended question. Categorizing these answers gives 55 health problems, 14 divorces, 6 (sexual) abuse, 10 loss of family member and 9 other diverging answers. There were seven family variables: (I) level of occupational activity. This was based on a full description of the parents' occupational activities and was coded according to the system used by the Dutch Central Bureau of Statistics. This code was then transformed to a 7-point scale, based on the mental complexity of the work, as rated by job experts (DGA, 1989). This 7-point score ranges from low skilled to academic labor and was divided into three levels for the present study; low (I, 2 and 3), middle (4 and 5), and high (6 and 7). For children living with both parents, the highest level was used; for the remaining children, the level of the parent with whom the child lived was used. Housewives and househusbands were included in the low category. (2) country of birth of the parents; (3) number of children; (4) position of child in sibship; (5) family structure; (6) maternal age at delivery; (7) professional mental support for the mother (whether mother receives treatment for psychiatric or mental health problems). There were two environmental variables: (I) type of school the child attended (school with or without an educational priority policy: in the Netherlands schools with more children at risk (e.g. foreigners, one-parent families) receive more money from the government), and (2) nursery after school hours. Most of the information was collected from the medical records of the Youth Health Care, although information about life event, mental support, and nursery attendance was supplied by the parents themselves. Table 7.I displays the distribution of the demographic characteristics of the group participating in the second stage $(N=403)$, and shows the weighted percentages 


\begin{tabular}{|c|c|c|c|}
\hline \multirow[t]{2}{*}{ Table 7.I } & \multicolumn{3}{|c|}{$\begin{array}{l}\text { characteristics of inves- } \\
\text { e }(N=403) \text { and weighted } \\
\text { sponder group }(N=13 \mid 7)\end{array}$} \\
\hline & $\mathrm{N}$ & $(\%)$ & $\begin{array}{l}\text { Weighted } \\
(\%)\end{array}$ \\
\hline \multicolumn{4}{|l|}{ Live event } \\
\hline Yes & 94 & $(24 \%)$ & (19\%) \\
\hline No live event & 307 & $(76 \%)$ & (81\%) \\
\hline Missing & 2 & $(0 \%)$ & $(0 \%)$ \\
\hline \multicolumn{4}{|l|}{ Parental occupation } \\
\hline High & 113 & $(28 \%)$ & (30\%) \\
\hline Middle & 105 & $(26 \%)$ & $(29 \%)$ \\
\hline Low & 178 & (44\%) & (40\%) \\
\hline Missing & 7 & $(2 \%)$ & $(1 \%)$ \\
\hline \multicolumn{4}{|l|}{ Nationality } \\
\hline Dutch & 343 & (85\%) & (86 \%) \\
\hline Foreign-born & 53 & (13\%) & (12\%) \\
\hline Missing & 7 & $(2 \%)$ & $(2 \%)$ \\
\hline \multicolumn{4}{|l|}{ Number of children } \\
\hline I & 66 & (16\%) & (15\%) \\
\hline 2 & 232 & (58 \%) & (59\%) \\
\hline$>2$ & 103 & $(26 \%)$ & $(26 \%)$ \\
\hline Missings & 2 & $(0 \%)$ & $(0 \%)$ \\
\hline \multicolumn{4}{|l|}{ Position of child in sibship } \\
\hline$\left.\right|^{\text {st }}$ & 199 & (49\%) & $(46 \%)$ \\
\hline $2^{\text {nd }}$ & 142 & (35\%) & (38\%) \\
\hline$>2^{\text {nd }}$ & 54 & (14\%) & (14\%) \\
\hline Missings & 8 & $(2 \%)$ & $(2 \%)$ \\
\hline \multicolumn{4}{|l|}{ Family structure } \\
\hline Living with two parents & 336 & (83\%) & (85\%) \\
\hline Living with one parent & 66 & (17\%) & (15\%) \\
\hline Missing & I & $(0 \%)$ & $(0 \%)$ \\
\hline \multicolumn{4}{|l|}{ Age mother at delivery } \\
\hline$>33$ & 73 & (18\%) & $(22 \%)$ \\
\hline $27-33$ & 221 & (55\%) & $(56 \%)$ \\
\hline$\leq 26$ & 108 & $(27 \%)$ & $(22 \%)$ \\
\hline Missing & I & $(0 \%)$ & $(0 \%)$ \\
\hline \multicolumn{4}{|l|}{ Mental support mother } \\
\hline Yes & 57 & (14\%) & (II \%) \\
\hline No & 343 & (85 \%) & (88 \%) \\
\hline Missing & 3 & $(1 \%)$ & $(1 \%)$ \\
\hline \multicolumn{4}{|l|}{ Type of school } \\
\hline Education Priority & 73 & (18\%) & (15\%) \\
\hline No Education Priority & 330 & (82 \%) & (85\%) \\
\hline \multicolumn{4}{|l|}{ Nursery after school hours } \\
\hline Yes & 47 & (12\%) & $(10 \%)$ \\
\hline No & 353 & (87 \%) & (90\%) \\
\hline Missing & 3 & (। \%) & $(0 \%)$ \\
\hline
\end{tabular}

\section{Stage 2: Interview}

The Amsterdam Diagnostic Interview for Children and Adolescents (ADIKA) (Kortenbout van der Sluijs et al., 1993) is the Dutch translation of the Diagnostic Interview for Children and Adolescents (DICA) (Herjanic and Campbell, 1977), which is based on the criteria of DSM- 
III-R (American Psychiatric Association, 1987). The criteria of DSM-IV were used for diagnosing Attention Deficit/Hyperactivity Disorder (Westereich, internal publication, 1998). Five major domains of psychopathology were assessed, namely, (I) 'Attention problems' $(\mathrm{N}=35)$, which include 'ADHD, inattentive, hyperactive, and combined type' as well as 'Borderline-ADHD' ( $\mathrm{N}=85)$, which includes those children in whom ADHD symptoms were present but in fewer than two situations; (2) 'Conduct/Oppositional disorders' ( $N=93)$, which include conduct disorder and oppositional disorder;(3) 'Mood disorders' $(\mathrm{N}=39$ ), which encompasses major depression, dysthymia (at present and past, with and without an underlying life event), and bipolar disorders; (4) 'Anxiety disorders' ( $N=133)$, which include overanxious disorder, avoidant disorder, phobias, and post-traumatic stress disorder; and (5) 'Elimination disorders' $(\mathrm{N}=66)$, which include functional enuresis and functional encopresis. These domains were only based on the ADIKA and not related to extra severity or impairment criteria. Although the Dutch version of the DICA-IIIR interview has not been separately validated, DICA and DICA-IIIR have been demonstrated to have high test-retest reliability and moderate correlations with clinician based diagnoses (Ezpeleta et al., 1996; Welner et al., 1987). Three skilled interviewers administered the ADIKAs. To optimize the reliability of the interview, the interviewers were trained and supervised intensively by a senior child psychiatrist. The interviewers and the child psychiatrist were blind to the $\mathrm{CBCL}$ screening results. Diagnoses were generated from the coded ADIKAs by a computer algorithm ignoring hierarchical DSM criteria (Rozendaal, 1998).

\section{Statistical Analysis}

Because the selection procedure in stage I was based on the $C B C L$ results, age, sex, and school, the selected group does not represent the entire responder group. For this reason, it was necessary to weight all analyses using the 'sampling weight option' of STATA (StataCorp, 200I), which permits adjustment for design characteristics such as 2-stage sampling. The weights used were consistent with the inverse of the probability of selection, so that the results can be interpreted as estimates appropriate for children in a community population.

To investigate which psychosocial risk factors at 5 to 6 years of age could predict different diagnoses, according to the ADIKA I.5 years later, logistic regression analyses were performed. In each regression analysis, the age and sex of the child at the moment of the ADIKA were entered as co-variates. The other demographic variables were entered separately as well as simultaneously (multi-variable logistic regression) as independent variables. In order to minimize lost cases in the analyses, separate categories were defined for missing items, for all different independent variables. Dependent variables were indicators for the five psychiatric domains mentioned in the previous section irrespective of comorbidity.

To examine the predictive value of different $\mathrm{CBCL}$ scales for later psychopathology, stepwise logistic regression analyses were used $(p<0.05)$. Because of the hierarchical 
relationship of the nine $\mathrm{CBCL}$ syndrome scales, the externalizing and internalizing scales, and the total problem scale, it was deemed appropriate to perform regression analyses on the three different sets of variables. The first set included the nine subscales, the second set included the externalizing and internalizing scores, and the third set included the total problem score. This stepwise method makes it possible to calculate the predictive value of the different $C B C L$ scales, as distinct from other $C B C L$ scales. Cut-off points for the $C B C L$ scales were chosen at borderline and clinical levels. The age of the child and sex were used as co-variates.

\section{RESULTS}

\section{Psychosocial risk factors}

Risk factors were calculated for the five domains and for the category 'Any disorder'. In addition, because 'Attention problems' encompass multiple diagnostic categories, risk factors for both 'ADHD' and 'borderline-ADHD' were also examined. Table 7.2 presents the impact of the selected risk factors on these domains. Confidence intervals are given for significant odds ratios. The occurrence of a life event was associated with 'ADHD', 'Mood disorders' and 'Anxiety disorders'. Whereas low-level parental occupation was a risk factor for 'Conduct disorders', middle-level parental occupation was protective, compared with a highlevel occupation, against 'Elimination disorders'. Except for low parental occupation, children also were at risk of developing 'Conduct disorders' if their parents were foreign-born. Being an only child was only associated with 'Anxiety disorders'. Single-parent families were a risk factor for the two internalizing domains, 'Anxiety and Mood disorders'. Children of younger mothers were at risk of 'Mood disorders' and 'ADHD', as were children whose mother needed mental support. The most important risk factors that distinguished between children with and without 'Any disorder' were low parental occupation, single-parent family, and occurrence of a life event.

After multi-variable logistic analyses (all variables were entered simultaneously) four of the eight child psychiatric domains still had significant odds ratios, namely, 'ADHD', 'Mood disorders', 'Anxiety disorders', and 'Any disorder'. Significant risk factors were: (I) life event $(O R=4.6 ; \mathrm{Cl}=1.5-13.6)$ for 'ADHD'; (2) Single-parent family $(O R=4.7 ; C l=1.9-1 \mathrm{I} .7)$, younger mother $(<27$ years: $O R=7.3 ; \mathrm{Cl}=1.5-36.1 ; 27-33$ years: $\mathrm{OR}=7.6 ; \mathrm{Cl}=1.8-31.8)$, life event $(\mathrm{OR}=4.3 ; \mathrm{Cl}=\mathrm{I} .4-\mathrm{I} 3.4)$, and mental support of the mother $(\mathrm{OR}=3.0 ; \mathrm{Cl}=\mathrm{I} . \mathrm{I}-8.7)$ for 'Mood disorders'; (3) Being an only child ( $2^{\text {nd }}$ position: $\mathrm{OR}=0.5 ; \mathrm{Cl}=0.2-\mathrm{I} .0$ ), older mothers (27-33 years: $O R=0.4 ; \mathrm{Cl}=0.2-0.8)$, and life event $(\mathrm{OR}=2.7 ; \mathrm{Cl}=1.4-5.3)$ for 'Anxiety disorders', and (4) life event $(\mathrm{OR}=2.9 ; \mathrm{Cl}=\mathrm{I} .5-5.7)$ for 'Any disorder'. 


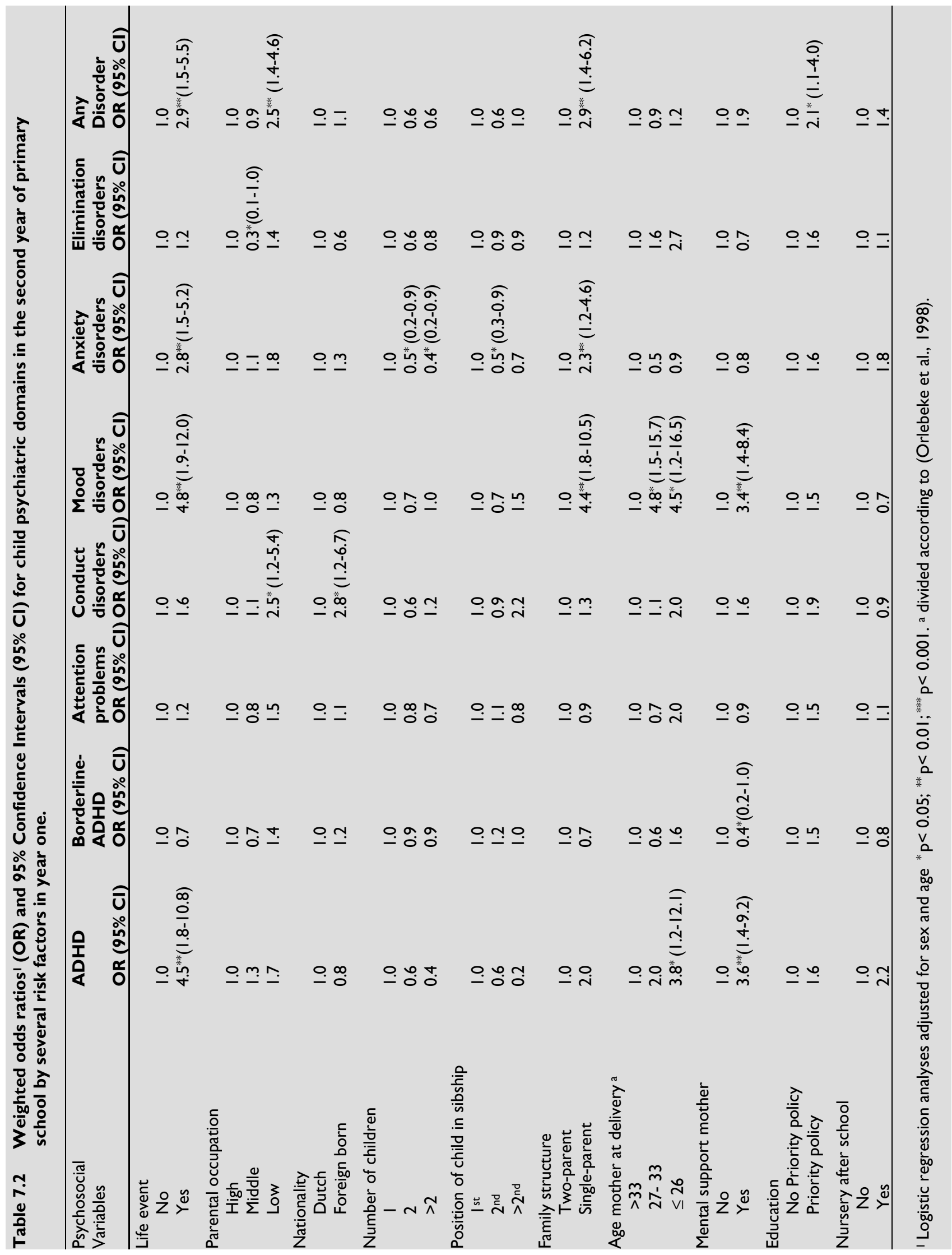




\section{CBCL scores as predictors}

Table 7.3 shows the predictive value of the $C B C L$ scores at 5 to- 6 years of age for psychopathology 1.5 years later. The 'aggressive behaviour sub-scale', the 'externalizing scale', and the 'total problem scale' of the CBCL were predictive of 'ADHD', 'BorderlineADHD', 'Attention problems' and 'Conduct disorders'. 'Attention problems' were predictors of 'ADHD' and 'Attention problems' but not of 'Conduct disorders' and 'Borderline-ADHD'.

'Mood disorders' and 'Anxiety disorders' were predicted by the 'total problem scale' and the 'internalizing scale'; however, the different sub-scales of the CBCL were rather specific in being predictive for one of the two internalizing disorders. More specifically, the CBCL subscales 'anxious/depressed', 'social problems' and 'thought problems' were predictive of 'Mood disorders' whereas 'withdrawn behaviour' and 'sex problems' were predictive of 'Anxiety disorders'.

While the sub-scales 'withdrawn behaviour' and 'delinquent behaviour' were the best predictors of 'Elimination disorders', borderline-levels for 'anxious/depressed' were associated with less frequent rates of this diagnosis. 'Elimination disorders' were the only disorders not predicted by the 'total problem scale' of the CBCL. 'Attention problems', 'withdrawn and aggressive behaviour' were the major predictive sub-scales of the category 'Any diagnosis'. In addition, the 'externalizing and internalizing scales' and the 'total problem scale' were predictors of 'Any diagnosis'. 


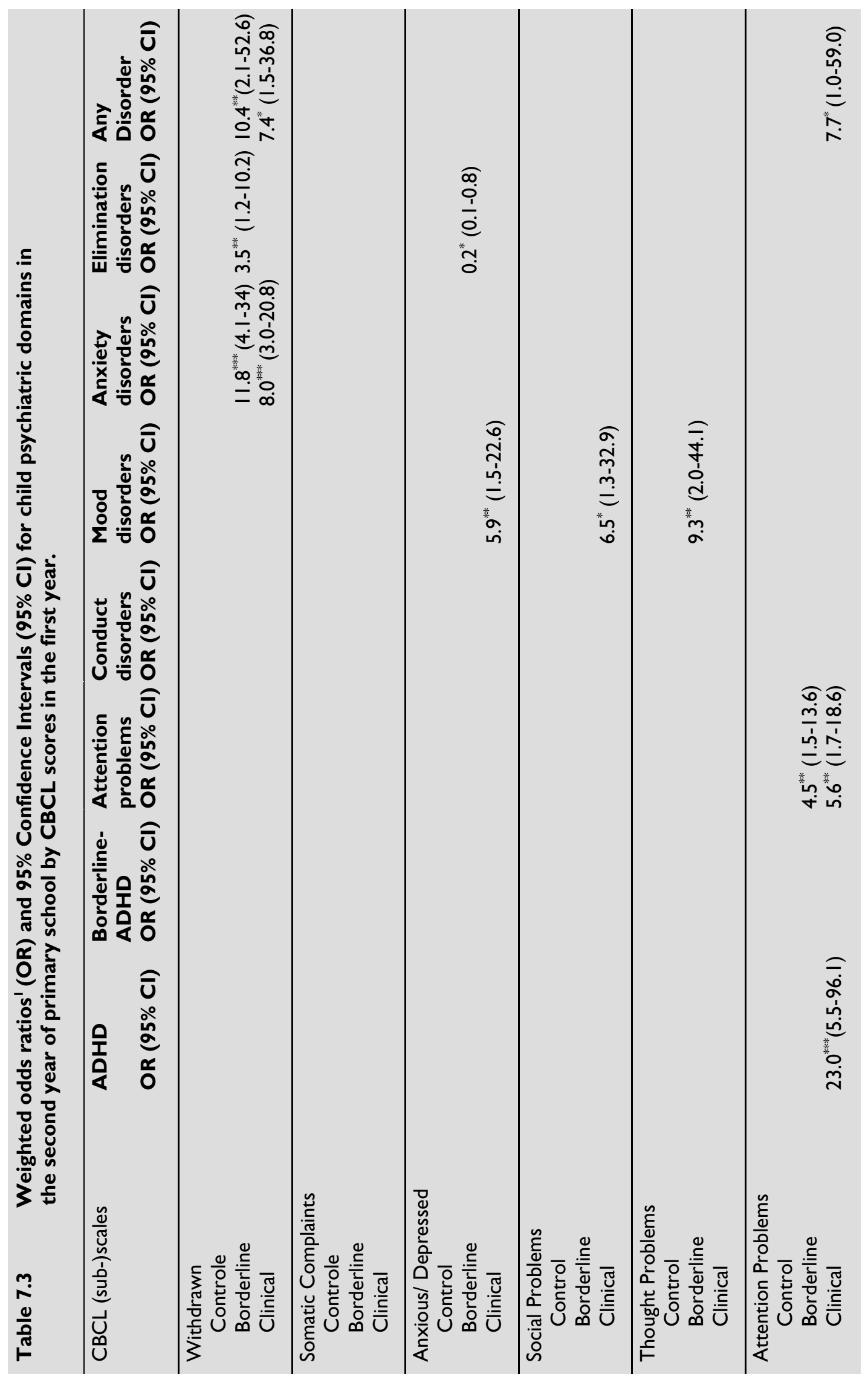




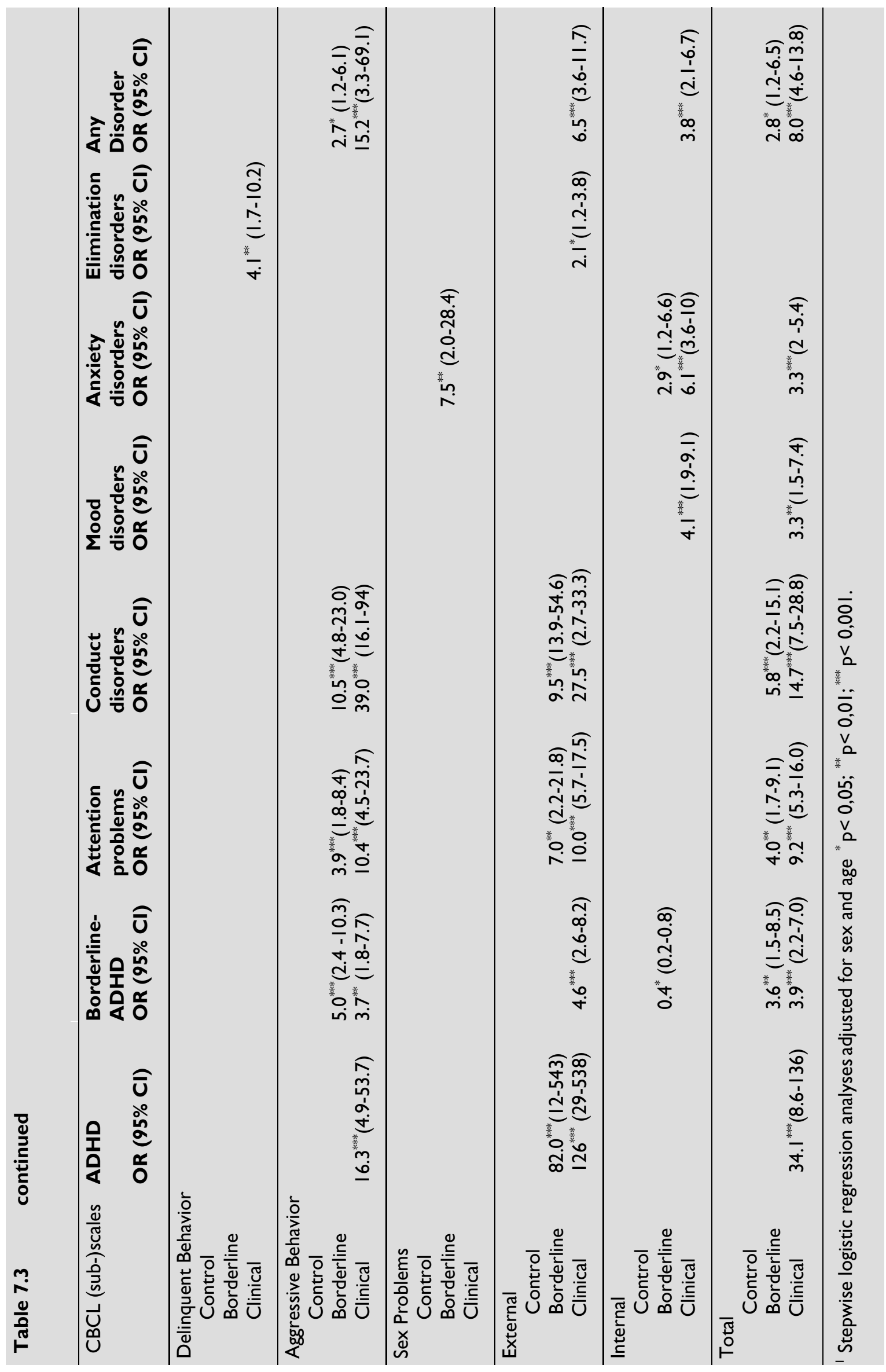




\section{DISCUSSION}

This paper reports the results of a longitudinal community study of a large population sample in the Netherlands. It describes the influence of psychosocial risk factors and CBCL scores at 5- to 6-years of age in relation to child psychiatric disorders 1.5 years later. While diagnostic groups were non-exclusive (irrespective of comorbidity) it is not possible to draw conclusions for 'pure' groups. However, this makes the study representative of psychopathology in the general population, in whom 'pure diagnoses' are rarely made (Angold, et al., 1999). To our knowledge this is one of the first reports of risk factors in relation to DSM-based diagnoses in young children, and the results are of interest because they could help to identify younger children at risk for psychopathology, which may improve our understanding of the etiology, prognosis, and ultimately the prevention of mental disorders.

\section{Psychosocial risk factors}

The most important risk factors differentiating between children with and without disorders were low-level parental occupation, single-parent family, and occurrence of a life event. These risk factors are consistent with those found in other studies focussing on older children (Costello et al., 1996; Velez et al., 1989; Williams et al., 1990). However, although Williams et al. (1990) found that risk factors discriminated between children with and without disorders rather than between children with different disorders, our results suggest that specific risk factors are associated with specific psychopathological outcomes.

For example, low-level parental occupation and foreign-born parents were associated with 'Conduct disorders', and being an only child was associated with 'Anxiety disorders'. Furthermore, single-parent family and the occurrence of a life event were risk factors for the internalizing ADIKA domains 'Mood disorders' and 'Anxiety disorders'. Thus, in contrast with former reports, we identified unique risk factors for different child psychiatric domains. A possible explanation for this difference is that the earlier studies did not have sufficient statistical power. Williams et al. (1990) recognized that while their sample was large enough to distinguish between children with and without disorders, the groups of children with different disorders were too small to detect statistically significant differences between the different diagnoses. Our two-stage design had the advantage of generating high rates of different diagnoses. Interestingly, the risk factors for 'ADHD' (low maternal age, the occurrence of a life event, and mental support for the mother) were also risk factors for the internalizing domains. This finding may reflect the degree of co-morbidity between 'ADHD' and other (internalizing) disorders in our sample (Kroes et al., 200I).

The environmental risk factors (school with priority policy and nursery after school) were not significant predictors of later psychiatric diagnoses. In this study, the children who attended nursery after school were on average 5.9 years old. Furthermore, we did not classify how often children attended nursery after school, and thus detailed information on 
nursery attendance and age might yield significant results. Regarding schools with and without a priority policy, all odds ratios were positive but most were not significant. It is important, however, to mention that $p$-values were rather low and varied from 0.07-0.4, which probably resulted in a significant contribution for 'Any disorder'.

Controlling for potential confounding by multi-variable logistic regression analyses strengthen the basis for causal interference. We found 'life event' to be a stable risk factor that remained significant after multiple regression analyses for four domains. Most mentioned life events successively were health problems (55), divorces (14), loss of family member (10), (sexual) abuse (6) and others (9). It is important, however, to realize that experience of a life event was rather subjective and based on parental appraisal. On the other hand multi-variable regression analyses may also weaken potential associations. For this reason, these analyses should always be interpreted next to those of the univariable analyses. Concerning the univariable analyses, however, type I errors could be crept in because of the relatively high number of analyses done.

\section{CBCL scores as predictors}

In general, we can conclude that high scores on the CBCL at 5 to 6 years of age correlate well with interview-based diagnoses 1.5 years later. Whereas the $C B C L$ is a suitable instrument to detect the presence of problem behaviour in children aged 4-18 years (Verhulst et al., 1996), many DSM-based diagnoses are made after the age of 6 . Bearing this in mind, our results may be of clinical importance when investigating young children. Although previous studies have shown the association between CBCL-based ratings and interview-defined diagnoses in older children (Chen et al., 1994; Kasius et al., 1997), these were all clinically based cross-sectional studies. Keenan et al. (1997), compared CBCLbroadband scales and psychopathology according to DSM-III-R in a community sample of children aged 5 from low-income families. They found moderate but significant associations and recommended longitudinal studies to clarify the utility of the CBCL. This study is the first to investigate the predictive value of the $C B C L$ in relation to interview-defined diagnoses in a prospective community study.

As found in other cross-sectional studies (Biederman et al., 1993; Chen et al., 1994; Kasius et al., 1997), the clinical range of 'attention problems' predicted the DSM-based diagnoses of 'ADHD'. In addition, 'Attention problems', as defined in this report, were also predicted by the corresponding CBCL sub-scale. While 'aggressive behaviour' was predictive for 'ADHD', 'Borderline-ADHD', 'Attention problems', and 'Conduct disorders', the sub-scale 'delinquent behaviour' was not. However it is important to remember that a stepwise logistic regression analysis was used. This method identifies the best predictive sub-scales, which does not necessarily rule out the possibility that univariable analyses would show a significant correlation between 'delinquent behavior' and 'Conduct disorders'. In the study of Kasius et al. (1997) stepwise analyses in a referred sample showed that 'delinquent behavior' did predict conduct disorder ( $\mathrm{OR}=7 \mathrm{I} .9)$. This contradiction is probably due to the dissimilarity of the populations studied. 
The odds ratios for the internalizing sub-scales of the CBCL were considerably lower than those for the externalizing scales. This finding corresponds with that of Jensen et al. (1993), who found that the $\mathrm{CBCL}$ generally performed worse as a screening instrument for internalizing disorders. Finally, the sub-scale 'withdrawn behaviour' was predictive of a broad range of DSM-based disorders. These results are quite similar to those found by Kasius et al. (1997).

\section{Weighting Analyses}

In contrast to some other authors (Lavigne et al., 1998; Verhulst et al., 1985) who investigated risk factors in a two-stage design, we weighted our analyses. The advantage of doing this is that calculated odds ratios can be interpreted as applying to children in a community population, which in general will differ from odds ratios corresponding to the same predictors in a selected population. In a posthoc analysis, we re-analyzed the data without the 'sampling weight option' of STATA (data not shown). Although in general the outcome was quite comparable, some important differences were noted.

The most important difference between weighted and unweighted analyses was that younger age of the mother in the unweighted analyses was a risk factor for 'Attention Problems' and 'Conduct disorders', a finding which disappeared after weighting of the analysis. Furthermore, low parental occupation appeared to be a risk factor for 'Attention Problem', but this phenomenon also disappeared after weighting. The results for the analyses with $\mathrm{CBCL}$ scores results were qualitatively the same, although generally the weighted odds ratios were slightly higher.

\section{Limitations}

Several comments must be made about the generalizability of our finding. First, our results reflect estimation for the entire responder group but not for the non-responder group. Although the comparison of demographic factors between a random sample of 200 responders and non-responders showed no significant differences, this does not necessarily allow to conclude that there are no differences between the groups. In addition, the low retention rate from the initial sample $(57.5 \%)$ must be mentioned as limitation of the study. Furthermore, the population of interest in our study was living in the south of the province of Limburg. Although this part of the Netherlands is quite similar to the rest of the country in many ways, there are relatively fewer foreign-born families and relatively more highly educated inhabitants. Concerning generalization to other countries (e.g. USA) we may assume that the direction of found associations would be the same because the investigated risk factors are 'general' and do not only bear on Dutch children. However, what their exact impact would be for other cultures should be investigated.

The lack of multiple informants and measures of impairment are other limitations. Incorporation of severity criteria ("impaired diagnoses") would probably increase the discriminatory ability of psychosocial risk factors and CBCL (sub-) scales. In a previous study, 
we described prevalence estimates of DSM-based diagnoses and those in combination with severity criteria (Kroes et al., 200I). Rates decreased drastically, which did not allow us to examine the association of risk factors and these impaired diagnoses.

In addition, our study design restricted us to determine whether psychosocial variables and $\mathrm{CBCL}$ scores in stage I predict new cases of disorders or correlate with disorders that already existed at an earlier time frame. This limitation is inherent to such large population studies. Nevertheless, the risk factors investigated can be of potential value in early diagnosis because they do predict psychopathology 1.5 years later irrespectively of whether this diagnosis is new or not.

\section{Clinical implications}

Despite these limitations, this longitudinal community study of relatively young children has increased our knowledge about relevant risk factors for different psychiatric diagnoses in a general population. In the Netherlands, it is common practice that the school doctors routinely examine all 5 to- 6 year old children. Based on this study it would be valuable to implement relevant psychosocial risk factors as well as $\mathrm{CBCL}$ questionnaires, which could help to identify children at risk for different types of psychopathology. In this age group, the weight of the $\mathrm{CBCL}$ is somewhat higher than that of the psychosocial risks factors in predicting outcome 18 months later. The weight of these risk factors is such, however, that we recommend taking them into account in addition to the results of the CBCL when determining the follow-up or intervention policy for an individual child. One can easily assume that these risk factors do not only play an important role in the outcome in this age group, but that they may have an important role in mediating the later course of the disorder. When determining policy for individual children, however, it is important to interpret the relevance of eventual risk factors and $C B C L$ outcome within the context of the results found during the examination of the child and the interview with the parents and school teachers. Children with high risk profiles could be monitored by the school doctor more extensively (extra summons) but concrete consequences should be individually be defined. Depending on the situation of the child, early support could be given on school-level (teacher training and support/ remedial teaching/ reference for special education), family level (video home training/ psycho-education) and, when needed, clinical-based treatment. We expect that these early intervention may prevent further difficulties. 


\section{REFERENCES}

Achenbach TM, Edelbrock C (1983), Manual for the Child Behavior Checklist and Revised Child Behavior Profile. Burlinton: University of Vermont Department of Psychiatry

American Psychiatric Association (1987), Diagnostic and Statistical Manual of Mental Disorders, 3rd revised editionrevised (DSM-III-R). Washington, DC: American Psychiatric Association

Angold A, Costello EJ, Erkanli A (1999), Comorbidity. Journal of Child Psychology and Psychiatry and Allied Disciplines 40: 57-87

Biederman J, Faraone SV, Doyle A, Lehman BK, Kraus I, Perrin J, Tsuang MT (I993), Convergence of the Child Behavior Checklist with structured interview-based psychiatric diagnoses of ADHD children with and without comorbidity. Journal of Child Psychology and Psychiatry and Allied Disciplines 34: I24 I-I 25 I

Campbell SB (1995), Behavior problems in preschool children: A review of recent research. Journal of Child Psychology and Psychiatry and Allied Disciplines 36: I I3-I49

Chen WJ, Faraone SV, Biederman J, Tsuang MT (1994), Diagnostic accuracy of the Child Behavior Checklist scales for attention-deficit hyperactivity disorder: a receiver-operating characteristic analysis. Journal of Consulting and Clinical Psychology 62: 1017-1025

Costello EJ, Angold A, Burns BJ, Stangl DK, Tweed DL, Erkanli A, Worthman CM (1996), The Great Smoky Mountains Study of Youth. Goals, design, methods, and the prevalence of DSM-III-R disorders. Achives of General Psychiatry 53: II29-II 36

Directoraat-Generaal voor de Arbeidsvoorziening (DGA) (1989), Handleiding voor de functie analyse [Manual functional analysis]. Den Haag: SDU Uitgeverij

Edelbrock C, Costello AJ, Dulcan MK, Kalas R, Conover NC (1985), Age differences in the reliability of the psychiatric interview of the child. Child Development 56: 265-275

Ezpeleta L, de la Osa N, Domenech JM, Navarro JB, Losilla JM (1997), Diagnostic agreement between clinicians and the diagnostic interview for children and adolescents-DICA-R in an outpatient sample. Journal of Child Psychology and Psychiatry and Allied Disciplines 38: 431-440

Herjanic B, Campbell W (1977), Differentiating psychiatric disturbed children on the basis of a structured interview. Journal of Abnormal Child Psychology 5: I27-134

Hermanns J, Leu HR (1998), Family risk and family support, theory, research and practice in Germany and in the Netherlands. Delft:: Eburon

Jensen PE, Salzberg AD, Richters JE, Watanabe HK (I993), Scales, diagnoses, and psychopathology: I. CBCL and DISC relationships. Journal of American Academy of Child and Adolescent Psychiatry 32: 397-406

Kalff A, Kroes M, Vles J, Bosma H, Feron F, Hendriksen J, Steyeart J, Zeben T, Crolla I, Jolles J (200 Ia), Factors affecting the relation between parental education as well as occupation and problem behaviour in Dutch kindergarten children. Social Psychiatry and Psychiatric Epidemiology 36: 324-33।

Kalff AC, Kroes M, Vles JSH, Hendriksen JGM, Feron FJM, Steyaert J, van Zeben TMCB, Jolles J, van Os J (200lb), Neighbourhood-level and individual-level SES effects on child problem behaviour: a multilevel analysis. Jounal of Epidemiological Community Health 55: 246-250 
Kasius MC, Ferdinand RF, van den Berg H, Verhulst FC (1997), Associations between different diagnostic approaches for child and adolescent psychopathology. Journal of Child Psychology and Psychiatry and Allied Disciplines 38: 625-632

Keenan K, Shaw DS, Walsh B, Delliquadri E, Giovannelli J (1997), DSM-III-R disorders in preschool children from low-income families. Journal of American Academy of Child and Adolescent Psychiatry 36: 620-627

Kortenbout van der Sluijs MJ, Levita MJ, Manen de R, Defares BP (1993), ADIKA, Amsterdams diagnostisch interview voor kinderen en adolescenten. Lisse: Swets \& Zeitlinger

Kroes M, Kalff AC, Steyaert J, Kessels AGH, Feron FJM, v.Someren AJWGM, Hurks PPM, Hendriksen JGM, v.Zeben TMCB, Rozendaal N, Crolla IFMA, Jolles J, Troost J, Vles JSH (200I), Child Psychiatric diagnoses generalized to a population of Dutch school children aged 6 to 8 years. Journal of American Academy of Child and Adolescent Psychiatry 40: 1401-1409

Lavigne JV, Arends R, Rosenbaum D, Binns HJ, Christoffel KK, Gibbons RD (1998), Psychiatric disorders with onset in the preschool years: II. Correlates and predictors of stable casus status. Journal of American Academy of Child and Adolescent Psychiatry 37: 1255-126 I

Manassis K, Hood J (1998), Individual and familial predictors of impairment in childhood anxiety disorders. Journal of American Academy of Child and Adolescent Psychiatry 37: 428-434

Orlebeke JF, Knol DL, Boomsma DI (1998), Frequency of parental report of problem behavior in children decreasing maternal age at delivery. Psychological Reports 82: 395-404

Reich W (2000), Diagnostic interview for children and adolescents (DICA). Journal of American Academy of Child and Adolescent Psychiatry 39: 59-66

Rozendaal N (1998), Handleiding computer algoritme ADIKA Maastricht: Vakgroep Psychiatrie en Neuropsychology, Universiteit Maastricht

StataCorp (200I), Stata, software for statistical analyses: release 7., College Station, TX: Stata Corporation

Velez CN, Johnson J, Cohen P (1989), A longitudinal analysis of selected risk factors for childhood psychopathology. Journal of American Academy of Child and Adolescent Psychiatry 28: 86I-864

Verhulst FC, Berden GF, Sanders Woudstra JA (1985), Mental health in Dutch children: (II). The prevalence of psychiatric disorder and relationship between measures. Acta psychiatrica Scandinavica Supplementum 324: $1-45$

Verhulst FC, Ende van der J, Koot HM (1996), Handleiding voor de CBCL 4-I8. Rotterdam: Afdeling Kinder en jeugdpsychiatrie, Sophia Kinderziekenhuis/Academisch Ziekenhuis Rotterdam/ Erasmus Universiteit Rotterdam

Welner Z, Reich W, Herjanic B, Jung KG, Amado H (1987), Reliability, validity, and parent-child agreement studies of the diagnostic interview for children and adolescents (DICA). Journal of American Academy of Child and Adolescent Psychiatry 26: 649-653

Williams S, Anderson J, McGee R, Silva PA (1989), Risk factors for behavioral and emotional disorders in preadolescent children Journal of American Academy of Child and Adolescent Psychiatry 29: 4I3-4I9 



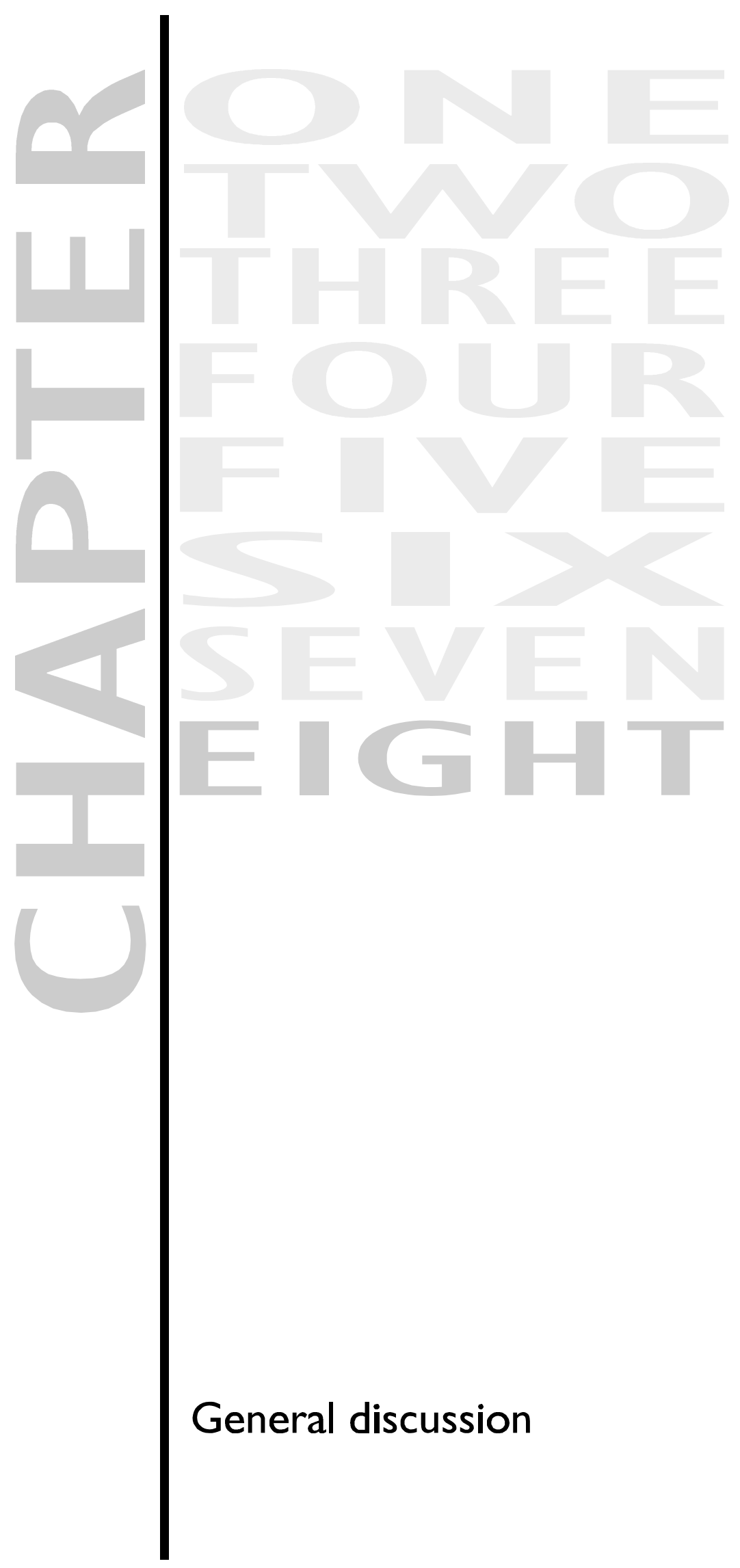



This thesis is focused in the first instance on the early characteristics of Attention Deficit/ Hyperactivity Disorder. In addition, it describes the development of the Maastricht Motor Test (chapter 3) and studies the prevalence rates (chapter 7) and risk factors (chapter 6) for other child psychopathologies. In line with the multidisciplinary purpose of the SAM project, different aspects and precursors of ADHD were studied, namely, motor performance (chapter 4), early behavioural symptoms (chapter 5), social context (chapter 6), CBCL scores (chapter 6), and prevalence estimates (chapter 7). In current chapter we draw the different aspects together and make some recommendations for future research concerning the SAM study and the Maastricht Motor Test.

\section{Maastricht Motor Test}

After 3 years of age especially qualitative aspects of motor performance reflect variation in motor development. Although integrative brain activity and maturation is poorly understood (Farber and Njiokiktjien, 1993), it is assumed that especially qualitative aspects of a movement reflect the maturity and integrity of the brain (Haddes-Algra and Groothuis, 1999; Prechtl et al., 1997). Moreover, clumsiness in preschool children is generally assumed to be a precursor of impaired academic performance, and psychological and developmental problems (Farber and Njiokiktjien, 1993; Wiart and Darrah, 200I). For this reason, our working hypothesis is that clumsiness at preschool age can be considered an underlying symptom of problems that become manifest at school age rather than a separate diagnosis. Research, however, will be needed to confirm or reject this hypothesis. Although in daily clinical practice the qualitative aspects of motor performance are routinely observed, the "outcome" of this observation depends on the experience of the physician. For this reason, the Maastricht Motor Test (chapter 3), an objective instrument, is a step forward in this field. It can be used for clinical practice and for research purposes. The results described in chapter 4 show that weak qualitative movements at 5 to-6-years of age are predictive of ADHD and not of conduct disorder. To what extent motor performance can be used as an indicator for other developmental disorders, however, need to be investigated.

\section{Early identification of ADHD}

In 2000 the Health Council of the Netherlands published their report "Diagnosis and treatment of ADHD” (Gezondheidsraad, 2000). One of the topics of this report concerned prevention, identification, and early intervention. At the moment, little is known about the predictive value of early characteristics of ADHD in the general population (Campbell, 1995; DuPaul et al., 200I; Gezondheidsraad, 2000; Mariani and Barkley, 1997). More insight into which children have a high risk of developing ADHD will lead to earlier interventions, which in turn may influence the natural course of the symptoms (Ghurman et al., 200 I; Rappaport et al., 1998; Sonuga-Barke et al., 200I). For this reason, one of the recommendations made by the Health Council of the Netherlands (Gezondheidsraad, 2000, p 122) is to develop new instruments to facilitate the early identification of children at risk for ADHD. In our opinion, the SAM study, which used a longitudinal design, is eminently suitable for this job. 


\section{Multidisciplinary approach}

As discussed in chapter I of this thesis, the SAM study is a multidisciplinary research project. It examines the precursors of ADHD from different viewpoints. The studies described in this thesis investigated the relation between performance on the Maastricht Motor Test (MMT; Kroes et al., submitted) and ADHD (chapter 3 and 4), the predicted value of the Precursors of ADHD Questionnaire (PAQ; Hendriksen and Steyaert, 1999; Kroes et al., 200I), which investigates early characteristics of ADHD (chapter 5), the influence of psychosocial risk factors (chapter 8), and the predictive value of the Child Behaviour Checklist (CBCL; Verhulst et al., 1996) (sub-)scales (chapter 8) (see figure 8.I). The question remains whether each aspect or feature studied in this thesis has an additional predictive effect independently of the other aspects. In other words, does a multidisciplinary approach contribute to the diagnosis of ADHD or does the predictive value of a certain feature disappear if other features are examined simultaneously?

Figure 8.I Multidisciplinary approach.

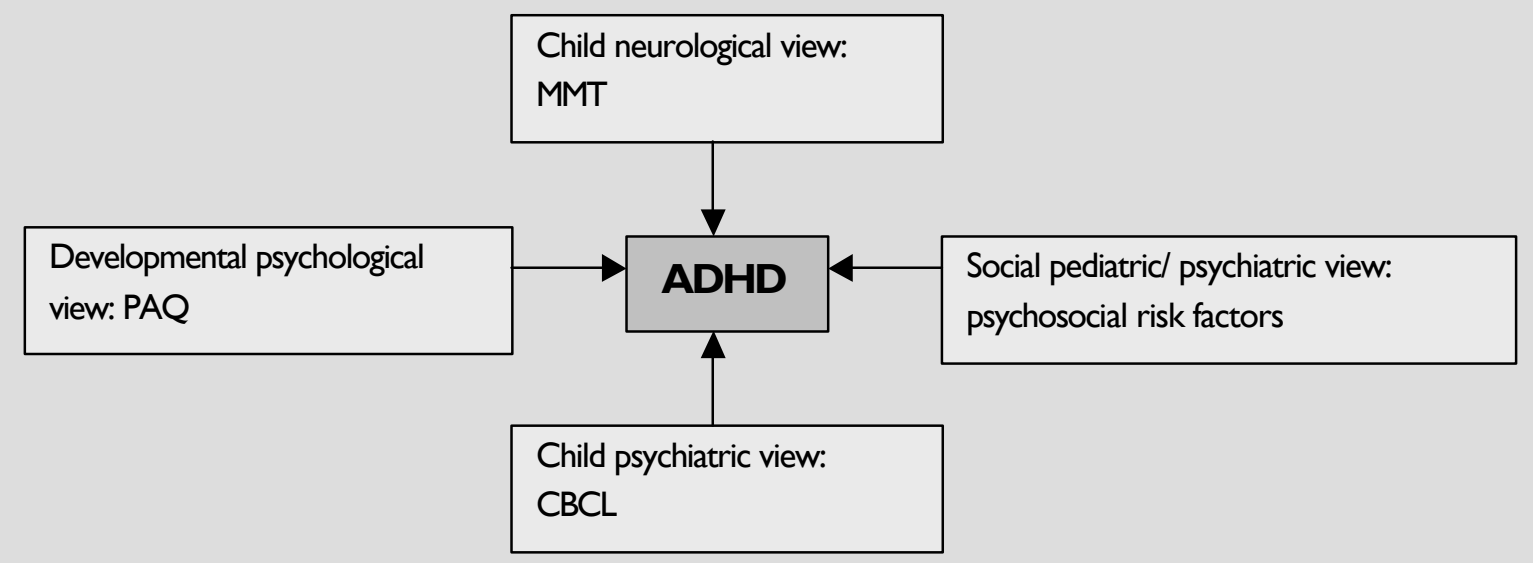

To answer to this question, stepwise logistic regression analyses were performed with STATA (StataCorp, 200I) to calculate the predictive value of individual features, independently of others. As in other analyses described in this thesis, the 'sampling weight option' in STATA was used, which permits adjustment for design characteristics such as the 2-stage sampling. Only significant components identified in the studies described in the preceding chapters were used in the model. 


\section{Do individual features contribute to the diagnosis ADHD? Preliminary findings.}

For easy reference, all independent variables were tri- or dichotomized. Independent variables were the $\mathrm{CBCL}$ subscales: attention problems, and aggressive behaviour ('normal', 'borderline', and 'clinical'); the total qualitative score of MMT (weak: 0-48 versus good: 49-72 points); the PAQ (weak: 9-32 versus good: 0-8 points); maternal age at delivery (according to Orlebeke et al. (1998): >33, 27- 32 and, $\leq 26$ years); life events (yes or no); and professional mental support for the mother (yes or no).

Table 8.I shows the preliminary results of the stepwise logistic regression analyses. From top to bottom variables were entered consecutively at steps I to 4. Except for the psychosocial risk factors (maternal age at delivery, professional mental support for the mother and life event), all other independent variables were included in the final model. This implies that each of these features make its own unique contribution to the diagnosis of ADHD, independently of the other features.

\begin{tabular}{|c|c|c|}
\hline \multirow{2}{*}{$\begin{array}{l}\text { Table 8. I } \\
\text { Features }\end{array}$} & \multicolumn{2}{|c|}{ prediction of ADHD in this } \\
\hline & OR & $95 \% \mathrm{Cl}$ \\
\hline $\begin{array}{l}\text { CBCL subscale: aggression } \\
\text { Clinical versus normal range }\end{array}$ & 6.7 & $2.0-22.8$ \\
\hline $\begin{array}{l}\text { MMT total qualitative score } \\
0-48 \text { versus } 49-72 \text { points }\end{array}$ & 7.2 & $2.8-18.4$ \\
\hline $\begin{array}{c}\text { CBCL subscale: attention problems } \\
\text { Clinical versus normal range }\end{array}$ & 8.7 & $1.8-41.9$ \\
\hline $\begin{array}{l}\text { PAQ total scale } \\
\quad 9-32 \text { versus } 0-8 \text { points }\end{array}$ & 9.3 & $2 .|-4| .5$ \\
\hline
\end{tabular}

A predicted probability (chance for ADHD based on the model used) can be calculated for each combination of test results. For example, without any additional investigations, the chance of ADHD is similar to the prevalence of the disorder reported in chapter 7, namely, 3.8 \% (Kroes et al., 200I). A clinically relevant score on the CBCL subscale "Aggression", however, increases this chance to $37.8 \%$. If children also have a poor qualitative motor score, the chance of ADHD increases to $58.6 \%$. Finally, a combination of poor results on tests for each of the investigated features yields a chance of $89.3 \%$. This impressive percentage, however, may give a distorted picture because only $7 \%$ of all children with ADHD had this combination of only poor results. In other words, a high predicted probability is accompanied by a high specificity but a low sensitivity, and a low predicted probability is accompanied by a high sensitivity and a low specificity. 
This is illustrated in the ROC curve (figure 8.2) for the model given in table 8.I. Each combination of test results yields a predicted probability which can be read off from the ROC curve. The right upper corner represents the highest predicted probability and the left under corner the lowest predicted probability.

Figure $8.2 \quad$ ROC curve

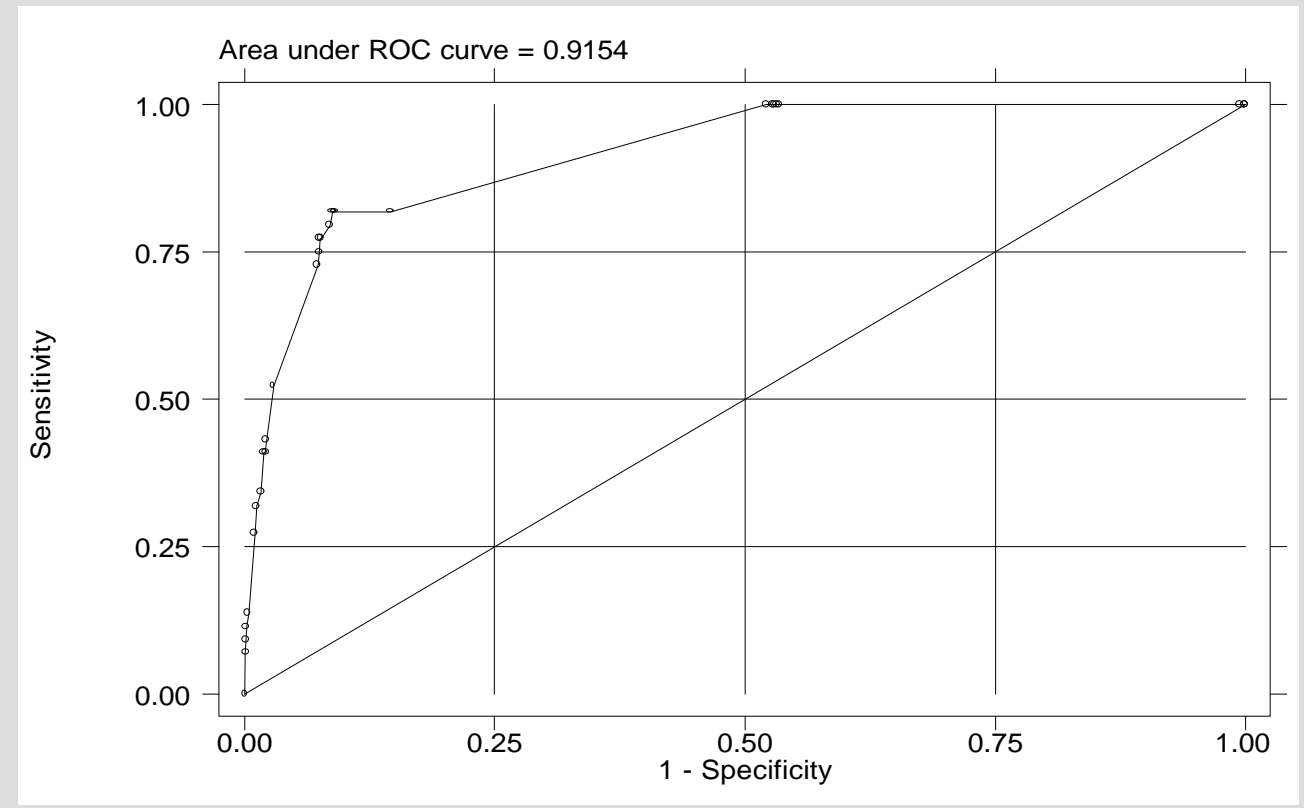

\section{A multidisciplinary approach to facilitate early characteristics of ADHD}

With the exception of psychosocial risk factors, all other investigated features at kindergarten age independently predict ADHD at school entry. Although psychosocial risk factors in this model do not independently predict ADHD, we assume that these factors may play an important mediating role in the course of the disorder. For this reason investigation of early risk factors is still very important. Moreover, as suggested by Hermanns and Leu (1998), the effect of the risk factors in psychopathology is not only determined by its content or severity, but mainly by its number. Concerning this risk accumulation concept, it would be interesting to examine predictive value of various numbers of risk factors. It is well possible that this approach would lead to independent contribution. Multidisciplinary approach, therefore, should be used when trying to improve the early identification of children at risk of ADHD. These findings can be interpreted in terms of developmental psychiatry. Within the field of developmental psychiatry, development represents a crucial link between genetic determinants and environmental variables. Modern views of development now include the importance of interactions between biology and the environment, and the necessity of integrating vertical, horizontal and longitudinal levels of analysis in order to understand an organism (Eisenberg, 1995; Munir and Beardslee, 1999). This developmental perspective can also lead to the formulation of preventive interventions, 
to be used before disorders emerge, based on an understanding of the development and the causal mechanisms involved.

Within this framework, the Youth Health Care (YHC), in particular, could play a central role in identifying children at risk for ADHD. This national organization is responsible for performing periodic systemic health examinations of all kindergarten children in a region (population based). This health check integrates information from different disciplines. Besides a physical examination (including motor performance), psychological and social features are also investigated. For this reason, these doctors could make an important contribution to the early identification of children at risk of ADHD (see also Gezondheidsraad, 2000). This, in turn, will facilitate early reference and could create the possibility for early intervention which may prevent further difficulties (Sonuga-Barke et al., 2001 ; Feron et al., in press).

\section{Further research SAM study}

As mentioned in chapter I, this thesis is part of the SAM study. For this reason, the model described above cannot be considered definitive. The creation of an optimal model requires the integration of information from the entire SAM study. Extra information (e.g. perinatal complications, neuropsychological functioning,(Kalff et al., submitted; Hurks et al., submitted) accumulation of psychosocial risk factors) may strengthen the model. Furthermore, in the current thesis, ADHD was defined according to the Amsterdam Diagnostic Interview for Children and Adolescents (ADIKA; Kortenbout van der Sluijs et al., 1993), which was revised by Westereich (1998) on the basis of the criteria of DSM-IV (American Psychiatric Association, 1994). Only information provided by the parents was used to diagnose ADHD. In order to increase the accuracy of the diagnosis, however, a combination of child, teacher, and parent information should be used in future research (Applegate et al., 1997; Bird et al., 1992; Gomes et al., 1999). In addition, the follow up (stage 4, see chapter I) will provide important information. In the current thesis, ADHD was diagnosed at school entry. It is possible that at this stage in particular children show characteristics of ADHD not because they have the disorder but as a reaction to the transition of leaving kindergarten and going to school. Follow-up of the children will show whether a certain behaviour is transient or not. Thus while this thesis provides a promising start, the end has not been reached yet. Future publications of the SAM study may provide additional information that can be used to define precursors of ADHD in a general population.

\section{Acknowledgements}

We thank Dr. G. ter Riet for his assistance with the statistical analyses. 


\section{REFERENCES}

Applegate B, Lahey BB, Hart EL, Biederman J, Hynd GW, Barkley RA, Ollendick T, Frick PJ, Greenhill L, McBurnett K, Newcorn JH, Kerdyk L, Garfinkel B, Waldman I, Shaffer D (1997), Validity of the age-ofonset criterion for ADHD: a report from the DSM-IV field trials. Journal of American Academy of Child and Adolescent Psychiatry 36: |2| I-21

American Psychiatric Association (1994), Diagnostic and Statistical Manual of Mental Disorders. 4th edition Washington D.C.: American Psychiatric Association

Bird HR, Gould MS, Staghezza BMPH (1992), Aggregating Data from Multiple Informants in Child Psychiatry Epidemiological Research. Journal of American Academy of Child and Adolescent Psychiatry 31: 78-85

Campbell SB (1995), Behavior Problems in Preschool Children: A review of Recent Research. Journal of Child Psychology and Psychiatry and Allied Disciplines 36: I13-149

DuPaul GJ, McGoey KE, Eckert TL, VanBrakle J (200I), Preschool children with attention deficit hyperactivity disorder: impairments in behavioral, social, and school functioning. Journal of American Academy of Child and Adolescent Psychiatry 40: 508-5I5

Eisenberg L (1995), The social construction of the human brain. American Journal of Psychiatry 152: 1563-1575

Farber D, Njiokiktjien C (1993), Developing brain and cognition. Ist edition, Vol. 4 Amsterdam: Suyi Publications

Feron FJM, Hendriksen JGM, Vles JSH (in press), Transmuraal ADHD-spreekuur jeugdgezondheidszorg: een samenwerkingsmodel in de regio Zuidelijk Zuid-Limburg. Nederlands Tijdschrift voor Jeugdgezondheidszorg.

Gezondheidsraad [Health Council of the Nederlands] (2000), Diagnostiek en behandeling van ADHD [Diagnosis and treatment of $A D H D]$. The Hague

Ghurman JK, Ginsburg GS, Subramaniam G, Ghuman HS, Kau ASM, Riddle MA (200I), Psychostimulants in preschool children with attention deficit/hyperactivity disorder: clinical evidence from a developmental disorder institution. Journal of American Academy of Child and Adolescent Psychiatry 40: 516-524

Gomes R, Harvey J, Quick C, Scharer I, Harris G (1999), DSM-4 AD/HD: Confirmatory Factor Models, Prevalence and Gender and Age Differences Based on Parent and teacher Ratings of Australian Primary School Children. Journal of Child Psychology and Psychiatry and Allied Disciplines 40: 265-274

Haddes-Algra M, Groothuis AMC (1999), Quality of general movements in infancy is related to neurological dysfunction, ADHD, and aggressive behaviour. Developmental Medicine \& Child Neurology 4I: 38I-39I

Hendriksen JGM, Steyaert J (1999), Ontwikkeling van de Vragenlijst Voorlopers ADHD. Interne publicatie, Academisch Ziekenhuis Maastricht

Hermanns J, Leu HR (1998), Family risk and family support, theory, research and practice in Germany and in the Netherlands. Delft: Eburon

Hurks PPM, Hendriksen JGM, Vles JSH, Kalff AC, Feron FJM, Kroes M, van Zeben TMCB, Steyaert J, Jolles J (submitted) Verbal fluency over time as a measure of automatic and controlled retrieval processes in ADHD: data embedded in a longitudinal cohort study.

Kalff AC, Hendriksen JGM, Kroes M, Vles JSH, Steyaert J, Feron FJM, van Zeben TMCB, Jolles J. Neuropsychological predictors of Attention Deficit/Hyperactivity Disorder: Results from a prospective population study in 5 and 6 year old children. Journal of Abnormal Child Psychology, under revision. 
Kortenbout van der Sluijs MJ, Levita MJ, Manen de R, Defares BP (1993), ADIKA, Amsterdams diagnostisch interview voor kinderen en adolescenten. Handleiding vragenlijst, vragenlijst ouder/verzorger. Lisse: Swets \& Zeitlinger

Kroes M, Hendriksen JGM, Steyaert J, Kalff AC, Feron FJM, van Zeben TMCB, Jolles J, Troost J, Vles JSH (200I), Vragenlijst Voorlopers ADHD: Ontwikkeling en enkele psychometrische kenmerken [Precursors of ADHD questionnaire: development and some psychometric features]. Kind en Adolescent I: 22-35

Kroes M, Vissers YLJ, Sleypen FAM, Feron F, Kessels AGH, Bakker E, Kalff AC, Hendriksen JGM, Steyaert J, van Zeben TMCB, Jolles J, Troost J, Vles JSH (submitted), Reliability and validity of a qualitative and quantitative motor test for kindergarten children.

Kroes M, Kalff AC, Steyaert J, Kessels AGH, Feron FJM, v.Someren AJWGM, Hurks PPM, Hendriksen JGM, v.Zeben TMCB, Rozendaal N, Crolla IFMA, Jolles J, Troost J, Vles JSH (200I), Child Psychiatric diagnoses generalized to a population of Dutch school children aged 6 to 8 years. Journal of American Academy of Child and Adolescent Psychiatry 40: I40I-I409

Mariani MA, Barkley RA (1997), Neuropsychological and academic functioning in preschool boys with attention deficit hyperactivity disorder. Developmental Neuropsychology I 3: I I I-129

Munir KM, Beardslee WR (1999), Developmental Psychiatry: Is there any other kind? Harvard Revised Psychiatry 6: $250-262$

Orlebeke JF, Knol DL, Boomsma DI (1998), Frequency of parental report of problem behavior in children decreasing maternal age at delivery. Psychological Reports 82: 395-404

Prechtl HF, Einspieler C, Cioni G, Bos AF, Ferrari F, Sontheimer D (1997), An early marker for neurological deficits after perinatal brain lesions. The Lancet 349: 136।-3

Rappaport GC, Ornoy A, Tenenbaum A (1998), Is early intervention effective in preventing ADHD? The lsrael Journal of Psychiatry and Related Science 35: $271-9$

Sonuga-Barke EJS, Daley D, Thompson M, Laver-Bradbury C, Weeks A (200I), Parent-based therapies for preschool attention deficit hyperactivity disorder: a randomized controlled trial with a community sample. Journal of American Academy of Child and Adolescent Psychiatry 40: 402-408

StataCorp (200I), Stata, software for statistical analyses: release 7., College Station, TX: Stata Corporation

Verhulst FC, Ende van der J, Koot HM (1996), Handleiding voor de CBCL 4-I8 Rotterdam: Afdeling Kinder en jeugdpsychiatrie, Sophia Kinderziekenhuis/Academisch Ziekenhuis Rotterdam/ Erasmus Universiteit Rotterdam

Westereich (1998), Amsterdams Diagnostisch Interview voor Kinderen en Adolescenten, ADHD-deel o.b.v. DSM-IV [Amsterdam Diagnostic Interview for Children and Adolescents, ADHD-part of DSM-IV criteria]. Brussels: Vrije Universiteit

Wiart L, Darrah J (200I), Review of four tests of gross motor development. Developmental Medicine \& Child Neurology 43: 279-285 



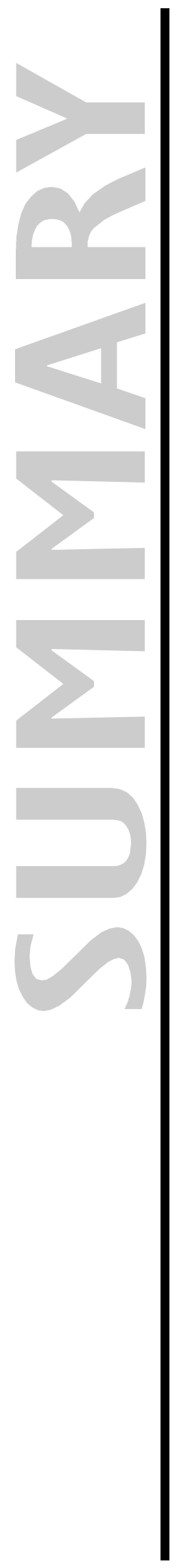



Attention-Deficit/ Hyperactivity Disorder (ADHD) is an early onset, clinically heterogeneous disorder of inattention, hyperactivity, and impulsivity. Although it is generally assumed that ADHD has its basis in the early years, it is usually first diagnosed during elementary school years. A problem with attempting to diagnose ADHD in children younger than 6 years is that much of the behaviour that is considered problematic at an older age falls within the limits of what is normal for toddlers or kindergarten children. To increase our knowledge about the developmental profile and risk factors for ADHD at 5 to-6-years of age, a multidisciplinary prospective research on kindergarten children was started in 1996; "the Study of Attention disorders in Maastricht (SAM-study)". This thesis described part of this prospective study and focused on motor performance, early behavioural characteristics, social context and prevalence rates of ADHD. In addition attention was given to prevalence rates and risk factors for other child psychopathology.

Chapter I provides the rationale of the research described in this thesis and outlines its content. It is clear that although a tremendous amount of research has been published on children with ADHD, the vast majority of this research has involved school-age children. Prospective community studies involving younger children are needed to promote early identification.

Chapter 2 presents a concise review of literature and focused on general aspects of ADHD, its aetiology, and associated problems. Special attention is paid to motor performance its relation to ADHD and because its known that dopaminergic neurotransmission is involved in both ADHD and sensorimotor integration, our hypothesis is that analysis of especially the qualitative aspects of a movement can help in early diagnosis for children at risk of ADHD.

Chapter 3 described the development of the Maastricht Motor Test. This test was developed to objectify and score both quantitative and qualitative aspects of different movements in 5 to-6-year-old children. A number of 487 subjects were recruited from year one of primary schools. To validate the test, the school doctor's global judgement was used as a form of expert validity. Sensitivity and specificity values are calculated for different cutoff points. Intraclass correlation coefficients (ICC) of inter-rater $(\mathrm{N}=42)$, intra-rater $(\mathrm{N}=24)$ and test-retest $(\mathrm{N}=43)$ agreement, were determined. ICCs of the qualitative total score range from 0.61 to 0.95 and are comparable with those of the total quantitative score. We concluded that the Maastricht's Motor Test proved to objectify both qualitative and quantitative aspects of movements.

Chapter 4 studied the utility of the Maastricht Motor Test to identify precursors of ADHD. Aims of this study were (I) to examine whether quantitative and/or qualitative aspects of motor performance in 5-to 6-year-old children can predict ADHD at later stage. (2) To investigate if this relation is also present in ADHDs' comorbid conduct disorder (CD). 
Opposed to quantitative aspects of motor performance, qualitative aspects turned out to predict ADHD. Concerning CD, motor performance was not predictive. Where behavioural characteristics appear not to be sufficient to distinguish between children with ADHD or not at an early age, examining the qualitative aspects of a movement as precursors of ADHD may be of additional value in the early identification of kindergarten children at risk of ADHD.

Chapter 5 described the development of the Precursors of ADHD Questionnaire. This questionnaire focuses on the early behavioural characteristic of ADHD. Factor analysis, in a group of 1317 pre-school children, reduced the questionnaire to 16 questions divided in four domains: socially inadequate behaviour, impulsivity, hyperactivity, and inattention. The instrument proved to be a reliable and valid test for the early detection of pre-school children at risk of ADHD. The use of this questionnaire will facilitate the early detection of kindergarten children at risk of ADHD.

Chapter 6 presents the prevalence and co-morbidity rates of child psychiatric diagnoses in a school-based population of children aged 6-8 in the south of the province of Limburg (the Netherlands). In a two-stage design 1317 children were screened using the Child Behavior Checklist (CBCL). From 403 of these children, child psychiatric information was obtained using the Amsterdam Diagnostic Interview for Children and Adolescents (ADIKA, DSM-IIIR/ IV). Data were generalized to the responder group $(N=|3| 7)$ and to the entire cohort $(\mathrm{N}=2290)$. For the latter procedure, a prediction model was used to generalize ADIKA results to the non-responders $(\mathrm{N}=973)$. Twenty-four percent of the entire cohort met criteria for a single disorder and $21.0 \%$ met criteria for two or more disorders. However, in only $5.7 \%$ of the cases parents did report a need for help.

Chapter 7 examine the extend to which certain risk factors in 5-to 6-year-old children predict later psychopathology in a population-based sample of children in the south of the province of Limburg (the Netherlands). Psychosocial risk factors and Child Behavior Checklist $(\mathrm{CBCL})$ scores were collected in a selected community sample of 5-and 6-year old children $(\mathrm{N}=403)$. One and a half years later, standardized psychiatric information was obtained. Weighted analyses were used in logistic regression analyses to investigate predictive values. Separate psychosocial risk factors made a unique contribution to specific child psychopathology. Furthermore, CBCL-based ratings at 5-6 years of age corresponded well with interview-defined diagnoses one and a half years later. We concluded that investigation of psychosocial risk factors and $\mathrm{CBCL}$ scores at the age of 5-6 could be helpful in predicting of child psychopathology and could help identify children at risk, who could receive timely attention.

Chapter 8 investigated the effect of integration of separate features and noted some recommendations for future research concerning the SAM study and the Maastricht Motor 
Test. The results showed that risk factors from several fields in kindergarten children each have their own unique contribution to ADHD in later years, independently from each of the others. For this reason we may advice a multidisciplinary approach to enhance early identification of children at risk of ADHD. In this framework, we feel that especially the Youth Health Care (YHC) could play a central role. Future research should be focused on follow-up of the children, and information of teachers, parents and children themselves will contribute to their final outcome. Concerning the Maastricht Motor Test we feel that future research should focus to what extend motor performance can be used as precursor for other developmental disorders as well. 



$$
\mid
$$



Aandachtstekortstoornis met hyperactiviteit (ADHD) is een klinische heterogene stoornis van aandachtsproblemen, hyperactiviteit en impulsiviteit. Ondanks dat men het er in het algemeen over eens is dat ADHD al op jonge leeftijd als volwaardig syndroom bestaat, wordt de stoornis meestal pas gediagnosticeerd als het kind in groep 3 (of verder) van de basisschool zit. Een probleem bij het vaststellen van de diagnose vóór de leeftijd van 6 jaar is, dat een groot deel van het later als problematisch beschouwde gedrag op de peuter-l kleuterleeftijd nog binnen de grenzen van het normale valt. Om onze kennis over het ontwikkelingsprofiel en de risicofactoren voor ADHD op kleuterleeftijd te vergroten, is men in Maastricht, in 1996, gestart met een multidisciplinair, longitudinaal onderzoek bij kleuters: "De Studie naar Aandachtsstoornissen in Maastricht (SAM-studie)". Dit proefschrift beschrijft een deel van dit onderzoek en richt zich met name op het motorisch functioneren, de vroege gedragskarakteristieken, de psychosociale aspecten en de prevalentie van ADHD. Daarnaast wordt ingegaan op de prevalentie cijfers en de risicofactoren voor andere vormen van psychopathologie.

In hoofdstuk I wordt ingegaan op de grondgedachte van het onderzoek en wordt de inhoud van het proefschrift beschreven. Ondanks de grote hoeveelheid aan publicaties met betrekking tot ADHD, wordt duidelijk dat het grootste gedeelte hiervan ingaat op de stoornis bij kinderen ouder dan 7 jaar. Longitudinale epidemiologische studies bij jongere kinderen zijn nodig om de vroege opsporing van deze kinderen te bevorderen.

In hoofdstuk 2 wordt een beknopt overzicht gegeven van de literatuur waarbij met name wordt ingegaan op de algemene aspecten van ADHD, de etiologie en de geassocieerde problemen. Speciale aandacht wordt besteed aan het motorisch functioneren en haar mogelijke relatie met ADHD. Omdat men weet dat de dopaminerge neurotransmissie een rol speelt bij zowel ADHD als bij de sensomotorische integratie, veronderstellen wij dat het bestuderen van met name de kwalitatieve aspecten van het bewegen behulpzaam kunnen zijn bij de vroege diagnostiek van kinderen met een risico voor ADHD.

In hoofdstuk 3 wordt de ontwikkeling van de Maastrichtse Motoriek Test beschreven. Deze test is ontwikkeld om zowel de kwantitatieve als de kwalitatieve aspecten van het bewegen bij 5 en 6 jaar oude kinderen te objectiveren. Aan dit onderzoek namen 487 kinderen uit groep 2 van de reguliere basisschool deel. Om de test te valideren werd het oordeel van de schoolarts, ten aanzien van het motorisch functioneren van het kind, gebruikt als uitkomstmaat. De sensitiviteit en specificiteit van de test werd berekend voor de verschillende afkappunten. De "Intraclass correlatie coëfficient (ICC)" van de interwaarnemer variantie $(N=42)$, de intrawaarnemer variantie $(N=24)$ en de test-hertest $(\mathrm{N}=43)$ werden gebruikt als maat voor de betrouwbaarheid. De ICC van de totale kwalitatieve score varieert van 0.61 tot 0.95 en komt overeen met die van de totale kwantitatieve score. We concluderen dat de Maastrichtse Motoriek Test gebruikt kan worden voor het objectiveren van zowel de kwantiteit als de kwaliteit van het bewegen. 
In hoofdstuk 4 wordt ingegaan op de bruikbaarheid van de Maastrichtse Motoriek Test voor het identificeren van kleuters at risk voor ADHD. De doelen van deze studie waren: (I) nagaan of het kwantitatieve en/ of kwalitatieve aspect van het motorisch functioneren op kleuterleeftijd, ADHD op oudere leeftijd kan voorspellen. (2) onderzoeken of een eventuele relatie ook bestaat voor de veel voorkomende comorbiditeit van ADHD: de gedragsstoornis. De kwalitatieve aspecten van het motorisch functioneren op kleuterleeftijd voorspellen ADHD. Dit geldt niet voor de kwantitatieve aspecten. Met betrekking tot de gedragsstoornis was het motorisch functioneren niet voorspellend. Waar enkel gedragskarakteristieken op jonge leeftijd blijkbaar niet altijd een onderscheid kunnen maken tussen kinderen met en zonder ADHD, kan het bestuderen, van de kwalitatieve aspecten van het bewegen op deze leeftijd een toegevoegde waarde hebben bij de vroege opsporing van kleuters die een verhoogd risico lopen op het ontwikkelen van ADHD.

In hoofdstuk 5 wordt de ontwikkeling van de Vragenlijst Voorlopers ADHD beschreven. Deze vragenlijst richt zich op de vroege gedragskenmerken van ADHD. Door middel van principale componentenanalyse bij een groep van 1317 kleuters uit groep 2 van het reguliere basisonderwijs, werd de vragenlijst gereduceerd van 32 tot 16 items. Deze waren verdeeld over 4 domeinen: sociaal inadequaat gedrag, impulsiviteit, hyperactiviteit en aandachtsproblemen. Het onderzoek laat zien dat het instrument een betrouwbare en valide bijdrage levert aan de opsporing van kleuters met een verhoogde kans op het ontwikkelen van ADHD.

In hoofdstuk 6 wordt de prevalentie van kinderpsychiatrische stoornissen en hun comorbiditeit voor kinderen van 6 tot 8 jaar op de reguliere basisscholen in zuidelijk zuidLimburg (Nederland) gepresenteerd. Het onderzoek werd uitgevoerd in twee fasen. In de eerste fase werden 1317 kinderen gescreend met de "Child Behavior Checklist (CBCL)". Van deze groep werd bij 403 kinderen kinderpsychiatrische informatie verkregen via het "Amsterdams Diagnostisch Interview voor Kinderen en Adolescenten (ADIKA, DSM-IIIR/ IV). Data werden gegeneraliseerd naar de gehele groep van responders $(N=|3| 7)$ en naar het gehele cohort $(\mathrm{N}=2290)$. Voor deze laatste procedure werd gebruik gemaakt van een voorspellingsmodel om de resultaten van de ADIKA te generaliseren naar de groep van nonresponders $(\mathrm{N}=973)$. Vierentwintig procent van het gehele cohort had de criteria voor één enkele stoornis en $21.0 \%$ had de criteria voor twee of meer stoornissen. Toch rapporteerde slechts $5.7 \%$ van de ouders dat zij hulp nodig hadden bij het opvoeden en begeleiden van hun kind.

In hoofdstuk 7 wordt de waarde van het bepalen van bepaalde risicofactoren bij 5 en 6 jaar oude kinderen binnen het reguliere onderwijs en hun relatie met psychopathologie op latere leeftijd bestudeerd. Psychosociale risicofactoren en de "Child Behavior Checklist (CBCL)" werden verzameld bij een groep van 403 kleuters uit groep 2. Anderhalf jaar later werd 
gestandaardiseerde psychiatrische informatie van deze groep verkregen. Door middel van een gewogen logistische regressie werd de voorspellende waarde van de verschillende risicofactoren berekend. De afzonderlijke psychosociale risicofactoren hebben een unieke bijdrage aan specifieke diagnoses. Ook de CBCL uitkomsten op kleuterleeftijd komen voor een groot deel overeen met de psychopathologie anderhalf jaar later. Wij concludeerden dat het inventariseren van psychosociale risicofactoren en de $C B C L$ vragenlijsten op 5 en 6 jarige leeftijd kan helpen bij het identificeren van kinderen "at risk". Het lijkt verstandig deze groep kinderen nadrukkelijk te volgen en te begeleiden.

In hoofdstuk 8 wordt het effect beschreven van de intergratie van de verschillende hoofdkenmerken zoals beschreven in de voorgaande hoofdstukken van dit proefschrift. Daarnaast beschrijft dit hoofdstuk aanbevelingen voor verder onderzoek met betrekking tot de SAM-studie en de Maastrichtse Motoriek Test. Het resultaat laat zien dat de karakteristieken van de verschillende invalshoeken op kleuterleeftijd hun eigen unieke bijdrage leveren bij het inventariseren van risicofactoren voor ADHD. Om deze reden adviseren wij een multidiciplinaire aanpak met het doel vroege onderkenning van kinderen, "at risk" voor ADHD, te bevorderen. Binnen dit bestek denken wij dat met name de Jeugd Gezondheids Dienst een centrale rol zou moeten innemen. Toekomstig onderzoek zal zich richten op de follow-up van deze kinderen en de informatie van zowel de ouders, de kinderen als de leerkrachten zal moeten worden meegenomen bij de uiteindelijke uitkomst. Met betrekking tot de Maastrichtse Motoriek Test zal toekomstig onderzoek ingaan op de vraag of deze test ook bruikbaar is bij het opsporen van andere ontwikkelingsstoornissen dan ADHD. 



$$
\mid
$$



Promoveren is een eenzame klus.

Echter, zonder de steun van een groot aantal mensen had dit proefschrift hier niet gelegen. Graag zou ik hierbij een aantal van hen met name noemen.

Prof. dr. Vles, beste Hans, ik vind het een grote eer je eerste promovenda te zijn en ik denk dat we dit, enigszins "uit de hand gelopen" student-assistentschap, tot een goed einde hebben gebracht. Zelden ontmoette ik iemand die zo, soms beangstigend direct, eerlijk, helder en duidelijk is. Dank voor de fijne samenwerking, je betrokkenheid, je bezorgdheid en begeleiding. Ik hoop dat onze "Maastrichtse Motoriek Test" een groot succes zal worden.

Lieve Ariane, Inge en Petra, het was een groot geluk jullie als directe collega's te hebben. Ariane Tjeenk, als "grondlegger" van het SAM-project ben je de basis van iets groots. Je steun was heel belangrijk voor me. Ik ben blij dat je straks naast me wilt staan en hoop binnenkort ook op jouw feest aanwezig te mogen zijn!

Inge Crolla, je "pietluttige precisie" en gedrevenheid hebben de SAM data tot een "goudmijntje" gemaakt. We kunnen ons geen betere onderzoeksassistent wensen. Het is een eer dat je mijn paranimf bent.

Petra Hurks, dank voor je dagelijkse steun en enthousiasme voor de wetenschap! Heel veel succes met jouw afrondingen.

Een speciaal woord van dank richt ik graag tot Frans Feron en de schoolartsendienst. Jullie bijdrage aan het SAM project is enorm. De gastvrijheid op jullie afdeling een feest.

Tevens wil ik graag de kleuters (inmiddels bijna tieners), hun ouders en de leerkrachten noemen. Zonder hen geen onderzoek, geen resultaten, geen proefschrift. Mijn dank is groot.

Beste Fons Kessels, hoeder van de waarheid. Helaas bleek het onmogelijk je tot copromotor te benoemen. Je zou het qua inspanning, betrokkenheid en bijdrage zeker hebben verdiend. Ik hoop dat je genoegen neemt met de titel Co-pro-io

De SAM-stuurgroep. Beste Jelle Jolles, Thea van Zeben, Jean Steyaert, Jos Hendriksen, Hans Vles en Frans Feron. Het was boeiend deel te mogen uitmaken van jullie werkgroep. De ervaring, dat een goede samenwerking niet altijd zómaar vanzelfsprekend is, was leerzaam voor mij. Toch ligt hier het eerste proefschrift uit een reeks die volgen gaat en tot stand komt uit het bundelen van jullie kundigheid op verschillende terreinen. Zoals ook één van mijn stellingen aangeeft: Door wrijving ontstaat glans!!

In het bijzonder wil ik bedanken mijn tweede promotor Prof. dr. Jolles en mijn co-promotor Dr. Hendriksen. Beste Jelle, ik bewonder je enthousiasme en creativiteit. Steeds weer voorzag je m'n eerste versies van opbouwende kritiek. Dank voor de steun die je me gaf. Beste Jos, na het uitkomen van mijn eerste artikel vond jij dat we hierop een borrel moesten drinken. Juist deze kleine dingen gaven het onderzoek doen iets extra's. Dank voor je betrokkenheid. 
Voor het testen van de kinderen, het interviewen van de ouders, het verwerken en invoeren van de gegevens hebben we enorm veel steun gehad van een groot aantal stagiaires, studenten en (tijdelijke) medewerkers. Met name wil ik noemen: Astrid van Someren, Wendy Candel, Elke Bollen, Tatjana Seute, Vivianne Bouwmans, Martijn en Erik Feron. In het bijzonder wil ik bedanken: Yvonne Vissers, voor het zeer grote aantal kleuters dat je testte met onze veelbelovende "Maastrichtse Motoriek Test"; het paradepaardje van dit onderzoek.

Voor het tot stand komen van deze test en zijn prachtige vormgeving wil ik in aanvulling op een aantal mensen die ik reeds noemde ook Frans Sleijpen, David Vles, Wil Bleus, Robin Janse en Geertjan van Zonneveld hartelijk danken.

Nico Rozendaal. Je logistieke ondersteuning in het hele computergebeuren was van groot belang bij het opzetten van onze database. Het programmeren van het ADIKA algoritme was voor jou een enorme klus en voor ons een essentiële bijdrage!

Mw. Sykes en mijn vroegere lerares Engels, Mw. Riedel, wil ik graag danken voor hun bijdrage om dit proefschrift tot een leesbaar engels geheel te maken. Desirée Breuer en Thera van Lieshout voor secretariële ondersteuning, wanneer en waar dan ook.

Prof dr J. Troost. Vanaf de zijlijn, maar toch betrokken, volgde u mijn onderzoek als hoofd van de vakgroep neurologie. Dank voor uw vertrouwen.

Het werken aan dit proefschrift was een leerzaam proces. Een van de dingen die ik zeker heb geleerd is, dat ik niet primair een onderzoeker ben.

Beste Pieter van de Ven, jij leerde me het huisartsenvak waarderen. De dinsdagen, waarop ik mee mocht werken in jouw praktijk vormden een wekelijks feest en gaven me een groot deel van de energie voor het afronden van dit proefschrift. Pieter, Nance en len, dank voor jullie gastvrijheid!

Van mijn vrienden wil ik er één in het bijzonder noemen. Lieve Margreet, jouw positieve kijk op het leven maakt alles heel betrekkelijk. Mijn boekje is af. Dat van jou is zeker zo boeiend en ik hoop dat ook dat binnenkort wordt uitgegeven...

Pap en Mam, dank voor jullie onvoorwaardelijke steun en vertrouwen. Hoewel het niet altijd te volgen was waren jullie altijd nieuwsgierig naar de vorderingen van mijn boekje. Het is af en het is voor jullie.

Lieve Bas,

Om... daarom! ;-) 


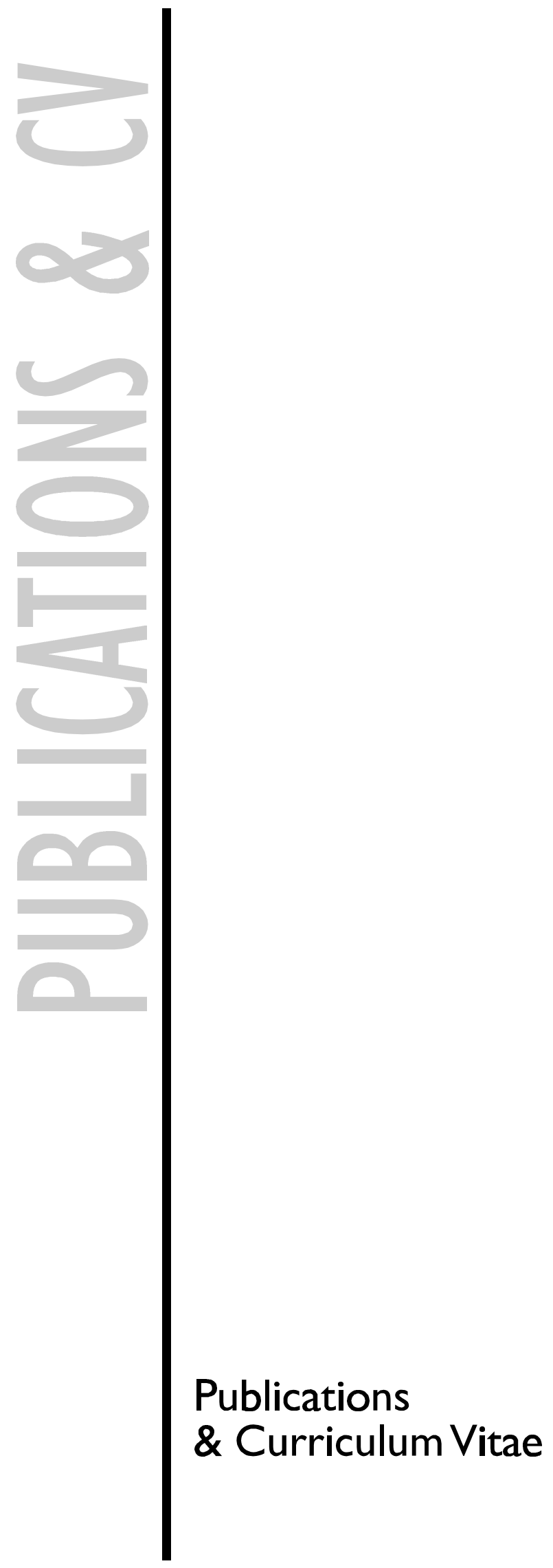





\section{This thesis is based on the following publications}

\section{Chapter 3}

Kroes M, Vissers Y, Sleypen FAM, Feron F, Kessels AGH, Bakker E, Kallf AC, Hendriksen JGM, Steyaert J, van Zeben TMCB, Jolles J, Troost J, Vles JSH Reliability and validity of a qualitative and quantitative motor test for children at kindergarten age. Submitted for publication.

\section{Chapter 4}

Kroes M, Kessels GH, Kalff AC, Feron FJM, Vissers Y, Jolles J, Vles JSH. Quality of movement as predictor of Attention Deficit / Hyperactivity Disorder: Results from a prospective population study in 5-and 6-year-old children, Developmental Medicine \& Child Neurology, under revision.

\section{Chapter 5:}

Based on the revised and adapted version of:

Kroes M, Hendriksen JGM, Steyaert J, Kallf AC, Feron FJM, van Zeben TMCB, Jolles J, Troost J, Vles JSH (200I) Vragenlijst Voorlopers ADHD: Ontwikkeling en enkele psychometrische kenmerken [precursors of ADHD questionnaire: development and some psychometric features]. Kind en Adolescent I: 22-35.

\section{Chapter 6:}

Kroes M, Kalff AC, Steyaert J, Kessels AGH, Feron FJM, v.Someren AJWGM, Hurks PPM, Hendriksen JGM, v.Zeben TMCB, Rozendaal N, Crolla IFMA, Jolles J, Troost J, Vles JSH (200I), Child psychiatric diagnoses in a population of Dutch schoolchildren aged 6 to 8. Journal of American Academy of Child and Adolescent Psychiatry 40: I40 I-I 409

\section{Chapter 7:}

Based on the slightly adapted version of:

Kroes M, Kalff AC, Steyaert J, Kessels AGH, Feron FJM, Hendriksen JGM, v.Zeben TMCB, Jolles J, Troost J, Vles JSH. A longitudinal community study: do psychosocial risk factors and $\mathrm{CBCL}$ scores at 5 to 6 years of age predict psychiatric diagnoses at a later stage? Journal of American Academy of Child and Adolescent Psychiatry, under revision. 


\section{Publications outside this thesis}

Kalff A, Kroes M, Vles J, Bosma H, Feron F, Hendriksen J, Steyeart J, Zeben T, Crolla I, Jolles $J(200 \mathrm{I})$, Factors affecting the relation between parental education as well as occupation and problem behaviour in Dutch kindergarten children. Social Psychiatry and Psychiatric Epidemiology 36: 324-331

Kalff AC, Kroes M, Vles JSH, Hendriksen JGM, Feron FJM, Steyaert J, van Zeben TMCB, Jolles J, van Os J (200I), Neighbourhood-level and individual-level SES effects on child problem behaviour: a multilevel analysis. Journal of Epidemiological Community Health 55: 246250

Kalff AC, Hendriksen JGM, Kroes M, Vles JSH, Steyaert J, Feron FJM, van Zeben TMCB, Jolles J. Neuropsychological predictors of Attention Deficit/Hyperactivity Disorder: Results from a prospective population study in 5- and 6-year-old children. Journal of Abnormal Child Psychology, under revision.

Kalff AC, de Sonneville L, Hurks PPM, Hendriksen JGM, Kroes M, Steyaert J, Feron FJM, van Zeben TMCB, Vles JSH, Jolles J. Speed, speed variability, and accuracy of information processing in 5/6-year-old children at risk of ADHD. Submitted for publication.

Kalff AC, de Sonneville L, Hurks PPM, Hendriksen JGM, Kroes M, Steyaert J, Feron FJM, van Zeben TMCB, Vles JSH, Jolles J. Low and high level controlled processing in executive motor control tasks in 5/6-year-old children at risk of ADHD. Submitted for publication.

Hurks PPM, Hendriksen JGM, Vles JSH, Kalff AC, Feron FJM, Kroes M, van Zeben TMCB, Steyaert J, Jolles J. Verbal fluency over time as a measure of automatic and controlled retrieval processing in ADHD: data embedded in a longitudinal cohort study. Submitted for publication. Submitted for publication.

Bakker EC, Vles JSH, Kester A, Kroes M, Blanco CE, Hornstra G. Long-chain polyunsaturated fatty acids at birht and motor function at 7 years of age. Submitted for publication.

Vles JSH, Kroes M (in preparation), Handleiding bij “Instructie CD-ROM Maastrichtse Motoriek Test" Leiden: PITS.

Hendriksen JGM, Steyaert J, Kroes $M$ (in preparation), Handleiding bij "Vragenlijst Voorlopers ADHD” Leiden: PITS. 


\section{Curriculum Vitae}

Mariëlle Kroes werd op II januari 1972 geboren in Almen. In 199I deed ze eindexamen WWO op het "Wagenings Lyceum" te Wageningen, waarna ze geneeskunde ging studeren aan de Universiteit Maastricht. Tijdens haar vierde jaar was zij student-assistent bij Prof. dr J. S.H. Vles (kinderneuroloog) en werd er een begin gemaakt met het huidige onderzoek. Haar co-schappen combineerde zij met een aanstelling als onderzoeker bij de vakgroep Neurologie in het Academisch Ziekenhuis Maastricht. In 1999 behaalde zij haar artsexamen. Van 1999-200I werkte ze, als artsonderzoeker, vier dagen per week aan het onderzoek en draaide één dag per week mee in een huisartspraktijk te Horn. In september $200 \mathrm{I}$ is zij gestart met de huisartsopleiding in Maastricht. 